Illinois State University

ISU ReD: Research and eData

Theses and Dissertations

3-1-2017

\title{
Students' Expectations And Faculty Approaches To Instructional Activities: Are Faculty Meeting The Needs Of This Generation?
}

Julie Ann Brines

Illinois State University, jaobrie@ilstu.edu

Follow this and additional works at: https://ir.library.illinoisstate.edu/etd

Part of the Curriculum and Instruction Commons, Educational Methods Commons, and the Higher Education Administration Commons

\section{Recommended Citation}

Brines, Julie Ann, "Students' Expectations And Faculty Approaches To Instructional Activities: Are Faculty Meeting The Needs Of This Generation?" (2017). Theses and Dissertations. 657.

https://ir.library.illinoisstate.edu/etd/657

This Dissertation is brought to you for free and open access by ISU ReD: Research and eData. It has been accepted for inclusion in Theses and Dissertations by an authorized administrator of ISU ReD: Research and eData. For more information, please contact ISUReD@ilstu.edu. 


\title{
STUDENTS' EXPECTATIONS AND FACULTY APPROACHES TO \\ INSTRUCTIONAL ACTIVITIES: ARE FACULTY MEETING \\ THE NEEDS OF THIS GENERATION?
}

\author{
Julie Ann Brines
}

202 Pages

Students who engage academically and socially with others on campus are more likely to stay at their institution and graduate, and the continued success of higher education institutions depends on the persistence of those students. An extensive body of literature for student retention and faculty teaching practices exists, but the present study focused on how student persistence may be affected by the interactions between students and faculty, especially when students and faculty were members of different generational cohorts. Investigating those interactions revealed there is a significant difference between students' expectations and faculty approaches to instructional activities inside and outside the classroom. The study used a cross-sectional survey research design that focused on Millennial characteristics, pedagogical characteristics, and faculty/student interaction, and collected the responses of students $(\mathrm{n}=1,261)$ and faculty $(\mathrm{n}=$ 131).

The findings demonstrated that, inside the classroom, faculty and students differed in their responses to whether students could still follow along in class while texting or surfing the internet, if students should get a $\mathrm{C}$ just for attending class, if students should be able to pass a class without the required textbooks or course materials, whether faculty should only cover the material for exams, whether exams should count for the majority of the class grade, and student input into classroom decisions. Outside the classroom, faculty and students differed in their 
responses to whether students used instructor feedback from assignments to prepare future assignments, whether students contacted instructors outside of class about class-related issues, whether it was important for faculty to get to know students and show an interest in them, and whether students contacted instructors outside of class about nonclass-related issues. While a single study cannot provide a sound basis for the practice of good teaching methods, this study and other studies with similar findings about Millennials would suggest there are strategies that faculty can use to improve their teaching methods and strategies that administrators can use to encourage collaboration and an institutional culture that advances student success.

KEYWORDS: Millennials, Pedagogy, Faculty Development, Persistence, Student Expectations, Student-Faculty Relationship 


\section{STUDENTS' EXPECTATIONS AND FACULTY APPROACHES TO}

INSTRUCTIONAL ACTIVITIES: ARE FACULTY MEETING

THE NEEDS OF THIS GENERATION?

JULIE ANN BRINES

A Dissertation Submitted in Partial

Fulfillment of the Requirements

for the Degree of

DOCTOR OF PHILOSOPHY

Department of Educational Administration and Foundations

ILLINOIS STATE UNIVERSITY 
(C) 2017 Julie Ann Brines 


\title{
STUDENTS' EXPECTATIONS AND FACULTY APPROACHES TO INSTRUCTIONAL ACTIVITIES: ARE FACULTY MEETING THE NEEDS OF THIS GENERATION?
}

\author{
JULIE ANN BRINES
}

COMMITTEE MEMBERS:

Wendy G. Troxel, Chair

Lydia Kyei-Blankson

Phyllis A. McCluskey-Titus

Claire Lamonica 


\section{ACKNOWLEDGMENTS}

I have numerous people to thank for my experiences and success in the Higher Education Administration program. Thank you to the faculty and staff of the Educational Administration and Foundations Department at Illinois State University, especially Carol Pfoff who answered all my questions and helped me throughout my years in the program. Thank you to my committee for giving me great support and guidance. Thank you Dr. Lydia Kyei-Blankson for the refresher in statistics and making it seem so easy to understand, and to my chair Dr. Wendy Troxel for your awesome insight and sticking with me even after moving on to new and exciting things. Thank you Dr. Phyllis McCluskey-Titus for asking the questions that made me a better writer and to Dr. Claire Lamonica for being my content expert.

The cohort experience was such a valuable part of my time at ISU, so I definitely need to thank my fellow cohort members and recognize the extra support I received from Melissa Pitcock and Jennie Hemingway even after our coursework was finished. Thank you for being my sounding board! Thank you to Rudy Radosevich for helping me distribute my surveys. I was lost before I found you! Thank you to Kilee Bell for your help with census data. You always answered my emails so fast and were so helpful. Thank you to my supervisor Michelle Yager for letting me have the time off from work to pursue my professional dreams and for also being a sounding board. And thank you to all the students and faculty who participated in my pilot study and final study because I could not have done it without you.

I also need to give special thanks to my family. If not for my brother Jeff taking on babysitting duties one weekend a month, I would not have been able to be in this program. Jeff, I know it wasn’t always easy to babysit Gabe, but I appreciate your help so much. Thank you to my parents for trying to understand just what I was trying to do. I know higher education isn't 
your thing, but you gave it a good shot, and you helped me out when I needed it. Thank you to my now teenage son Gabe. I know I didn't always have a lot of time to hang out, but things are going to change now. And thank you to my husband Adam for your patience while I made my way through this doctoral program. I know we met in the middle of it, so I'm guessing you won't know what to think when I actually have some free time. And, finally, thank you to God for all you have given me and blessed me with in this life. Without you, I would not be the person I am today.

J. A. B. 


\section{CONTENTS}

\section{Page}

ACKNOWLEDGMENTS

CONTENTS

ii

TABLES

viii

FIGURES

$\mathrm{X}$

CHAPTER

I. INTRODUCTION TO THE STUDY

Overview

Statement of the Problem

Purpose of the Study

Important Terms

Research Questions and Hypotheses

Methodology

Significance of the Study

Limitations of the Study

Summary

II. REVIEW OF RELATED LITERATURE 15

$\begin{array}{ll}\text { Introduction } & 15\end{array}$

Statement of the Problem 15

The Benefits and Necessity of Student Persistence 16

$\begin{array}{ll}\text { Persistence and Retention Nomenclature } & 18\end{array}$

A History of Student Persistence and Retention 20

Sociological perspective of retention $\quad 21$

Tinto 21

Validating Tinto's theory $\quad 25$

$\begin{array}{ll}\text { Psychological perspective of retention } & 27\end{array}$

$\begin{array}{ll}\text { Bean and Eaton } & 27\end{array}$

$\begin{array}{ll}\text { Gaps in persistence research } & 30\end{array}$ 
Generational Cohort Theory

The Boomers $\quad 33$

Gen Xers $\quad 34$

Millennials $\quad 34$

Generation Z $\quad 35$

Millennial Typology 36

First-generation millennial students $\quad 38$

Millennial expectations and learning $\quad 40$

Pedagogy and Faculty Best Practices 44

$\begin{array}{ll}\text { Active Learning } & 47\end{array}$

Teaching Norms and Violations $\quad 49$

$\begin{array}{ll}\text { Summary } & 49\end{array}$

III. METHODOLOGY AND PROCEDURES 51

Introduction $\quad 51$

Statement of the Problem 51

Purpose of the Study 51

Research Questions and Hypotheses $\quad 52$

Research Design

Research Setting

Participants $\quad 55$

Instrumentation $\quad 55$

Institutional Integration Scale $\quad 56$

Russo Instrument $\quad 57$

Study Instruments $\quad 57$

Pilot Study Procedures $\quad 59$

Present Study Procedures $\quad 64$

Data Analysis $\quad 66$

$\begin{array}{ll}\text { Reliability } & 67\end{array}$

Ethical Considerations $\quad 69$

$\begin{array}{ll}\text { Summary } & 70\end{array}$

IV. RESULTS AND ANALYSIS

$\begin{array}{ll}\text { Introduction } & 71\end{array}$ 
$\begin{array}{ll}\text { Study Participants } & 71\end{array}$

$\begin{array}{ll}\text { Student Profile } & 72\end{array}$

$\begin{array}{ll}\text { Faculty Profile } & 75\end{array}$

Research Question One $\quad 81$

Research Question Two $\quad 85$

Research Question Three $\quad 87$

Research Question Four $\quad 92$

Research Question Five $\quad 94$

Instructional Activities Inside the Classroom Subscales 96

$\begin{array}{ll}\text { Research Question Six } & 102\end{array}$

Other Data-Qualitative 103

$\begin{array}{lr}\text { Student Responses } & 104\end{array}$

Faculty Responses 109

Other Data-Institutional and Goal Commitment 114

Summary 116

V. SUMMARY, DISCUSSION, IMPLICATIONS, AND RECOMMENDATIONS 118

$\begin{array}{lr}\text { Introduction } & 118\end{array}$

$\begin{array}{ll}\text { Purpose of the Study } & 118\end{array}$

$\begin{array}{ll}\text { Participants } & 119\end{array}$

Research Design and Methodology 119

$\begin{array}{lr}\text { Research Question One } & 120\end{array}$

Research Question Two 125

Research Question Three $\quad 127$

Research Question Four $\quad 130$

Research Question Five 131

$\begin{array}{ll}\text { Research Question Six } & 135\end{array}$

$\begin{array}{ll}\text { Contextual Considerations } & 138\end{array}$

Limitations and Delimitations 139

$\begin{array}{ll}\text { Implications } & 140\end{array}$

Recommendations for Practice 142

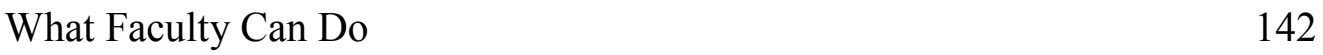

$\begin{array}{ll}\text { Feedback } & 143\end{array}$

Lecturing and active learning 143

Instructor interest and contact 145

Technology use 146

No textbook/no problem 147 
APPENDIX A: Pascarella and Terenzini's 1980 Institutional Integration Scale (IIS) (Five-Point Likert-Type Items)

APPENDIX B: Russo’s 2013 Survey (Five-Point Likert-Type Items)

APPENDIX C: Present Study Student Instrument 
APPENDIX T: Large Figure 2

APPENDIX U: Large Figure 3

APPENDIX V: Large Figure 4

APPENDIX W: Large Figure 5

APPENDIX X: Large Figure 6 


\section{TABLES}

Table

Page

1. Pilot Student Participant Demographic Characteristics

2. Pilot Faculty Participant Demographic Characteristics

3. Cronbach's Alpha Coefficients for Pilot Study

4. Cronbach's Alpha Coefficients for Present Study

5. Cronbach's Alpha Coefficients for Subscales of Present Study

6. Student Participant Demographic Characteristics

7. Student Participant Socioeconomic Characteristics

8. Student Participant Educational Characteristics

9. Faculty Participant Demographic Characteristics

10. Faculty Participant Institutional Characteristics

11. Faculty Participant Pedagogical Characteristics

12. Faculty Participant Professional Development Characteristics

13. Student Expectations of Instructional Activities Inside the Classroom

14. Student Frequencies and Modes for Expectations of Instructional Activities Inside the Classroom

15. Student Expectations of Instructional Activities Outside the Classroom

16. Student Frequencies and Modes for Expectations of Instructional Activities Outside the Classroom

17. Faculty Approaches to Instructional Activities Inside the Classroom

18. Faculty Frequencies and Modes for Approaches to Instructional Activities Inside the Classroom

19. Faculty Approaches to Instructional Activities Outside the Classroom 
20. Faculty Frequencies and Modes for Approaches to Instructional Activities Outside the Classroom

21. Results from t-test Comparing Responses of Faculty and Students for Instructional Activities Inside the Classroom

22. Frequencies and Modes for Instructional Activities Inside the Classroom

23. Student Instrument-Millennial Characteristics Subscale

24. Student Instrument-Pedagogical Characteristics Subscale

25. Faculty Instrument-Millennial Characteristics Subscale

26. Faculty Instrument_Pedagogical Characteristics Subscale

27. Results from t-test Comparing Responses of Faculty and Students for Millennial Characteristics Subscale

28. Results from t-test Comparing Responses of Faculty and Students for Pedagogical Characteristics Subscale

29. Results from t-test Comparing Responses of Faculty and Students for Instructional Activities Outside the Classroom

30. Frequencies and Modes for Instructional Activities Outside the Classroom

31. Student Open-Ended Questions

32. Student Frequencies for Words from Instructors Meeting Needs

33. Student Frequencies for Words from Instructors Not Meeting Needs

34. Student Frequencies for Words from Open Comments About Instructors

35. Faculty Open-Ended Questions

36. Faculty Frequencies for Words from Needs of Generation

37. Faculty Frequencies for Words from Develop Relationships

38. Faculty Frequencies for Words from Open Comments About Students

39. Student Institutional and Goal Commitment

40. Student Frequencies and Modes for Institutional and Goal Commitment 


\section{FIGURES}

Figure $\quad$ Page

1. Word Cloud for Instructors Meeting Needs 105

2. Word Cloud for Instructors Not Meeting Needs 107

3. Word Cloud for Open Comments About Instructors 108

4. Word Cloud for Needs of Generation $\quad 110$

5. Word Cloud for Develop Relationships 112

6. Word Cloud for Open Comments About Students 113

7. Percentages of Combined Agree and Strongly Agree Student Responses for Instructional Activities Inside the Classroom

8. Percentages of Combined Agree and Strongly Agree Student Responses for Instructional Activities Outside the Classroom

9. Percentages of Combined Agree and Strongly Agree Faculty Responses for Instructional Activities Inside the Classroom

10. Percentages of Combined Agree and Strongly Agree Faculty Responses for Instructional Activities Outside the Classroom

11. Percentages of Combined Agree and Strongly Agree Faculty and Student Responses for Instructional Activities Inside the Classroom

12. Percentages of Combined Agree and Strongly Agree Faculty and Student Responses for Instructional Activities Outside the Classroom 


\section{CHAPTER I}

\section{INTRODUCTION TO THE STUDY}

\section{Overview}

Students enter college with a multitude of background characteristics, individual attributes, and expectational and motivational attributes that influence their satisfaction with the collegiate environment and their decision to persist or withdraw from a particular institution (Tinto, 2007). These background characteristics and individual attributes include gender, age, ethnicity, sexual orientation, socioeconomic status, and generational cohort (Moore, 2007). Institutions have no control over their students' prior experiences or the variables that influence them before they come to college, but they do have control over institutional actions once a student comes to their campus (Tinto, 2007, 2012).

The quality and impact of instructional activities and interactions between faculty and students is significant for students' integration into an institution (Pascarella \& Terenzini, 1980). "The more students are academically and socially engaged with other people on campus, especially with faculty and student peers, the more likely (other things being equal) they will stay and graduate from college" (Tinto, 2012, p. 65). Faculty interest in students and good teaching methods are positive influences in how a student perceives the commitment of his institution to his welfare (Braxton et al., 2014). The increasing diversity of college students calls for more faculty development, and practices recommended and previous outcomes achieved 10 years ago are probably not relevant for the present day (Beach, 2016). According to Levine and Dean (2012), "colleges and universities will have to change substantially" (p. 35) to provide students with the education they need to live in the world of the future, and "higher education lags far behind its students technologically and pedagogically and must transform itself if it is to 
educate current undergraduates" (p. xii). The student population Levine and Dean (2012) refer to in their research is the Millennial generation cohort.

In 2013, based on information collected in the U.S. Department of Education Integrated Postsecondary Education Data System (IPEDS), 97\% of full-time students at 4-year public institutions were 34 and younger (National Center for Education Statistics, 2015). According to generational theory expert Howe (2014), Millennial students are classified as being born between 1982 and 2004. This indicates the majority of those full-time students enrolled in 4year public institutions were most likely Millennials, as the oldest members of this generation were around the age of 31 in 2013. Although there is debate on the boundaries for generations, as "developing a popular and expert consensus on what marks the boundaries between one generation and the next takes time" (Fry, 2016, para. 3), thus rendering the actual number of Millennials an arguable figure, there is no question Millennials represent the largest number of students on a college campus based on the figures from IPEDS.

Unlike students, the majority of faculty are not members of this generation. According to 2015 data from the Faculty Survey of Student Engagement (FSSE) from 133 bachelor's granting institutions, $11 \%$ of faculty were 34 or younger, $23.4 \%$ were between 35 and $44,26.1 \%$ were between 45 and 54, and 39.5\% were 55 and over (A. BrckaLorenz, personal communication, March 15, 2016). Based on the definitions of Baby Boomers, Generation X, and Millennials, with Baby Boomers being born between 1943 and 1960, Generation X being born between 1961 and 1981, and Millennials being born between 1982 and 2004 (Howe \& Strauss, 2007; Howe, 2014), approximately $39.5 \%$ of faculty were Baby Boomers or older, $49.5 \%$ of faculty were Generation X, and $11 \%$ of faculty were Millennials in 2015. This age distribution supports the assertion that the majority of faculty are not members of the Millennial generation. 
"Students of different generations have different motivations and learning styles" (Worley, 2011, p. 32). The same can also be applied to faculty and their teaching styles as "many college faculty and administrators are from earlier generations that present different learning and teaching styles than those of the net” (Worley, 2011, p. 31), or Millennial generation. These generational differences indicate a need for faculty and staff to assess their teaching styles and methods of instruction to successfully reach the Millennial generation (Worley, 2011). But are faculty doing this and adapting their teaching style and methods to the needs of the Millennials? How do their approaches to the instructional activities they provide inside and outside the classroom meet up with students' expectations of those activities?

\section{Statement of the Problem}

Renn and Reason (2013) note that student retention has arguably been "the primary goal of higher education institutions for several decades and the focus of much research effort among higher education scholars" (p. 173). Yet, according to Tinto (2012), "despite years of effort, institutions have yet to develop a coherent framework to guide their thinking about which actions matter most and how they should be organized and successfully implemented" (p. 5). Institutions must change the way they think about retention by focusing on student persistence and how it may be affected by the relationships between students and faculty and their opinions of student learning.

Both faculty and students have concerns about the quality of student learning. Faculty are concerned with low student attendance by mid-semester, the attention given to mobile devices, lack of completing reading assignments, low energy levels, a focus on grades rather than learning, and textbooks that contain so much information, it is difficult to cover it all (Fink, 2013). Students are concerned about uninteresting courses, the bigger textbooks that cost more 
money and have too much information to learn, a lack of hands-on learning, and too much reliance on lectures and taking notes (Fink, 2013).

Reason (2009) suggests looking at persistence as a multidimensional problem as there are "multiple forces operating in multiple settings that influence persistence" (p. 675), and recommends greater exploration of the campus climate, such as in the areas of classroom experiences and out-of-classroom experiences, to learn how these areas influence student persistence. To understand the complexities of student-faculty relationships, it was important for a quantitative study to be conducted to examine the differences between students' expectations and faculty approaches to instructional activities inside and outside the classroom. Comparing the differences in attitudes between faculty and students provides context for informing curricular decisions and designing and implementing strategies to help students advance their academic goals and further entrench their integration into university life.

\section{Purpose of the Study}

The purpose of this study was to compare student expectations of instructional activities inside and outside the classroom to faculty approaches to instructional activities inside and outside the classroom at a four-year comprehensive Midwestern public university. It was intended to identify areas of congruence and incongruence between students and faculty in attitudes toward class structure, feedback and assessment, technology use, faculty/student interaction, personal regard, class planning, and use of resources to be able to reinforce successful persistence practices and highlight target areas for faculty and staff development.

Research shows that the more a student is integrated and engaged with his faculty and others on campus, the more he commits to new levels of involvement with the institution and the stronger his commitment to the institution and the goal of college completion (Astin, 1984; 
Braxton, Bray, \& Berger, 2000; Spady, 1970; Swail, 2004; Tinto, 1975; Tinto, 2004; Tinto 2007). Students feel more connected when they have frequent interactions with faculty; live in the residence halls; participate in extracurricular activities and research projects; and hold a parttime job on campus. All of these factors of involvement, or the amount of energy spent physically and psychologically on the academic experience, contribute to students remaining in college (Astin, 1984).

Much of the research on Millennial students in higher education outlines how faculty can adapt their pedagogy to meet the needs of this generation (Black, 2010; Mangold, 2007; Moore, 2007; Wilson \& Gerber, 2008; Worley, 2011), but the research does not indicate whether faculty members have adjusted their instructional strategies to account for these generational differences. Are faculty adjusting to the students, or are the students adjusting to the faculty? If the latter is more predominant, how does that affect the student-faculty relationship, especially since that relationship is so vital for student persistence according to researchers such as Astin (1984), Chickering and Gamson (1987), Kuh, Kinzie, Schuh, and Whitt (2005) and Tinto (2007)? Do pedagogical assumptions and practices contribute to disengagement (Cook-Sather, Bovill, \& Felten, 2014)?

It is the actions of others and how those actions shape a person's social and academic communities that affect his degree of academic integration and social integration (Skipper, 2005), and Tinto's (1975) model of student integration argues a person's academic integration and social integration have the most effect on his continued participation in college. The more a student is integrated and engaged, the more she commits to new levels of involvement with the institution and the stronger her commitment to the institution and the goal of college completion. 


\section{Important Terms}

Academic Integration/Engagement—grade performance and intellectual development during the college years (Tinto, 1975). Academic engagement factors are also defined as preparedness for class, time spent reading and studying for class, contributions to class, assistance from instructors, interacting with faculty during class, and the instructor knowing students' names (Soria, Stebleton, \& Huesman, 2011).

Active Learning - "umbrella term for pedagogies focusing on student activity and student engagement in the learning process" (Roehl, Reddy, \& Shannon, 2013, p. 45). In active learning, students have doing experiences and observing experiences, and then reflect on those experiences (Fink, 2013).

Baby Boomers - refers to people born between 1943 and 1960 (Howe \& Strauss, 2007). First-Generation Students—students whose parents have not graduated from college (Petty, 2014).

Generational Cohort_-"a cohort-group whose length approximates the span of a phase of life and whose boundaries are fixed by peer personality" (Strauss \& Howe, 1991, p. 60). Strauss and Howe (1991) also note "generations can be imprecise at the boundaries" (p. 59).

Generation X-refers to people born between 1961 and 1981 (Howe \& Strauss, 2007.

Generation Z - refers to people born in 2005 and after. Also referred to as the Homeland Generation (Howe, 2014).

Instructional Activities Inside the Classroom — refers to teaching and teaching-related activities and interactions such as answering students' questions in class, facilitating group activities, taking attendance, giving lectures, using technology for classroom materials, providing instructions on assignments, communicating class rules, going over the syllabus, 
giving specific grading guidelines, using textbooks and other resources, providing study guides, telling students about resources, and awarding points for participation.

Instructional Activities Outside the Classroom — refers to teaching-related activities and interactions such as answering students' emails, offering individualized attention, grading assignments, giving feedback on assignments, using an online course management system, contacting students outside of class, mentoring students, interacting informally with students outside of class, getting to know students, communicating through social media, and talking to students outside of class about other topics besides class-related material.

Millennials - refers to people born between 1982 and 2004 (Howe, 2014).

$N A C A D A-$ a global organization for academic advising professionals that was chartered in 1979 (NACADA, 2006).

Pedagogy — "the systematic study of both the art and science of teaching" (Randall, 2008).

Peer Personality - A sum of attributes of a generational cohort. It distinguishes that group with its own unique biography (Strauss \& Howe, 1991). Strauss and Howe (1991) call it "a caricature of its protypical member" (p. 63).

Persistence - Individual phenomenon necessary for student success. A student persists to his educational goals. "Persistence is a positive outcome of college attendance" (Reason, 2009, p. 661).

Retention Rate - "A measure of the rate at which students persist in their educational program at an institution, expressed as a percentage. For 4-year institutions, this is the percentage of first-time bachelors (or equivalent) degree-seeking undergraduates from the previous fall who are again enrolled in the current fall" (IPEDS, 2016, p. 28). Retention is often 
used interchangeably with persistence although the two terms have different meanings (Hagedorn, 2012; Reason, 2009). (See the "Persistence and Retention Nomenclature" section in Chapter II for a more thorough explanation.)

Scholarship of Teaching and Learning (SoTL) _ "the study of teaching and learning and the communication of findings so that a body of knowledge can be established" (Bishop-Clark \& Dietz-Uhler, 2012, p. 1).

Social Integration/Engagement - interactions between the student, who has a given set of characteristics, and others at the institution, who also have varying characteristics (Tinto, 1975). Social engagement factors are also defined as participation in clubs, time spent socializing and a sense of social belonging (Soria et al., 2011).

Student Involvement — the amount of physical and psychological energy a student devotes to his academic experience (Astin, 1984). It can also be used to refer to student engagement (Roberts \& McNeese, 2010).

\section{Research Questions and Hypotheses}

Using survey instruments, faculty and student responses with regard to instructional activities inside and outside the classroom were compared to determine whether expectations and approaches differed. This study contributed to the research in student persistence by answering the following research questions.

1. What are students' expectations of instructional activities inside the classroom?

2. What are students' expectations of instructional activities outside the classroom?

3. What are faculty approaches to instructional activities inside the classroom?

4. What are faculty approaches to instructional activities outside the classroom? 
5. To what extent do faculty approaches to instructional activities inside the classroom differ from students' expectations of those instructional activities?

6. To what extent do faculty approaches to instructional activities outside the classroom differ from students' expectations of those instructional activities?

Based on the above research questions, the following hypotheses were proposed.

$\mathrm{H}_{0}$ : There will be no significant difference between students' expectations of instructional activities inside the classroom and faculty approaches to instructional activities inside the classroom.

$\mathrm{H}_{1}$ : Students' expectations of instructional activities inside the classroom are significantly different than faculty approaches to instructional activities inside the classroom.

$\mathrm{H}_{0}$ : There will be no significant difference between students' expectations of instructional activities outside the classroom and faculty approaches to instructional activities outside the classroom.

$\mathrm{H}_{2}$ : Students' expectations of instructional activities outside the classroom are significantly different than faculty approaches to instructional activities outside the classroom.

\section{Methodology}

This was a quantitative study using a cross-sectional online survey design at a 4-year Midwestern public university consisting of one survey administered to students to examine expectations of instructional activities inside and outside the classroom and one survey administered to faculty to examine approaches to instructional activities inside and outside the classroom. Variables used for the research design were based on class structure, feedback and assessment, technology use, faculty/student interaction, personal regard, class planning, use of resources, pedagogy, Millennial characteristics, and institutional and goal commitment. The 
location of the study was chosen for several reasons, such as its higher-than-the-nationalaverage persistence rate, undergraduate enrollment between 15,000 and 20,000, high graduation rate, and diverse campus with almost $25 \%$ of undergraduates coming from underrepresented groups. The data from the student and faculty surveys were analyzed and compared using descriptive and inferential statistics to determine whether differences existed and if there was statistical significance for those differences.

\section{Significance of the Study}

Exploring the differences in expectations of students versus the approaches of faculty toward instructional activities inside and outside the classroom has implications for the Scholarship of Teaching and Learning (Bishop-Clark \& Dietz-Uhler, 2012), which is applicable for the professional development of faculty and other institutional staff. Results from the study may help inform the strategy for changing faculty teaching methods and interactions to influence the student-faculty relationship and student success and persistence.

Randall (2008) explains that faculty may opt out of professional development opportunities because of the need for service contributions, scholarly productivity, and the demand for effective teaching; however, "a rapidly changing knowledge base, the lightning speed of advancing technologies, and the unique characteristics of today's learners all demand that the professoriate give high priority to their own professional development" (p. 18). This development could be in areas such as active learning, multimedia use, and classroom assessment (Randall, 2008).

Randall (2008) also points out that if faculty have the opportunity to apply their new pedagogical skills in the context of the curriculum of their classes, the transfer of this theory to practice is greatly increased. There is a common misconception that knowledge of a subject and 
research expertise naturally lead to effective teaching methods. Randall (2008) notes this pedagogy is "best taught, not caught" (p. 21). Ribera, Fernandez, and Gray (2012) also encourage the pursuit of staff development. They point out that although faculty have extensive development in their discipline, they are not always prepared to teach or explore the teaching and learning that occurs in a classroom setting.

Research about the differences between student expectations and faculty approaches also contributes to the research about student characteristics, and thus student development theory, which is useful to both student affairs practitioners and faculty. Student development theory provides insight into how students develop intellectually and emotionally and behave (Skipper, 2005). Faculty can use student development theory as a framework for understanding how their students learn. With this framework, they can review their instructional methods to see how well they align with the ways current students are learning, and then make informed decisions on how to implement new strategies in their courses (Williams, 2004).

Student affairs practitioners enhance learning outside the classroom and focus on "the learning and personal development associated with participating in student affairs programs and services" (Schuh \& Gansemer-Topf, 2010, p. 8). Due to their educational preparation and training, student affairs practitioners "are very knowledgeable about how students learn and develop throughout college and about the type and scope of experiences that can enhance students' learning and development" (Schuh \& Gansemer-Topf, 2010, p. 9). In essence, they are also teaching their students, and although it is not a traditional student-faculty relationship, learning about the differences in student expectations and faculty approaches to instructional activities inside and outside the classroom can also inform the strategies for programming and interacting with students in this field. 
College student persistence is also a critical issue for administrations of institutions of higher learning. Student persistence is a characteristic of student success; it is a driver of student retention, and thus graduation. In their educational endeavors, students aim to persist to their goals, whether that goal is graduation or some other objective (Reason, 2009). A student makes the effort to succeed, to persist. He is retained, whether institutionally or systemically, and if he completes his degree requirements, he graduates.

Institutions are very committed to graduation rates for several reasons. First, states are implementing accountability systems that use retention and persistence as a key piece of criteria for determining funding for institutions (Berger, Ramirez, \& Lyons, 2012). Policy makers and politicians are advocating for performance-based funding for institutions rather than enrollmentbased funding (The Lawler Group, 2014; AASCU, 2015). This type of funding stems from the need to improve completion rates and address gaps in degree attainment. The amount of funding is distributed to institutions based on performance. If institutions cannot meet performance metrics, their funding is cut (AASCU, 2015).

Second, the Student Right-To-Know and Campus Security Act of 1990 requires institutions receiving federal student aid to report the graduation rate of degree-seeking, fulltime students entering those institutions (Library of Congress, 1990). Graduation rates are also reported on the U.S. Department of Education's College Scorecard website, which is intended to provide:

Free, transparent, and nationally comparable data on the full universe of higher education institutions and their performance on student outcomes, such as graduation rate... information that can help students apply to and enroll in colleges that serve them well. (U.S. Department of Education, 2015, p. 4)

Students and their parents are looking at an institution's graduation rate, making the rate a competitive indicator in the higher education landscape. The number of high school graduates is 
declining until at least 2019 (The Lawlor Group, 2014), resulting in a smaller pool of potential students. It is likely that institutions want to represent themselves positively with the highest graduation rate possible to capture those potential students in their enrollment numbers.

Third, former President Barack Obama expressed the need to improve American higher education graduation rates to keep the United States competitive in the global marketplace. In his first joint address in 2009 to Congress, he set a goal for the United States to have the highest percentage of college graduates in the world by 2020. In his State of the Union Address, President Obama noted higher education is "no longer just a privilege for some, but rather a prerequisite for all" (The White House, Office of the Press Secretary, 2012, para. 1). The U.S. Department of Education estimates that 8 million more people would need to obtain college degrees by 2020 to reach President Obama's goal (U.S. Department of Education, 2011).

Most academic plans are designed for 4 years of college, yet the percentage of 4-year college students at public institutions who earn a degree within 5 years of entering school was $45.3 \%$ in 2016 (ACT, 2016). This is a slight increase from $41.9 \%$ in 2000 . The retention rate for first-year students at public institutions who return for their second year was 73.5\% in 2016 and $72.1 \%$ in 2000 (ACT, 2016). With retention rates remaining stagnant and the number of high school graduates declining in over 30 states through 2019 (The Lawlor Group, 2014), the number of graduates needed for President Obama's goal seems statistically impossible unless something is done to improve student persistence with the ultimate goal of graduation.

\section{Limitations of the Study}

The limitations of a research study come from factors that impact the quality of the study but cannot be controlled. For this study, the limitations are: 
1. Generational boundaries are poorly defined. This can make it difficult to draw generational lines.

2. Generational cohorts are broad generalizations, as not everyone born during that time will share the same characteristics, such as members of marginalized groups. Overgeneralizing can lead to stereotyping.

3. The retention of students is varied based on the institutional environment and the specific needs of students. What may work well at one institution may not work well at another depending on the type of institution and the students it enrolls.

4. The study is narrow in scope as it only includes one institution, in particular, one that has a higher persistence rate than the national average.

\section{Summary}

Student persistence is a serious issue for higher education institutions. If students do not feel integrated academically and socially through the interactions they have with their faculty inside and outside the classroom, they may leave their institution. The majority of faculty and students represent different generational cohorts. Examining students' expectations of instructional activities inside and outside the classroom and faculty approaches to instructional activities inside and outside the classroom can provide faculty and student affairs practitioners with the foundation for developing new strategies to help students be more successful in the classroom, thus encouraging institutional fit. 


\section{CHAPTER II \\ REVIEW OF RELATED LITERATURE}

\section{Introduction}

This chapter explores how academic integration and social integration affect student persistence with a review of key theories in the retention literature and an examination of generational theory and pedagogy. Stakeholders in higher education have analyzed retention through both a sociological (Tinto, 1975) and psychological lens (Bean \& Eaton, 2000) to gain a better understanding of why students persist and what institutions can do to make that happen. Reviewing persistence through a generational lens provides another viewpoint as to how the relationship between faculty and students might be affected by the differences in their generational cohort, and how faculty's teaching methods may deviate from students' expectations. As further research into the differences between student expectations and faculty approaches to instructional activities inside and outside the classroom was needed to expand the literature, this study investigated a variety of social, psychological, environmental, and pedagogical factors that may contribute to a lack of persistence.

\section{Statement of the Problem}

Retaining students is a primary goal of higher education institutions, but despite years of research, they've been unable to develop or implement a framework that has achieved high levels of success (Renn \& Reason, 2013; Tinto, 2012). Persistence is not a one-dimensional problem; it affects every aspect of an institution. Research shows that faculty and students are concerned with the quality of student learning (Fink, 2013). Therefore, studying student expectations and faculty approaches related to student learning, as well as the differences between those expectations and approaches, fills a gap in the research about how student 
persistence may be affected by the interactions between students and faculty.

\section{The Benefits and Necessity of Student Persistence}

The successful persistence of students to graduation in higher education has multiple benefits for the student, for the institution and for society. Tierney (1992) gives a very clear-cut explanation of these benefits that still applies almost 25 years later:

The student will be able to reap the rewards that a college degree affords, the college or university will be able to maintain the income that derives from the student's attendance, and society will be able to utilize the skills of students in becoming more productive. (p. 604)

Historically, states provided access to higher education by “appropriating funds for public colleges and universities, covering part of the cost of institutional operations directly" (Baum, Kurose, \& McPherson, 2013, p. 27). In 1980, state appropriations accounted for 44\% of public postsecondary institutions' revenue (Baum et al., 2013). In 2012, that figure was 23\%. State funding trends continue to shift public institutions' share of revenue from state appropriations to tuition dollars (Government Accountability Office, 2014). When students do not persist, not only do institutions lose the tuition dollars, they need to stay solvent, but institutions also fail to complete their educational mission (Bean, 1990).

Society benefits from successful persistence of students to graduation as people with a college education are more likely to contribute to community service, participate in governance of the nation, commit fewer crimes and consume less public services (Tinto, 2004). Habley, Bloom, and Robbins (2012) add that college-educated people give twice as much in charitable donations than high school graduates at the same income level. They have improved working conditions, are more likely to be employed, have more transferable skills, have an increased environmental awareness, make better use of their leisure time, and make better savings choices. They also have higher salaries and better benefit packages (Habley et al., 2012). 
In 1975, full-time workers who had a bachelor's degree made approximately 1.5 times more income than those with just a high school diploma (Tinto, 2004). By 2013, young adults with a bachelor's degree made $62 \%$ more than those with a high school diploma and $103 \%$ more than those without a high school diploma. They also earned $29 \%$ more than individuals with an associate's degree. There is an even bigger income gap for those who go on to earn master's degrees or higher (National Center for Education Statistics, 2015). The difference in lifetime earnings between a person with a college education and a person with a high school education ranges between $\$ 1$ million and \$2 million (Habley et al., 2012; Tinto, 2012).

A student's failure to succeed is viewed as an institutional responsibility (Habley et al., 2012) and a "campus-based phenomenon" (Berger et al., 2012, p. 8). "Students who fail to achieve their educational goals at an institution because of either personal or institutional shortcomings represent a departure problem" (Bean, 1990, p. 171). Tinto (2004) points to how "student persistence is primarily an institutional event" (p. 11). This makes student persistence primarily the responsibility of the institution, and for public institutions, it is also a responsibility of the states governing those institutions (Tinto, 2004). Not only have resource allocations been tied to retention rates, but retention is a core indicator for accrediting agencies, and is used in national rankings that serve as a guide in college choice (Berger et al., 2012).

Student retention has been an issue for over half a century, yet "most institutions have not been able to translate what we know about student retention into forms of action that have led to substantial gains in student persistence and graduation" (Tinto, 2007, p. 5). Five years later, Tinto (2012) added that a coherent framework for retention had still not been developed. His opinions are supported by data that show retention rates and graduation rates have remained almost stagnant for at least the last 16 years (ACT, 2016), and call for more research 
into student persistence using different variables, such as generational cohort and pedagogy.

\section{Persistence and Retention Nomenclature}

Hagedorn (2012) points out the terms "retention" and "persistence" are often used interchangeably, yet retention should be viewed as an institutional measure and persistence as a student measure; "institutions retain and students persist” (Hagedorn, 2012, p. 85). Persistence is an individual phenomenon, while retention is an organizational phenomenon. Persistence focuses "attention on individual-level student goal attainment rather than the institution-level goal of keeping students" (Reason, 2009, p. 660). It is also referred to as "a student's postsecondary education continuation behavior that leads to graduation" (Arnold, 1999, p. 5).

There is a complexity to the definition of retention, resulting in a lack of agreement in the literature, and a reason for persistence and retention being used interchangeably. There are different types of retention (Hagedorn, 2012), and retention itself can have multiple definitions (Habley et al., 2012). According to Hagedorn (2012), institutional retention is defined as the proportion of students who stay enrolled at the same institution from one year to the next. It is the most common type of retention referred to in the literature. System retention is focused on the student; it does not matter if the student is enrolled at the same institution (Hagedorn, 2012). However, by the nature of these two definitions, system retention would therefore result in a lack of institutional retention.

Using the standardized definition of the term "retention rate" from the U.S. Department of Education Integrated Postsecondary Education Data System (IPEDS) (see retention rate under the "Important Terms" section in Chapter I), if an institution does not continually enroll the student, it does not achieve successful institutional retention. If a student transfers directly to another institution, or drops out only to enroll later at another institution, his initial 
institution has not successfully retained him; however, system retention has been achieved.

Nonetheless, even though the student was not successfully retained at his initial institution, he did persist. According to Bean (1990), a student is successful if he transfers to another institution or drops out, as long as he has met his educational goals. Students may enter college, achieve their goal, even if it is one class, and then leave the institution. The student's goal was to only attend the institution for a semester or to only take one class. He persisted in his goals (Bean, 1990). If he transferred, he was retained in the system but not at the institution. If he took one class or stayed only one semester and dropped out never to return, he was not successfully retained at any level, but he did persist as long as he met his goals.

Not all students enter college with a desire to get a degree or certificate; some want to upgrade their work skills, attend courses of specific interest, or explore postsecondary education. If they meet these goals, these students have all achieved student success but do not meet the definition of retention (Habley et al., 2012). Kuh, Kinzie, Buckley, Bridges, and Hayek (2006) include persistence as part of their definition of student success and note a key factor in persistence is the effort put forth by a student. The amount of time and effort put forth by students in their studies and activities leads to the outcomes and experiences that result in student success and is one key component of student engagement. The other key component is the way institutions allocate resources and organize "learning opportunities and services to induce students to participate in and benefit from such activities" (Kuh et al., 2005, p. 9). If principles of good practice are used to organize the curriculum and college experience, students are more likely to put forth the effort to succeed, to persist.

The above examples highlight the differences between retention and persistence as institutional and student measures. Persistence is needed for the successful retention of students 
and graduation as "all graduates have persisted" (Hagedorn, 2012, p. 85); however, not all persisters are graduates. Noel-Levitz (2008) states the difference in the nomenclature between persistence and retention has not been widely accepted, also reiterating that the terms are frequently used interchangeably. IPEDS (2016) has a standardized definition for retention rate but not a definition for persistence. In reviewing the two terms, Wyrick (2014) explains how persistence and retention should be binding activities that create a personal relationship between students and their institutions.

\section{A History of Student Persistence and Retention}

As detailed in the previous section, the terms "retention" and "persistence" are often used interchangeably, yet retention should be viewed as an institutional measure and persistence as a student measure; "institutions retain and students persist" (Hagedorn, 2012, p. 85). However, the majority of the literature focuses on "student retention." Because this review of the literature is a synthesis and evaluation of the research, the word "retention" will be used more often and may refer to what Hagedorn (2012) and Reason (2009) define as "persistence."

A strong base of retention research began to emerge in the late 1960s. According to Berger et al. (2012), "prior to the 1960s the study of retention, and even the higher education enterprise as a whole, was still developing” (p. 11). Research in student retention was focused on a student's connectedness through a psychological lens, viewing his ability to be retained as a result of personality attributes (Berger et al., 2012; Tinto, 2007). If the student did not succeed, it was because he was less motivated, able or willing to take advantage of the benefits of a college education. It was the student's fault, not the institution's fault for his inability to be retained (Tinto, 2007). 
Sociological perspective of retention. In the 1970s, the way in which higher education viewed retention began to change. Spady (1970) was the first to focus attention on the interaction between student attributes and the institutional environment, pointing out the importance of academic and social systems as frameworks for examining the dropout process. Spady (1971) calls these patterns of interaction "normative congruence." This congruence occurs when there is compatibility between a student and his environment. A limitation of his model was that it applied more directly to a single institution rather than multiple institutions (Morrison \& Silverman, 2012).

Tinto. Tinto (1975) expanded on Spady's (1970, 1971) work with his student integration model, also taking concepts from Durkheim's (1951) theory of suicide, most notably Durkheim's description of egoistic suicide in which a lack of integration into society causes a person to commit suicide. Rather than putting the responsibility of success solely on the student, Tinto's (1975) student integration model, also referred to as Tinto's interactionalist theory of college student departure, looked at retention through a sociological lens, where a student's environment and the people who shape the environment can also affect his level of integration and engagement (Demetriou \& Schmitz-Sciborski, 2011; Tinto 2007).

Central to Tinto's (1975) student integration model is the "concept of integration and the patterns of interaction between the student and other members of the institution especially during the critical first year of college and the stages of transition that marked that year" (Tinto, 2007, p. 3). Thus, a core component of the model involves looking at how students interact with others around them, especially faculty members, during their first year on a college campus. Tinto's (1975) model is also affected by the variety of attributes a student brings with him to the institution. These include background characteristics, such as social status and high 
school experiences; individual attributes, such as sex and ability; and expectational and motivational attributes, such as levels of motivation and career and educational expectations.

Tinto (1975) argues that a student's integration into the social and academic systems of an institution most directly relates to his continued enrollment at that institution. A student's level of expectation helps specify the psychological orientations he brings with him to college. These orientations are important predictors for how a student interacts in a college environment (Tinto, 1975). Thus, a student's expectations of instructional activities inside and outside the classroom may influence how he will behave in that class. Braxton et al. (2014) describe violations of teaching norms that might influence students' perceptions of their institution's commitment to them, thus affecting both academic and social integration. These norms include condescending negativism, particularistic grading, inattentive planning, personal disregard, uncommunicated course details, and moral turpitude. Faculty violations can affect the intellectual and academic development of students (Braxton, 2006).

Students enter college with a multitude of background characteristics, individual attributes, and expectational and motivational attributes that influence their satisfaction with the collegiate environment (Tinto, 1975; Tinto, 2007). Again, institutions have no control over these variables, but they do have control in ensuring reasonable expectations are met. If a student does not get what he needs from his academic experience, he may decide to transfer to another institution or end up being academically dismissed. Faculty often believe a lack of retention stems from a lack of skills and motivation on the part of the student; however, Tinto (2007) points out successful retention is "a reflection of successful student education. That is the job of the faculty" (p. 9). This is why more research into comparing faculty approaches to instructional activities inside and outside the classroom to students' expectations of those 
instructional activities is needed.

In Tinto's (1975) model, a student's academic integration can be measured by his grade performance and intellectual development. Grade point average is an indicator of a student meeting the standards set by the academic system of the institution, while intellectual development is a representation of how a student identifies with the system. Insufficient integration occurs when there is lack of congruence between intellectual development, or evaluation of the academic system, and the normative climate of the academic system (Tinto, 1975). A student's social integration is enhanced by his congruence to his social environment. It occurs through the interactions he has with his friends, faculty, and staff, and in his involvement with extracurricular activities (Tinto, 1975). Thus, an incongruence in students' expectations of instructional activities inside and outside the classroom with faculty approaches to instructional activities inside and outside the classroom could lead to a lack of integration, both academically and socially.

Tinto (2012) explains that current students may not fit the traditional mold, as they are likely to have a job, not live on campus, and attend school part time. The traditional students who were the focus of older retention models now only make up about $25 \%$ of the student population. According to Tinto (2012), institutions have neglected the classroom in their retention efforts, yet this is "the one place on campus, perhaps only place, where the great majority of students meet the faculty and one another and engage in formal learning activities" (Tinto, 2012, p. 5). Tinto (2012) calls for institutions to focus retention actions on the way classes are structured and taught, and thus experienced by students. If the current student population is more likely to eschew the traditional student typology, then the classroom is where the essential college experience takes place. 
Because of his earlier work and continued work in the field, Tinto is considered one of the most well-known theorists on college student retention. He has continued to revise his model, adding in additional variables for a better understanding of the college student retention process (Demetriou \& Schmitz-Sciborski, 2011). Due to Tinto's (2012) belief that institutions have invested in an "uncoordinated patchwork of actions whose sum impact on student retention is less than it could or should be" (p. 5), he developed a framework for institutional access built on past retention research that highlights four conditions of student success: expectations, support, assessment and feedback, and involvement. A review of these conditions shows the academic and social integration concepts of Tinto's (1975) model, which he refers to as academic and social engagement in his later research, have been incorporated into the four conditions.

Research from Astin (1984) and Tinto (2012) also support the claim that involvement in extracurricular activities, such as membership in organizations, is directly related to college persistence. This involvement can provide academic and social benefits that increase a person's commitment to the institution (Astin, 1984, Spady; 1971; Tinto, 1975). Take for example a student who is a member of an organization related to her major. Not only does the student reap the social rewards of working with her peers and a faculty advisor but she learns more about her field of study, thus helping her excel in her courses. Her peers are also in similar or the same courses. They can gather together to form study groups and work on group projects that provide academic rewards and more firmly entrench the student's academic and social integration. The student then develops "profound" relationships, or rather those that have significant meaning, rather than "profane" relationships that are superficial and casual. Without these profound relationships, the student is more likely to drop out (Spady, 1970). 
Validating Tinto's theory. Pascarella and Terenzini (1980) conducted a study of 773 freshmen to examine the predictive validity of the Institutional Integration Scale, an instrument they designed to assess academic and social integration based on Tinto's (1975) model (see Appendix A). Their purpose was to determine whether their instrument would discriminate between freshman students who persisted and those who voluntarily withdrew. The thought was the results of the study would be helpful to institutions when allocating resources for retention interventions. Based on the results, Pascarella and Terenzini (1980) determined the quality and impact of student-faculty informal interactions is significant for students' institutional integration and as a result, their persistence. Their findings emphasize the "potential importance of faculty, in both their formal teaching and informal nonteaching, roles, as an influence on freshman students' decisions to persist or withdraw from a particular institution" (Pascarella \& Terenzini, 1980, p. 72).

Results from Bean's (1985) student attrition study challenge the premise that informal faculty interactions are essential for retention. His findings indicate informal faculty contacts are not as important for a student's retention as contacts with peers. However, Bean does point out the sample used in his study was from a large research institution where there is a low expectation of faculty interacting informally with undergraduates, and formal faculty contact at a large university is more likely to affect a student's socialization than informal faculty contact.

Other results from Bean's (1985) study show significance of academic integration on institutional fit. Bean promotes the use of peers in programs to help freshmen fit in and make a commitment to the institution, as peer influence seems to have the most significance on students' socialization. Bean (1985) also recognizes his model was generally consistent with the models of Spady (1970) and Tinto (1975) as to the importance of socialization in 
influencing retention. Both Bean (1990) and Tinto (1975) see integration as a necessary component of retention, although Tinto proposes that a good match between a student's commitment and institutional environment leads to higher social and academic integration and thus persistence, while Bean argues it is a student's attitude, shaped by his beliefs, that predicts retention (Hagedorn, 2012).

Cabrera, Nora, and Castaneda (1993) note there is overlap between Tinto's (1975) student integration model and Bean's (1985) student attrition model. Both models view persistence as a longitudinal process of complex interactions affected by students' precollege characteristics. Both theories also have commonalities in their organizational variables, such as courses and academic integration, and commitments to the institution, such as institutional fit, institutional quality and institutional commitment (Cabrera et al., 1993). Cabrera et al. (1993) adapted parts of Pascarella and Terenzini's (1980) Institutional Integration Scale, along with other instruments, to test their model that incorporated both theoretical frameworks. Integrating both models revealed that rather than environmental factors merely shaping commitments, they are more likely to influence students' social and academic experiences. Cabrera et al. (1993) suggest focusing on variables that are predictive of students' intentions to persist rather than focusing on past behavior to develop intervention strategies to improve retention.

To validate the internal consistency of Tinto's (1975) model, Braxton, Sullivan, and Johnson (1997) reviewed empirical evidence for the model. Their findings show strong confirmation for social integration positively affecting institutional commitment, but academic integration did not have as strong empirical support. Braxton and Lien (2000) explored this further with an assessment of multi-institutional tests and single-institutional tests. They found that the influence of academic integration on retention varies between these two tests. There 
was strong support for the multi-institutional tests and only modest support for the singleinstitutional tests. Braxton and Lien (2000) suggest rethinking the measurement of academic integration or abandoning the construct altogether. Their research seems to imply that academic integration and social integration are equally as important in Tinto's (1975) model, yet Tinto (1987) points out "integration of either sort in one system need not imply comparable integration in the other" (p. 107).

In a study examining the reliability and validity of Pascarella and Terenzini's (1980) Institutional Integration Scale, French and Oakes (2004) found that academic and social integration are not mutually exclusive and may coexist at different levels. Their study also found that student interactions with faculty may enhance both academic and social integration rather than just social integration as the model originally suggests. French and Oakes (2004) recommend that improvement of measurements of noncognitive constructs such as institutional integration "is essential to developing accurate models of student success and persistence" (p. 96).

Psychological perspective of retention. To shift the attention from sociological theories of student retention back to psychological theories and practices that provide a consistent psychological approach that includes the importance of student traits in the retention process, Bean and Eaton (2000) provide a psychological model of college student retention through a lens of four psychological theories: attitude-behavior theory, coping behavioral theory, self-efficacy theory and attribution theory. These theories can be used to "explain the relationships proposed in Tinto's model” (Bean and Eaton, 2000, p. 58).

Bean and Eaton. Combining aspects of the four theories provides a psychological model for understanding the individual processes that occur during the retention process (Bean 
\& Eaton, 2000). The attitude-behavior theory states that if a student believes he fits into an academic environment, and doing well will help him succeed later in life, this leads to a positive attitude about his education and the desire to study more, attend class, and get involved. "Over time, beliefs lead to attitudes, which lead to intentions, which lead to behavior" (Bean \& Eaton, 2000, p. 50).

According to the coping behavioral theory, students who cope well with their college experiences are able to achieve positive outcomes, including reducing their stress levels. Because of students' coping abilities, they are more likely to adopt the positive attitudes that lead to successful academic and social integration. When a student experiences this integration, he is much more likely to persist (Bean \& Eaton, 2000).

A student who does not go to class or study exhibits signs of academic avoidance behaviors. A student who seeks out tutoring or asks questions in class exhibits signs of academic approach behaviors. Academic avoidance behaviors have a negative relationship with academic integration, while academic approach behaviors have a positive relationship with academic integration (Bean \& Eaton, 2000). With social behaviors, a student who attends parties, joins a campus organization, or holds a leadership position within an organization displays signs of social approach behaviors. A student who has an off-campus job or spends lots of weekends at home or off campus displays signs of social avoidance behaviors. As with academic approach behaviors, social approach behaviors have a positive relationship with social integration. Conversely, social avoidance behaviors have a negative relationship with social integration (Bean \& Eaton, 2000).

Self-efficacy refers to a person's perception of his ability to accomplish goals or tasks. According to Bandura's (1977) model of self-efficacy, "an efficacy expectation is the 
conviction that one can successfully execute the behavior required to produce the outcomes" ( $p$. 193). The more a person recognizes his competency in a task, the more confidence he gains and the more likely he is to persist in that task in the future. This can be applied to academic integration and how students view their peers. If they see others succeed, they are apt to believe they can succeed, and then invest in that endeavor (Bean \& Eaton, 2000). It is similar for social integration as students who have "a strong sense of self-efficacy with regard to the particular events and situations that compose campus life" (Bean \& Eaton, 2000, p. 53) gain confidence in their abilities.

The attribution theory focuses on locus of control. A person's locus of control provides a causal perspective for the outcomes he experiences. If he has an internal locus of control, he perceives his internal attributes as responsible for the outcomes he experiences. For example, the time he spends studying for an exam, taking notes and attending class affects his performance in that class (Bean \& Eaton, 2000). Rotter (1966), who developed the concept of locus of control, states the effect of reinforcing a behavior "depends upon whether or not the person perceives a causal relationship between his own behavior and the reward" (p. 1). If the student has an external locus of control, he views the outcome as a result of things outside his control (Bean \& Eaton, 2000). In this case, a student may not produce the right amount of effort to succeed in a class because he does not see how his efforts will make a difference.

Astin (1984) proposes that student time is a precious institutional resource. How students spend their time and the energy they expend are affected by institutional policy and practice. Through the lens of the attribution theory (Bean \& Eaton, 2000), a student might see the amount of energy he expends as within his internal locus of control, but sees the policies and practices, such as the availability of office hours for faculty or academic advisors or the 
availability of class times for courses in a specific major, within his external locus of control. This could also apply to how a student interacts with a faculty member inside and outside the classroom.

Bean and Eaton's (2000) model incorporating the four theories is intended to explain student behavior in the retention process. Students have initial perceptions from when they enter the institution, such as an attributional perception about how things are supposed to work at the institution. They also bring with them personal characteristics. The institutional environment affects all of these characteristics, and students react to these new experiences. Bean and Eaton (2000) posit that a student who navigates these psychological processes successfully experiences "positive self-efficacy, reduced stress, increased efficacy, and internal locus of control" (p. 58). The outcome for the student is social and academic integration, and thus academic success.

Gaps in persistence research. The successful persistence of students can depend on many variables such as student involvement (Astin, 1984), students' attitudes (Bean, 1985), individual psychological processes (Bean \& Eaton, 2000), student-faculty interactions (Pascarella \& Terenzini, 1980), the interaction between student attributes and the institutional environment (Spady, 1970, 1971), and academic and social integration (Tinto, 1975). Tinto’s (1975) model of student integration has been called the "foundation" (Renn \& Reason, 2013), "most widely recognized sociological perspective" (Habley et al., 2012), and "base" of retention literature (Demetriou \& Schmitz-Sciborski, 2011), and is of "paradigmatic stature" (Braxton et al., 2014) from an "early pioneer" in retention research (Hagedorn, 2012). Morrison and Silverman (2012) state, "it is Tinto's model of academic and social integration that is generally the cornerstone of the research, along with the notion of institutional fit" (p. 77). 
Tierney (1992) notes a possible limitation of Tinto's (1975) model as minority students may not fit the schema since institutions reflect the culture of the dominant culture. Since that dominant culture is White, this theory does not take into account the cultures of minorities as these students are integrated into the rituals of the institution. Retention literature of the 1990s and 2000s was been more focused on the needs of underrepresented populations and diverse college students (Demetriou \& Scmitz-Sciborski, 2011; Hagedorn, 2012). As the characteristics of underrepresented populations were not variables explored in this study, this review of the literature was concentrated on research prior to those later studies.

Most theories of retention have been focused on students at 4-year institutions. These have generally been traditional-aged students who go to school full time and live on campus (Morrison \& Silverman, 2012). Tinto downplayed the importance of external events that tend to have more of an effect on students in 2-year colleges and acknowledged that integration into those communities might not be as important. His emphasis on integration in the model is why it has generally been used for four-year institutions and why studies that followed have mostly focused on 4-year institutions (Morrison \& Silverman, 2012).

This study explored how generational cohort may have an effect on students' expectations of instructional activities inside and outside the classroom and faculty approaches to instructional activities inside and outside the classroom. A generational cohort is a group of people who are bound by a phase of life of approximately 22 years, and by peer personality, which is a sum of attributes of the cohort. The peer personality distinguishes the cohort group from others with its own unique biography (Strauss \& Howe, 1991). The traditional-aged students of current retentions studies would be classified as the Millennial generation according to the definition of the Millennial cohort (Howe, 2014). A further review of generational 
cohorts, and Millennials in particular, reveals how this variable might affect student expectations.

\section{Generational Cohort Theory}

A generational approach to understanding college student behaviors and perceptions suggests people born within a certain "generation" share common beliefs and behaviors due to a series of defining events that occur within the generational time period (Moore, 2007). These beliefs and behaviors help to form the cohort group's personality, although it is important to realize this is a broad generalization as not everyone born during that time shares the same characteristics, such as marginalized groups (Moore, 2007).

Not only are generations shaped by the events that occur during their formative years, but they are also shaped by their interactions with other generations. Generations have peer personalities, which are partly defined by their perceived membership in their generation (Coomes \& DeBard, 2004; Strauss \& Howe, 1991). Generations are different due to life cycle effects, period effects, and cohort effects (Taylor, 2014). The use of generation theory can be helpful when determining how students, faculty and staff interact with each other. According to Worley (2011), “today’s college classrooms are a variable mix of generations. This mix of generations brings different characteristics, attitudes, experiences, and expectations to the classroom" (p. 32).

Black (2010) explains that “today's college students, unlike their counterparts 40 years ago, are from diverse cultural, economic, and geographic backgrounds” (p. 93). Most faculty, staff and students on college campuses represent three generations, Baby Boomers, Generation X and Millennials (Coomes \& DeBard, 2004; Howe \& Strauss, 2007), although the oldest members of the newest generation, Generation $\mathrm{Z}$, are making their way through junior high and 
high school and will soon be on college campuses based on dates for the generational cohort from Howe (2014).

\section{The Boomers}

The Baby Boomers, named for the large increase in population from the spike in births after World War II (Taylor, 2014), were born between 1943 and 1960, making them between the ages of 74 and 57 (Howe \& Strauss, 2007). Sandeen (2008) predicts Boomers will stay employed past retirement age due to their lack of saving for retirement and willingness to buy on credit. Boomers value recognition and are career-focused. Coomes and DeBard (2004) point out it was the Boomers who were responsible for significant enrollment growth at college campuses in the 1980s and 1990s when this group returned to college as adult learners.

The Baby Boomers grew up before the computer was invented, and as such, may not be as comfortable with using technology, although they did see the dawning of a new age with the television. Defining events for the Baby Boomers include the Civil Rights Movement, the Vietnam War, Watergate and the Kennedy assassinations. Boomers are individualistic, competitive and self-sufficient. They have a strong work ethic and sense of responsibility (Worley, 2011). According to Mangold (2007), Baby Boomers do not like discomfort in the learning environment. In her research of Millennial student expectations of learning processes and teachers, Russo (2013), a faculty member at the University of Kansas, calls attention to her membership in the Baby Boomer cohort and admits because of this, she is "not well-connected to millennial cultural touchstones" (p.5). Rather, she is "hardly connected at all, as some hilarious interactions in my classes demonstrate" (Russo, 2013, p. 5). 


\section{Gen Xers}

Generation X, also called the Thirteeners for being the 13th generation after the generation of Puritans who founded the nation (Coomes \& DeBard, 2004), were born between 1961 and 1981, making members of this cohort between the ages of 56 and 36 (Howe \& Strauss, 2007). Members of this generation want feedback to gauge how they are doing and appreciate opportunities for learning. Generation $\mathrm{X}$ was also the first generation to grow up with computers, so it is somewhat comfortable with technology (Sandeen, 2008; Worley, 2011). Taylor (2014) notes Generation $X$ takes a more liberal position than older generations and is a dividing line between older and younger generations on many issues such as politics. Similar to Baby Boomers, Generation $\mathrm{X}$ is also concerned about its financial future and having enough money for retirement.

Defining events that occurred during this generation include the energy crisis, the women's rights movement, high divorce rates and the increase of single-parent families. Gen Xers are independent, self-sufficient and challenge authority (Worley, 2011). Members of Generation $\mathrm{X}$ are children of the divorce revolution and Reagan revolution. They are also more likely to be accepting of social diversity than older generations (Taylor, 2014).

\section{Millennials}

The Millennials, also referred to as Generation $\mathrm{Y}$ for being the generation that came after Generation X, or the Net Generation because of growing up during the time of an exploding technological revolution (Worley, 2011), were born between 1982 and 2004 (Howe, 2014). This is the generation representing traditional-aged students. Members of this cohort are between the ages of 35 and 13, indicating college and university educators will continue to see Millennial students enroll in higher education institutions for the next few years. 
There is some debate as to the end date for the Millennial generation. Many different sources cite the ending date as 2000 (Worley, 2011; Moore, 2007), 2002 (Carter, 2008; Coomes

\& DeBard, 2004; Much, Wagener, Breitkreutz, \& Hellenbrand, 2014), or 2003 (Sandeen, 2008; Wilson \& Gerber, 2008), but Howe (2014), a well-known researcher of generation theory, places a tentative starting date for Generation $\mathrm{Z}$ as 2005, thus giving the Millennial generation a default end date of around 2004. This puts it at the 22 year-life phase defined by Strauss \& Howe (1991) as a generational cohort. Defining events for Generation Y include school shootings, the Sept. 11 terrorist attacks, the Clinton impeachment and the Monica Lewinsky sex scandal (Worley, 2011).

\section{Generation Z}

Just when higher education thought it had a grasp on the characteristics of the Millennial generation, a new generation is going to walk through the door. This group of students is stressed about the economy, wants information immediately at their fingertips, and is hooked on social networks (Benhamou, 2015). According to Howe (2014), the opening window for this cohort is between 2000 and 2006, although he has tentatively chosen 2005 due to defining events of the decade. Generation $\mathrm{Z}$ is also referred to as the "Homeland Generation" because of events that occurred in the 2000s, such as the war on terror, creation of the Department of Homeland Security, and the protective nature of parents that keeps this generation of children home more than any earlier generation of children (Howe, 2014).

Seemiller and Grace (2016) claim Generation Z is already here and is comprised of people born between 1995 and 2010. The research on Generation $\mathrm{Z}$ is still extremely vague, with Seemiller and Grace's (2016) Generation Z Goes to College being the first definitive book on this up-and-coming generation, but experts warn that members of this generation will be 
very different from Millennials and have very different needs (Benhamou, 2015), requiring educators to continue to adapt to changing generations and the necessity for more persistence research focused on generational differences.

\section{Millennial Typology}

Howe and Strauss $(2000,2007)$, well known for their research on generational theory, and Millennials in particular, provide insight into this generation by identifying seven distinguishing characteristics of the Millennial typology: special, sheltered, confident, teamoriented, achieving, pressured, and conventional. These seven characteristics have been used in the research to try and predict behavior and help higher education practitioners better understand the needs of their students.

Millennial students have been told all their lives they are special. They have been made to feel vital by their parents and are seen as the "builders" of the future. Millennials have been rewarded for effort and participation, even if it means they got eighth place in a competition (DeBard, 2004; Monaco \& Martin, 2007). High expectations abound for them. Millennials have also been sheltered from harm's way. They expect rules to be communicated and enforced but also to receive due process. They trust and count on authority (DeBard, 2004).

This generational group has a high degree of confidence. They are master negotiators and believe in themselves (DeBard, 2004). Because of technology, information is at their fingertips, increasing their self-confidence (Monaco \& Martin, 2007). Millennials are teamoriented; they like to work with others. They want to cooperate and be seen as cooperative. "As students, they enjoy working on academic project teams" (DeBard, 2004, p. 37). Monaco and Martin (2007) note how Millennial students are not as comfortable working independently because there is a higher risk of failure. 
Millennials need to achieve. They are optimistic and expectant about their futures. If they work hard enough, they believe they can achieve the American Dream. Millennial students have high expectations about their performance in college and assume they will earn a college degree (DeBard, 2004). Because of their high need to achieve and their high hopes for the future, Millennials feel pressured to succeed. With all the opportunities available to them and the mantle of "builders of the world," they do not have a lot of room to fail. Millennials accept social rules and cultural differences. Baby Boomers have encouraged them to make better choices than their generation and support Millennials who follow convention (DeBard, 2004). Because of this feeling of being pressured, Millennials need feedback. They thrive on it and "become paralyzed, often unable to proceed forward, without feedback and direction" (Monaco \& Martin, 2007, p. 43).

Much et al.'s (2014) research on Millennial students reveals university staff's perceptions of Millennial characteristics. Several themes emerged from interviews conducted of student affairs professionals and academic advisors. One of these themes is the idea Millennial students see themselves as the exception to the rule. They expect rules to be changed for them. It is possible this stems from their parents telling them they are special and their confidence in their ability to negotiate (DeBard, 2004). Additional themes include a tendency to blame others and to ignore problems, hoping they go away; expecting others to solve problems; and reliance on parental involvement (Much et al., 2014).

There are noted limitations to the Millennial typology originally created by Howe and Strauss $(2000,2007)$. Hesel and May (2007) point out how Howe and Strauss' (2000) original research on Millennials was only conducted on a small sample in an affluent suburb. The Class of 2000 Survey was given to 660 high school students in Fairfax County, Virginia, in 1999. A 
Fairfax Teacher's Survey was given to 200 elementary, middle, and high school teachers. Results from these surveys were used to compose the portrait of the Millennial generation (Howe \& Strauss, 2000). Further investigation by Hesel and May (2007) revealed the population in Fairfax is "three times more Asian Americans and one-third fewer African Americans than the rest of the United States" (para. 6). They also question how the survey was conducted and its results.

Hesel and May (2007) propose that the longitudinal data collected by the Cooperative Institutional Research Program (CIRP) at the University of California, Los Angeles Higher Educational Research Institute (HERI) is a better source of data for understanding generational differences and patterns, and it offers some contradictory conclusions regarding generational differences. One of these differences is related to academic pressure. Where Howe and Strauss (2000) conclude that students are worried about grades and college admission, and spend more time on homework and housework, CIRP data instead shows students spend less time studying, and the number has declined 33\% from 1987 to 2002 (Hesel \& May, 2007). Hesel and May (2007) recommend institutional leaders be careful about making broad conclusions and examine methods used in the research on generalizations of a student population. They also maintain "a one-size-fits-all generational theory works against" (Hesel \& May, 2007, para. 32) the goal of meeting the individual needs of students.

First-generation millennial students. In providing an overview of the Millennial typology, it would be remiss to ignore the research on first-generation students, who also represent a large population of students on college campuses and may technically be Millennials. These students are most commonly defined as those whose parents did not complete a college degree, and they are more than likely to be nontraditional, such as married, 
employed, attending college part-time, older, parents, and less engaged in campus activities. Because of their nontraditional status, there is a challenge in motivating these students to devote enough time to achieve success and completion (Petty, 2014).

Soria and Stebleton (2012) note that "because first-generation students do not possess the same levels of social capital as their non-first generation peers, they are likely to face more challenges in navigating the university and in becoming fully engaged in their academic pursuits" (p. 673). First-generation students are less likely to engage in those social and academic activities that integrate them into the institution. These activities include using support services, interacting with others on campus, studying in peer groups, participating in extracurricular activities, or asking for help.

Soria and Stebelton's (2012) study found that first-generation students consistently reported lower levels of academic engagement than their peers who were not first-generation. These students were less likely to contribute to class discussions, bring up ideas that connect different courses, interact with faculty during lectures or ask insightful questions in class. Collier and Morgan (2007) point out that first-generation students have less mastery of the college student role. This is an "important resource for recognizing what their instructors expect of them and for responding appropriately to those expectations" (Collier \& Morgan, 2007, p. 427). This may be from a lack of parental coaching or lower level of cultural capital that makes it difficult for them to become role experts. Less mastery may make it more difficult for first-generation students to do well. In their study of undergraduate students and faculty, Collier and Morgan (2007) determined that first-generation students were uniquely concerned about student-teacher contacts in the classroom because how a professor spoke in class influenced their willingness to approach the professor for help, suggesting this dissonance in 
the student-faculty relationship may disproportionately affect first-generation students.

Tinto (2012) notes that current students may not fit the traditional mold since they are likely to attend school part time, have a job, and not live on campus. This population could include first-generation students as they are more than likely to be nontraditional by being employed and attending college part-time. As such, focusing persistence strategies on the way classes are structured, taught, and experienced by students is more likely to capture the expectations of these different subsets of Millennials rather than just the traditional-type student.

Millennial expectations and learning. Montag, Campo, Weissman, Walmsley, and Snell (2012) point out that Millennial students show dissatisfaction with the availability of faculty to offer advice and the size of classes. They want individualized attention from faculty and staff. They have different expectations of their educational experience than past generations and are used to handholding throughout the educational process (Monaco \& Martin, 2007). Nilson (2010) notes how Millennials are challenging to work with and view educators in the role as customer service. She states "Millennials can be demanding, discourteous, impatient, time-consuming, and energy sapping" (p. 12). Because of this, institutions have been bending over backward to upgrade services and keep students happy to "retain" them. Nilson (2010) also points out positives of this generation. Millennials "have career goals, positive attitudes, technological savvy, and collaborative indications" (p. 12).

The teaching-centered classroom where the faculty member completely controls the learning environment through lectures is not the learning-centered classroom or creative content delivery needed to engage and challenge Millennial students inside and outside the classroom. Mangold (2007) notes this type of learning environment is how Baby Boomers were 
educated. They were "dependent on educators to give them information and this usually occurred in the lecture format" (Mangold, 2007, p. 21). Baby Boomers are also more concerned about the process rather than the outcome.

Moore (2007) provides some insight into how Millennial students perceive their academic environment. For example, Millennials are not necessarily keen on listening to a faculty member lecture in front of the classroom for an hour; they want more interactive experiences, and they want technology. They grew up working in teams, and their learning style is probably not being addressed by Baby Boomer and Generation X instructors whose lectures, memorization requirements, and multiple choice tests may no longer be effective for teaching this generation. Millennials are very connected to their peers; they see peer grading and evaluation as a way to show they matter (Moore, 2007).

Millennials expect immediacy, which means quick feedback on assignments and regular posting of grades. They want information in real time just like they would get on the Internet with live chats and 24-hour customer service (Moore, 2007). They view disorganization, an inability to stick to a syllabus, ill preparation, and an inability to follow through as unprofessional, especially since they led such tightly organized childhoods (Nilson, 2010). These students worry about grades and want to be evaluated. They want higher education practitioners to outline "a clear goal, define an objective measure of success, explain possible strategies, structure their work in teams, and offer frequent feedback on their progress" (Howe \& Strauss, 2007, p. 158).

Also referred to as "digital natives," this group has been immersed in the Internet and a digital world. They are fluent in the use of technological tools, multitask and are more visual learners (Black, 2010). They have been exposed to the tools of technology from a very young 
age and their access to it is greater than any past generation (Roehl et al., 2013). This is in opposition to faculty and staff, who are mostly likely Boomers or Gen Xers and "digital immigrants," rather than digital natives (Levine \& Dean, 2012). Black (2010) suggests that, due to their use of technology and the expectation of on-demand services, Millennials may have shorter attention spans and lack depth in their learning abilities. But what does this mean for teaching? It is likely that Millennials find traditional methods boring and cannot relate to an instructor who only lectures at the front of the classroom.

Students also use social media in many aspects of their lives and expect to interact on those platforms (Levine \& Dean, 2012), yet an Inside Higher Ed and Babson Survey Research Group study of 4,564 faculty from institutions of all types reveals that $44.7 \%$ never interact with their students via social media (Allen, Seaman, Lederman, \& Jaschik, 2012). Another onefifth of faculty does so rarely. The study also revealed that $40.9 \%$ of faculty who teach traditional courses use simulations or video as part of their teaching method. This indicates a shift toward more active learning methods.

In an examination of three generations, Baby Boomers, Generation X and Generation Y, Monk et al. (2010) found that all survey respondents, both faculty and students, viewed modern students as being higher in technology knowledge and use than faculty. They also had significant results for mean differences between faculty and student generational perceptions of faculty and student classroom behaviors and attitudes. However, Monk et al.'s (2010) study did not focus on Millennial students, as $70 \%$ of the student respondents were female graduate students who represented Generation X. The majority of faculty respondents were tenure-track female assistant professors. 
To determine if the argument "Millennial students are different enough from previous generations that successfully teaching them requires revising pedagogies and tools" (Russo, 2013, p. 1) has merit, Russo (2013) created an instrument designed around five of Howe and Strauss' $(2000,2007)$ seven distinguishing Millennial characteristics: special, sheltered, confident, team-oriented, and conventional (see Appendix B). She also conducted three focus groups. In addition to items focused on the five characteristics, Russo (2013) included items examining technology use, student consumerism, and expectations of classroom practices and teacher interaction.

Responses from students reflect a desire for attention, support, and clearly enunciated classroom instructions from faculty. However, responses were not consistent with claims of Millennials favoring group interactions, and desiring extensive integration of technology in the classroom and feedback. Responses were also inconsistent for expectations of faculty and students' educational experience. Russo (2013) recommends a revised survey with open-ended questions to gather more data about students' expectations of the learning experience. Russo's study was also limited to 204 students in a speech communication class who received research credit for completing the survey. This was the first time her instrument was tested, and the sample size was small and primarily consisted of Caucasian females.

Carter (2008) used past research on Millennial characteristics and expectations to adapt a six-hour secondary education course using a constructivist approach, which focuses on the learner creating knowledge of topics rather than having it disseminated to him by someone else. Revised teaching methodologies focused on the student being in an active role rather than a passive role in the learning process. This included creating class definitions of concepts, working in small groups, and creating learning centers. The faculty member served as a 
facilitator and guided the classroom experiences through his role as the expert in the classroom (Carter, 2008).

Carter's (2008) adapted teaching methods were designed to align with Millennial expectations of "streamlined communication environments, networking opportunities with other novices and experts, immediate evaluative feedback, and continually-improving use of multiple tools and resources" (p. 25). Anecdotal evidence from student reflections showed positive regard for the learning approaches. In formal teacher evaluations, students selfreported meeting the course objectives. These evaluations also indicated the instructor was effective and motivated student learning. Assessments the following semester suggested the students utilized what they learned and applied it to their internship experience. Carter's (2008) findings imply that adapting teaching methods using a generational approach has a positive impact on student engagement.

\section{Pedagogy and Faculty Best Practices}

The faculty in higher education institutions are the only teachers, from kindergarten through high school, who do not receive much development to teach their students (Tinto, 2004; Tinto, 2007). Davis and Arend (2013) point out "the overall effort to prepare graduate students as teachers still has not caught on in most graduate programs in major universities" ( $p$. 7). Once graduate students become college professors, they teach how they were taught. They give lectures, answer students' questions, and then give tests, and they're not necessarily encouraged to use other methods since lecturing and discussion is the dominant paradigm for teaching and learning (Davis \& Arend, 2013).

However, Bain (2004) notes that highly effective teachers are willing to try new things and do not follow traditions blindly. The best educators think "of teaching as anything they 
might do to help and encourage students to learn" (Bain, 2004, p. 49). Everything they do is based on their strong concern for students and understanding student development (Bain, 2004). These instructors give feedback and let their students revise and improve their work before getting an actual grade. They have clear learning objectives and provide intellectual and emotional support for students. The best college teachers genuinely care about their students (Bain, 2012). These teaching methods appeal to the Millennial generation who want clear guidelines for assignments and projects, frequent feedback and assessment, and active learning in the classroom (Tinto 2004; Worley, 2011).

Fink (2013) points out that "good teaching and learning also requires good interactions between teachers and students" (p. 283), and these interactions are affected by teacher credibility, which is whether teachers are perceived to be competent, trustworthy or dynamic regardless of whether they possess those qualities. Part of being trustworthy is following through on promises, giving immediate feedback, being flexible, treating all students the same, and offering a rational explanation for grading (Fink, 2013). Most of these are also teaching strategies recommended for Millennial learners (Worley, 2011).

Results from Astin's (1984) longitudinal study of college dropouts in 1975 that included samples of more than 200,000 students revealed that "frequent interaction with faculty is more strongly related to satisfaction with college than any other type of involvement, or indeed, any other student or institutional characteristic" (p. 304). The actions of faculty in the classroom have been established as a vital component of enhancing student retention, yet the role of faculty has largely been absent from retention efforts (Tinto, 2007). Retention efforts are calling for pedagogical skills that may be absent from a faculty member's skill set (Tinto, 2004). 
If these pedagogical skills are absent from a faculty member's skill set, a shift in how faculty view the importance of the Scholarship of Teaching and Learning (SoTL) may indicate a willingness for faculty to seek them out. In a 2001 survey of the Professional and Organizational Development Network (POD), SoTL was listed in the top 10 services for faculty development. Results from a 2012 survey showed "SoTL is now among the top five services related to teaching and learning and remains in the top ten of all services offered by faculty development professionals" (Beach, 2016, p. 16).

In a study of 238 faculty about increasing faculty attendance at professional development events, survey items under the faculty motive of efficacy, or sense of having made a difference, had the highest ratings (Burdick, Doherty, \& Schoenfeld, 2015). The highest rated item was "My involvement will help me grow as a teacher." Another highly rated item was "My involvement will have a positive impact." Burdick et al. (2015) also report that faculty members are likely to attend faculty development events if the topic addresses a problem the campus has faced for several years. As indicated by the research (Habley et al; 2012, Renn \& Reason, 2013; Tinto, 2012), successful persistence of students continues to be an issue on college campuses.

Freire (2004) analyzes the teacher-student relationship and criticizes what he calls the "banking" concept of education, the traditional education system in which teachers make deposits of information into students, who are the receptacles. "In the banking concept of education, knowledge is a gift bestowed by those who consider themselves knowledgeable upon those whom they consider to know nothing" (Freire, 2004, p. 319). With the banking model, "the teacher teaches and the students are taught," "the teacher talks and the students listen," and "the teacher knows everything and the students know nothing" (p. 320). The 
teacher is the absolute in the knowledge process, and critical thinking is a casualty. This concept is antithesis to principles of active learning teaching methods.

\section{Active Learning}

According to Roehl et al. (2013), "active learning is an umbrella term for pedagogies focusing on student activity and student engagement in the learning process" (p. 45). This is a movement from traditional methods of surface learning, or rote memorization, to deep learning, where students develop understanding by exploring a topic rather than sitting in a lecture. With passive learning, students receive the information and ideas from a lecture or book but may not necessarily reflect and make connections, but with active learning, faculty give students more experiential learning activities, and then give them the opportunity to reflect on what those activities mean (Fink, 2013).

Active learning is not a new concept. In Chickering and Gamson's (1987) often-cited seven principles for good practice in undergraduate education, the third principle states that good practice "uses active learning techniques." However, "although the language and vision of active learning have initiated a significant movement in the United States and Canada, professional practice still lags woefully behind" (Fink, 2013, p. xii). Lecture formats are still the primary teaching method in college classrooms (Davis \& Arend, 2013; Roehl et al., 2013) even though this teaching practice has been proven to be less effective (Fink, 2013). The general definition of a lecture is a professor standing alone at the front of the room while students in rows or tiered seating take notes (Davis \& Arend, 2013). Research of lecture as a teaching practice by itself reveals it has limited effectiveness in helping students retain info, transfer knowledge to other situations, develop thinking and problem-solving skills, and change attitudes (Fink, 2013; Fry, Ketteridge, \& Marshall, 2003). 
Fry et al. (2003) stress that using a lecturing approach is still an essential component of classroom structure. Faculty can use lectures to show their enthusiasm or passion for the subject material, provide students with new information they may not find in the textbook or other sources, highlight differences and similarities between key concepts, share personal insights, and organize their subject matter to highlight the importance of certain concepts or course objectives. To be more effective, though, lecturing needs to be combined with other teaching methods that help the student become more active rather than passive (Fry et al., 2003).

Students working in partnership with faculty to help design and teach a course is one example of active learning (Chickering \& Gamson, 1987). Rather than students being an object where information is deposited like in Freire's (2004) banking model, they are considered partners in shaping and implementing the course (Fink, 2013). The faculty member shares his or her power with the students by asking about learning goals, feedback and assessment, and teaching and learning strategies, and by incorporating those opinions into the course design (Fink, 2013).

Other examples of active learning include participating in real settings, case studies, simulations, role playing, and classroom discussions; direct observation of phenomena; and indepth reflective dialogue on the learning process. However, there are risks to incorporating active learning in the classroom. Students may not participate willingly in the activities, there may not be enough time to cover as much content, or students may not learn as well (Fink, 2013). Before coming to college, students were taught to be passive learners and to follow a prescribed curriculum; partnering with faculty is not a traditional method of interaction (CookSather et al., 2014). 


\section{Teaching Norms and Violations}

Through their research, Braxton et al. (2014) point to 13 forces that may influence student perceptions of institutional commitment, including good teaching, faculty interest in students, active learning practices, and violations of teaching norms. Norms, or proscribed patterns of behavior, in the teaching profession "safeguard the welfare of students as clients of teaching role performance" (Braxton et al., 2014, p. 105). How students perceive the commitment of their institution to their well-being may be influenced by violations in teaching norms, which make up the normative structure of college teaching at the undergraduate level (Braxton et al., 2014). Violations can include inattentive planning, condescending negativism, personal disregard, uncommunicated course details and particularistic grading (Braxton \& Bayer, 1999), which could be areas of incongruity identified by the study. As the quality and impact of instructional activities and interactions between faculty and students is significant for students' integration into an institution (Pascarella \& Terenzini, 1980), a dissonance in students' expectations of their faculty and the approaches faculty use could cause a disruption in the student-faculty relationship, leading to a lack of engagement, both academically and socially.

\section{Summary}

The successful persistence of students is needed for a myriad of reasons: continued success of higher education institutions; public and private economic benefits; and public and private social benefits (Baum et al., 2013; Habley et al., 2012; Tinto, 2004). Retention research points to the importance of the student-faculty relationship (Astin, 1984, Tinto, 2007), and generational differences between students and faculty is one variable that can affect the academic and social integration of students into their institution, which Tinto's (1975) student 
integration model reveals is critical for institutional fit. Thus, it is possible that a significant difference in students' expectations of instructional activities inside and outside the classroom and faculty approaches to instructional activities inside and outside the classroom could lead to a disruption in the interactions between faculty and students that are so vital for student engagement. 


\section{CHAPTER III}

\section{METHODOLOGY AND PROCEDURES}

\section{Introduction}

A student's failure to meet educational goals can lead to an inability to persist (Bean, 1990; Reason, 2009), and research shows there is a link between persistence and graduation (Arnold, 1999; Hagedorn, 2012). Thus, it is up to institutions to determine what barriers stand in the way of student persistence and try to remove them. There are many dimensions to the persistence problem, one of which is how students relate to their academic environment. "Students' interactions with their environments matter" (Reason, 2009, p. 675) as evidenced by the influences of organizational context, individual student experiences, the student-peer environment, and precollege characteristics on student persistence (Reason, 2009).

\section{Statement of the Problem}

A significant part of students' interactions with their educational environment is how they interact with faculty (Astin, 1984). Tinto (2007) suggests the links between faculty pedagogy and student retention need to be more fully explored and tested. As a result of their research study on faculty teaching skills and the influence of those skills on student departure for first-time, full-time students, Braxton et al. (2000) also note how more attention needs to be given to the interactions that occur inside the classroom. The present study sought to expand the research of student persistence and how it may be affected by the interactions between students and faculty.

\section{Purpose of the Study}

The purpose of this study was to compare student expectations of instructional activities inside and outside the classroom to faculty approaches to instructional activities inside and 
outside the classroom at a 4-year comprehensive Midwestern public university to identify areas of congruence and incongruence between students and faculty in attitudes toward class structure, feedback and assessment, technology use, faculty/student interaction, personal regard, class planning, and use of resources.

\section{Research Questions and Hypotheses}

The use of a quantitative survey design was appropriate for the present study. In a quantitative study, the research data are able to represent a larger proportion of the population compared to qualitative studies that generally use much smaller samples (Mason, 2010). The following research questions were used:

1. What are students' expectations of instructional activities inside the classroom?

2. What are students' expectations of instructional activities outside the classroom?

3. What are faculty approaches to instructional activities inside the classroom?

4. What are faculty approaches to instructional activities outside the classroom?

5. To what extent do faculty approaches to instructional activities inside the classroom differ from students' expectations of those instructional activities?

6. To what extent do faculty approaches to instructional activities outside the classroom differ from students' expectations of those instructional activities?

Based on the above research questions, the following hypotheses were proposed.

$\mathrm{H}_{0}$ : There will be no significant difference between students' expectations of instructional activities inside the classroom and faculty approaches to instructional activities inside the classroom. 
$\mathrm{H}_{1}$ : Students' expectations of instructional activities inside the classroom are significantly different than faculty approaches to instructional activities inside the classroom.

$\mathrm{H}_{0}$ : There will be no significant difference between students' expectations of instructional activities outside the classroom and faculty approaches to instructional activities outside the classroom.

$\mathrm{H}_{2}$ : Students' expectations of instructional activities outside the classroom are significantly different than faculty approaches to instructional activities outside the classroom.

\section{Research Design}

The quantitative data for this study were acquired through a cross-sectional online survey design of a student survey and a faculty survey. According to Creswell (2009), "a survey design provides a quantitative or numeric description of trends, attitudes or opinions of a population by studying a sample of that population" (p. 145). Likert-type items combined into Likert scales were used to measure these attitudes and opinions. Likert-type items are single questions or statements, while Likert scales "are composed of a series of four or more Likerttype items that are combined into a single composite score/variable during the data analysis process" (Boone \& Boone, 2012, para 6).

Likert scales are easy to construct and tend to be highly reliable (Vogt \& Johnson, 2011). Jamieson (2004) notes how "Likert scales are commonly used to measure attitude, providing a range of responses to a given question or statement" (p.1217). Categories of responses often include a range from "strongly disagree" to "strongly agree," where strongly disagree represents 1 and strongly agree represents 5 , and the three middle responses are 
“disagree," "neutral," and "agree" (Jamieson, 2004). Although Likert scales are popular for trying to quantify people's opinions on various issues (Bishop \& Herron, 2015), weaknesses can include acquiescence bias, social desirability bias, and central tendency bias (Gingery, 2009; Vogt \& Johnson, 2011).

Acquiescence bias occurs when respondents try to be agreeable and give positive answers to please the researcher. Vogt and Johnson (2011) point out there is not much evidence this kind of bias is common. Social desirability bias occurs when respondents try to answer how they think "good people" should answer or what they think is socially acceptable rather than what they actually feel or believe. As with acquiescence bias, there is also little evidence of social desirability bias. It is difficult to study, and people who take the time to fill out surveys generally want to give honest answers (Vogt, 2007; Vogt \& Johnson, 2011). Central tendency bias occurs when survey respondents are hesitant to select choices at either end of the scale, such as strongly disagree or strongly agree. They are more apt to choose the middle response, such as neutral (Gingery, 2009). However, "allowing respondents to express themselves fully is almost always a good idea, whether this means having neutral options on Likert scales or encouraging comments and leaving space for respondents to make them" (Vogt, 2007, p. 89).

Variables for the present study focused on Millennial characteristics, pedagogical characteristics, and faculty/student interaction. In data analysis, Likert-type items of attitudes were combined to form scales as these scales were likely to be more reliable than single Likerttype items for parametric statistics (Bishop \& Herron, 2015; Brown, 2011). 


\section{Research Setting}

The location of the study was chosen for several reasons. It has a higher persistence rate than the national average, and its undergraduate enrollment is between 15,000 and 20,000. The institution had a record-breaking freshmen class in 2015, the highest since 1989. It is a 4-year comprehensive Midwestern public university, is centrally located and one of 12 public universities in its state, and offers over 160 bachelor's degree options. Its high graduation rate puts it in the top $10 \%$ of all U.S. universities, and it has a diverse campus. According to census data from the fall of 2016, the institution employs just over 1,200 departmental faculty, and almost $25 \%$ of its 2016 freshmen class came from underrepresented groups.

\section{Participants}

The target student population was comprised of traditional-age undergraduate students born between 1992 and 1998 who were enrolled at a 4-year comprehensive Midwestern public university in the fall of 2016. The students were surveyed in late fall of 2016 to determine their expectations of faculty teaching methods and faculty interactions inside and outside the classroom. The group of students in this age bracket represented the Millennial generation, individuals born between 1982 and 2004 (Howe, 2014).

The target faculty population was undergraduate faculty at a 4-year comprehensive Midwestern public university with approximately 10 or more years of teaching experience at 4year public institutions. The faculty were also surveyed in late fall of 2016 to determine their approaches to instructional activities inside and outside the classroom.

\section{Instrumentation}

The survey instruments used in this study were constructed by the researcher and adapted from Pascarella and Terenzini's 1980 Institutional Integration Scale (see Appendix A) 
and Russo’s 2013 survey for examining Millennial characteristics for classroom strategy changes (see Appendix B). Both Dr. Ernie Pascarella and Dr. Tracy Russo gave permission for their instruments to be used and adapted (see Appendices E and F). In addition, Pascarella and Terenzini's (1980) Institutional Integration Scale was used with the permission of The Ohio State University Press. Each of the two instruments was constructed of 5-point, Likert-type items.

\section{Institutional Integration Scale}

The Institutional Integration Scale (IIS) was designed to assess academic integration and social integration and was based on Tinto's (1975) model. It includes five subscales with a total of 30 items. These sections are peer-group interactions; interactions with faculty; faculty concerns for student development and teaching; academic and intellectual development; and institutional and goal commitment. Psychometric properties of the Institutional Integration Scale were examined by French and Oakes (2004). The coefficient alpha for internal consistency reliability was .83 for the 30 -item scale. Coefficient alphas for the five subscales ranged from .61 for the academic and intellectual development subscale to .86 for the interactions with faculty subscale.

Model fit was evaluated by examination of the Goodness-of-Fit Index (GFI), the Comparative Fit Index (CFI) and the Root Mean Square Error of Approximation (RMSEA), where the five subscales were divided between two factors: academic integration and social integration. Values of over .90 for the GFI and CFI indicate reasonable fit of the model. For the RMSEA, values less than .05 indicate a close fit. The fit indices results were GFI $=1.00, \mathrm{CFI}=$ .99 , and RMSEA $=.04$. These results indicate the model is a good fit, although a review of parameters for the factors of academic integration and social integration show values outside 
the expected range; they exceeded 1.0 with an estimated correlation of 1.17 (French \& Oakes, 2004).

\section{Russo Instrument}

The Russo instrument includes eight sections with a total of 58 items. The sections are special, conventional, confident, team-oriented, sheltered, technology, instructors, and consumers. Five of the sections were designed based on Millennial characteristics from Howe and Strauss $(2000,2007)$. Russo's study in 2013 was the first time the instrument was tested. Russo (2013) notes some of the items on the instrument are ambiguous. The study was not originally meant to establish statistical relationships or generalize beyond the group of students in her class. Russo points out additional investigation should frame items to gather "more finegrained and nuanced information, particularly in terms of student expectations of the learning experiences" (p. 15). The instrument was tested on a small sample of 204 students who were mostly Caucasian females. No information on the psychometric properties of reliability or validity was available.

\section{Study Instruments}

The student instrument for the present study was divided into five sections (see Appendix C). The first section consisted of questions to determine specific characteristics about the respondents. The next three sections were constructed of Likert-type items for instructional activities inside the classroom, instructional activities outside the classroom, and institutional and goal commitment. The fifth section was a qualitative section with three open-ended questions. The Likert-type items were developed drawing on the research of Millennial characteristics, retention and persistence, and pedagogy. Braxton et al. (2000) suggest the classroom is the "gateway for student involvement in the academic and social communities of a 
college" (p. 216) as the frequent interactions students have with faculty mostly occur in the classroom. With this in mind, the section for instructional activities inside the classroom was designed to have the most Likert-type items.

Millennial variables explored were the special and sheltered Millennial characteristics. All their lives, Millennials have been told they are special. They are "made to feel vital to their parents' sense of purpose" (DeBard, 2004, p. 35) and see themselves "as special and highly expectant" (DeBard, 2004, p. 35). Millennials expect rules to be clearly communicated and enforced fairly. They have a need for structure; their parents and their educational systems have provided it for them since they were young. Because of the pressure they feel to perform, another Millennial characteristic, they need that structure (DeBard, 2004). Other variables used for the research design were class structure, feedback and assessment, technology use, faculty/student interaction, personal regard, class planning, use of resources, pedagogy, and institutional and goal commitment. According to Pascarella and Terenzini (1980), "as level of institutional and goal commitment increases there is a corresponding increase in the likelihood of persisting at the institution" (p. 62).

The faculty instrument for the present study was divided into four sections (see Appendix D). The first section consisted of questions to determine specific characteristics about the respondents. The next two sections were constructed of Likert-type items for instructional activities inside the classroom and instructional activities outside the classroom. The fourth section was a qualitative section with three open-ended questions. For comparison, items under the instructional activities' sections were the same as the students' items but worded differently for faculty. 
Since the adapted instruments for the present study were untested, a pilot study assisted in testing "the feasibility, reliability and validity of the proposed study design" (Thabane et al., 2010, p. 2). The results of the pilot study were used to assess whether the instruments were reliable and valid forms of measurement. Reliability refers to whether the measure is consistently repeatable. Validity refers to whether the study is measuring what it is supposed to measure. The pilot study also assessed the feasibility of the study process (Thabane et al., 2010).

\section{Pilot Study Procedures}

The target student population for the pilot study was comprised of students born between 1992 and 1998 who were enrolled at a 4-year comprehensive Midwestern public university in the fall of 2016. This was a different 4-year comprehensive Midwestern public university than the location for the present study. Potential student participants were contacted with a recruitment email (see Appendix G) through the institution's mass electronic communications system from a list of members in a registered student organization given to the researcher. The researcher is an advisor of the student organization and is regularly given a membership roster. Email addresses were obtained through the online public University Directory. These email addresses are considered directory information according to the Family Educational Rights and Privacy Act, and can be publicly disclosed.

The researcher recognized a possible power differential between students and organization advisors, and took care on the consent form to emphasize there was no risk to the members of the organization in their decision to take the survey or not take the survey. Respondent identity was kept anonymous, and the advisor had no power to affect organizational membership or participation. The organization is a representative sample of 
students between the ages of 18 and 24, although membership is typically characterized by one gender.

A total of 78 students were contacted for the pilot study. Student responses were 19, for a response rate of $24 \%$. Table 1 shows the frequencies and percentages of selected demographic characteristics. Participants were female (100\%), with the majority being White/Caucasian (89.5\%). The highest number of participants was represented by the junior class (52.6\%). Most participants were not classified as first-generation students (72.2\%). For the purposes of this study, students with a parent who graduated from college were considered non-first-generation college students.

Table 1

Pilot Student Participant Demographic Characteristics

\begin{tabular}{lcc}
\hline Demographic Characteristics & Frequency & Percent \\
\hline Gender & & \\
$\quad$ Female & 19 & 100.0 \\
Birth Year & & \\
1994 & 4 & 21.1 \\
1995 & 6 & 31.6 \\
1996 & 7 & 36.8 \\
1997 & 2 & 10.5 \\
Race/Ethnicity & & \\
$\quad$ White/Caucasian & 17 & 89.5 \\
$\quad$ Multiracial & 2 & 10.5 \\
Class Year & & \\
$\quad$ Freshman & 1 & 5.3 \\
$\quad$ Sophomore & 2 & 10.5 \\
$\quad$ Junior & 10 & 52.6 \\
$\quad$ Senior & 6 & 31.6 \\
First Generation & & \\
$\quad$ Yes & 5 & 27.8 \\
$\quad$ No & 13 & 72.2 \\
\hline
\end{tabular}

Note. Due to missing data, total may be less than 19. 
The target faculty population for the pilot study was undergraduate faculty with approximately 10 or more years of teaching experience at 4-year public institutions who were teaching at a 4-year comprehensive Midwestern public university in the fall of 2016. This was a different 4-year comprehensive Midwestern public university than the location of the present study. Potential faculty participants were contacted with a recruitment email (See Appendix H) through the institution's mass electronic communications system from a list compiled by the researcher. The names of faculty currently teaching classes at the institution are available through an open access course search feature on the institution's website. The year faculty started at the institution is available in the Faculty and Professional Staff section of the Undergraduate Catalog, which can be downloaded from the institution's website. Email addresses were obtained through the online public University Directory. These email addresses are considered directory information according to the Family Educational Rights and Privacy Act, and can be publicly disclosed. The researcher had no power to affect any aspect of faculty standing with the institution.

A total of 32 faculty were contacted for the pilot study. Faculty responses were 10 . One response was removed for a missing birth year, for a final total of nine responses. The resulting response rate was $28 \%$. Table 2 shows the frequencies and percentages of selected demographic characteristics. Participants were almost evenly divided between male (55.6\%) and female (44.4\%), with the majority between the ages of 35 to 55 (88.9\%), or Generation X, and White/Caucasian (88.9\%). All participants had at least 10 years of experience teaching at a 4-year public institution. Most participants were tenured (66.7\%). There was a mix of academic ranks with the highest amount represented by associate professors (44.4\%). 
Table 2

Pilot Faculty Participant Demographic Characteristics

\begin{tabular}{lcc}
\hline Demographic Characteristics & Frequency* & Percent \\
\hline Gender & 5 & 55.6 \\
$\quad$ Male & 4 & 44.4 \\
$\quad$ Female & & \\
Age & 8 & 88.9 \\
$\quad 35$ to 55 & 1 & 11.1 \\
56 to 73 & & \\
Race/Ethnicity & 8 & 88.9 \\
$\quad$ White/Caucasian & 1 & 11.1 \\
$\quad$ Asian/Pacific Islander & & \\
Years of Experience & 9 & 100.0 \\
$\quad>10$ Years Experience & & \\
Academic Rank & 2 & 22.2 \\
$\quad$ Instructor & 1 & 11.1 \\
$\quad$ Assistant Professor & 4 & 44.4 \\
$\quad$ Associate Professor & 2 & 22.2 \\
Full Professor & & \\
Tenure Status & 66.7 \\
Tenured & 3 & 33.3 \\
$\quad$ Not on Tenure Track & & \\
\hline
\end{tabular}

All participants in the pilot were given 2 weeks to complete the survey with one weekly reminder (See Appendices I and J) to increase the response rate. An informal presentation letting the students know about the recruitment email was given at a Monday evening organization meeting and posted on the group's Facebook page to catch anyone who was not at the meeting and to mitigate any concerns of risk. Based on results from the pilot study, including comments from participants, minor adjustments were made to the survey instruments, such as adding an N/A option, an option for 0 or 1 , or an option for other; changing the estimated time for survey completion on the consent form; and making the consent question mandatory. A few minor modifications were also made to the recruitment and reminder emails. 
The modifications provided clarity for several questions on the instrument and also provided context for the participants. For example, for the present study, a statement was added to the instructions for the Likert-type items on the student survey asking students to think of their overall experience with college courses and instruction. A statement was added to the instructions for the Likert-type items on the faculty survey asking faculty to focus on one faceto-face class they taught. Another statement was added asking faculty to answer the survey questions based on how they actually taught rather than how they would prefer to teach. The latter statement was intended to reduce the likelihood of social desirability bias. Alreck and Settle (1995) note that wording and formatting of questions "may increase or decrease the degree to which it will evoke a socially desirable response, rather than the true answer" (p. 99).

Statistical analysis of the results for the pilot study revealed a high level of internal consistency for each of the scales on the two instruments. Cronbach's alpha was used to measure the internal consistency. The minimum for reliability is . 70 on a 0 to 1.0 scale. Less than .70 indicates the statements are not all measuring the same thing (Vogt, 2007). Table 3 lists the Cronbach alpha coefficients for the items on the student instrument related to instructional activities inside the classroom and instructional activities outside the classroom, and items related to institutional and goal commitment, as well as the coefficients for the items on the faculty instrument. All scales of Likert-type items had a coefficient above that of the minimum for reliability. 
Table 3

Cronbach's Alpha Coefficients for Pilot Study

\begin{tabular}{lcc}
\hline Instrument & Items & Coefficient \\
\hline Student & & \\
Instructional Activities Inside Classroom & 31 & .89 \\
Instructional Activities Outside Classroom & 13 & .72 \\
Institutional and Goal Commitment & 11 & .83 \\
All Items & 55 & .83 \\
Faculty & & \\
Instructional Activities Inside Classroom & 31 & .80 \\
Instructional Activities Outside Classroom & 13 & .81 \\
All Items & 44 & .80 \\
\hline
\end{tabular}

\section{Present Study Procedures}

The present study target populations were comprised of traditional-age undergraduate students born between 1992 and 1998 who were enrolled at a 4-year comprehensive Midwestern public university in the fall of 2016, and undergraduate faculty with approximately 10 or more years of teaching experience at four-year public institutions. Potential participants were contacted with a recruitment email (See Appendices K and L) through the institution's mass electronic communications system from a list generated by the institution's technology office after the researcher was given Institutional Review Board (IRB) approval to conduct the study. Research surveys to on-campus recipients must have IRB approval and the prefix "Research" in the subject line.

Participants were given 3 weeks to complete the survey with two weekly reminders (See Appendices M and N) to increase the response rate. According to Roberts (2004), a disadvantage of questionnaire studies is a low response rate. In one study, researchers found that response rates to online surveys were lower than for on-paper surveys given with face-to- 
face administration in 14 out of 16 cases (Nulty, 2008). However, by sending repeat reminder emails to students and academics and offering incentives "in the form of prizes for respondents awarded through a lottery" (Nulty, 2008, p. 303), online response rates are often boosted. Strategies to boost response rates include sending at least three email reminders, including the survey URL in the email, involving academics, persuading respondents that their survey responses will be taken seriously, providing rewards, extending the duration of the survey, assuring anonymity, and keeping the questionnaires brief (Nulty, 2008).

Respondents were encouraged to take the surveys for the present study based on their good will for helping with research and an incentive of winning a $\$ 100$ online gift card to Amazon. Research company Qualtrics (2007) notes that incentives usually produce larger response rates. "Incentives distributed as drawings allow the researcher to control the costs of the survey and spread the budgeted amount across a larger number of respondents" (Qualtrics, 2007, para. 5). Appealing to a participant's good will uses his self-perception to increase online response rates. The participant sees himself helping to further the research in the field and as a kind and generous person (Qualtrics, 2007). At the end of the surveys for the present study, participants had the opportunity to open a separate link where they could enter their email for a raffle. Their email address was not connected to their previous responses in any way as the link was to a web page that only collected their email address for the raffle.

Two faculty members and two students each won a $\$ 100$ gift card. The winners were chosen randomly using RandomResult.com and then emailed their code. Any duplicate raffle entries were removed, indicating some participants completed the survey more than once. Duplicate entries could not be avoided since email addresses were not connected to previous responses in any way. Entries with an email address other than an institutional email address 
were also removed as participants were instructed to provide a university email address. This was intended to stop duplicate raffle entries.

\section{Data Analysis}

Descriptive statistics are used to summarize information about a range of data, such as the gender or age of survey respondents. They are usually univariate, exploring one variable at a time (Vogt, 2007). Frequency descriptive statistics were used for analyzing section one of the student survey, which had questions about demographic, socioeconomic, and educational characteristics, and the faculty survey, which had questions about demographic, institutional, and pedagogical characteristics. The data for this section were discrete; the participants chose separate categories for their answers, resulting in categorical variables. For the sections about instructional activities inside the classroom and instructional activities outside the classroom, Likert-type items were used to gather responses for research questions one through four. In addition to frequency descriptive statistics, central tendency descriptive statistics of mode were used to describe the groups' responses to these items. Likert-type items were used to gather responses for the section about institutional and goal commitment on the student survey. Frequencies and modes were also used to describe this section.

Researchers use inferential statistics to make estimations about populations from the sample population. These statistics indicate how likely the relationship between two or more variables is to be true of a population (Vogt, 2007). To answer research questions five and six, the independent samples t-test was used to compare the mean scores of each group based on Likert scales developed from Likert-type items for instructional activities inside the classroom and Likert-type items for instructional activities outside the classroom. In addition to the independent samples t-test inferential statistic, descriptive statistics of mean and standard 
deviation were also reported for these two questions.

Both the student survey and the faculty survey had a section for three open-ended questions. The qualitative data gathered from these questions were analyzed with a word cloud, which reveals the frequency in which certain words are used within text in a visual representation. Word clouds can be a helpful tool for validating previous responses and giving a basic understanding of the data (McNaught \& Lam, 2010). They can be "particularly useful for studies that involve qualitative/thematic analyses of written or transcribed spoken text” (McNaught \& Lam, 2010, p. 631), but should be used as a supplemental research tool not as a standalone tool. As this was a quantitative study, a basic understanding of the qualitative data from the open-ended questions with word clouds was suitable for providing context for the other research findings.

\section{Reliability}

After the data were collected for the present study, Cronbach's alpha was used to measure the internal consistency of the scales. Table 4 lists the Cronbach alpha coefficients for the items on the student instrument related to instructional activities inside the classroom and instructional activities outside the classroom, and items related to institutional and goal commitment, as well as the coefficients for the items on the faculty instrument. Statistical analysis of the results revealed a high level of internal consistency for each of the scales on the student instrument. Consistency levels were slightly lower for the faculty instrument. 
Table 4

Cronbach's Alpha Coefficients for Present Study

\begin{tabular}{lcc}
\hline Instrument & Items & Coefficient \\
\hline Student & & \\
$\quad$ Instructional Activities Inside Classroom & 31 & .83 \\
Instructional Activities Outside Classroom & 13 & .72 \\
Institutional and Goal Commitment & 11 & .79 \\
All Items & 55 & .85 \\
Faculty & & \\
Instructional Activities Inside Classroom & 31 & .65 \\
Instructional Activities Outside Classroom & 13 & .58 \\
All Items & 44 & .73 \\
\hline
\end{tabular}

Since the scale for instructional activities inside the classroom consisted of 31 Likerttype items, it was broken down into two subscales for more analysis for research question five. These subscales were Millennnial characteristics and pedagogical characteristics. Table 5 lists the Cronbach alpha coefficients for these subscales on the student and faculty instruments. Statistical analysis of the results revealed a high level of internal consistency for each of the scales on the student instrument. Consistency levels were slightly lower for the faculty instrument.

Table 5

Cronbach's Alpha Coefficients for Subscales of Present Study

\begin{tabular}{lcc}
\hline Instrument & Items & Coefficient \\
\hline Student & & \\
$\quad$ Millennial Characteristics & 16 & .75 \\
$\quad$ Pedagogical Characteristics & 15 & .70 \\
Faculty & & \\
$\quad$ Millennial Characteristics & 16 & .59 \\
$\quad$ Pedagogical Characteristics & 15 & .51 \\
\hline
\end{tabular}




\section{Ethical Considerations}

Approval to conduct the research was granted by the university's Institutional Review Board (IRB). Based on this approval, the location of the pilot study was approved as a recruitment site by that university's Institutional Review Board. The surveys for both the pilot study and the present study were uploaded into SelectSurvey software. The account with the raw data was password protected.

The first part of the electronic surveys was used to obtain consent (See Appendices O and $\mathrm{P}$ ). The waiver of written documentation of consent or alteration did not adversely affect the rights and welfare of the participants. Completion of the surveys in this research presented no more than minimal risk of harm to the participants and required no procedures for which written consent was required. Recruitment and reminder correspondence for each group were the same for all participants, regardless of completion of the survey.

The surveys were designed to require participants to select whether they agreed or disagreed to participate in the study after they read the consent information. Participants who selected "yes" continued with the study. Participants who selected "no" were redirected to the end of the survey, which they could then close. Neither electronic or handwritten signatures were obtained, further protecting confidentiality. The surveys were voluntary, and participants had the option to skip questions they did not want to answer or leave the survey at any time by closing it out, with the exception of the consent question. Data were only used from participants who provided consent to participate in the study.

Data from all survey participants were kept anonymous. None of the participants were connected to their survey responses. At the end of the survey, they had the option to go to another link where they could enter their email address for a raffle to win a $\$ 100$ gift card. This 
was also voluntary. Only email addresses were collected for the raffle.

\section{Summary}

The present study was administered at a 4-year comprehensive Midwestern public university to faculty and students. Results from faculty and student surveys were compared to examine the differences between student expectations of instructional activities inside and outside the classroom and faculty approaches to instructional activities inside and outside the classroom. The relationships between faculty and students are vital for student persistence. Knowing about the differences between these two groups can help faculty and student affairs practitioners develop better methods for meeting students' needs. 


\section{CHAPTER IV}

\section{RESULTS AND ANALYSIS}

\section{Introduction}

Institutions must change the way they think about retention by focusing on student persistence and how it may be affected by the relationships between students and faculty. To understand the complexities of student-faculty relationships, a quantitative study was conducted to examine the differences between students' expectations of instructional activities inside and outside the classroom and faculty approaches to instructional activities inside and outside the classroom at a 4-year comprehensive Midwestern public university. Six research questions guided the cross-sectional online survey design, the collection of data from two populations, and the analysis of the data for both a pilot study and the present study. The surveys were constructed by the researcher and adapted from Pascarella and Terenzini's 1980 Institutional Integration Scale (see Appendix A) and Russo's 2013 survey for examining Millennial characteristics for classroom strategy changes (see Appendix B). This chapter provides a profile of the present study's participants, and is then organized by the six research questions and other data.

\section{Study Participants}

The present study target populations were comprised of traditional-age undergraduate students born between 1992 and 1998 who were enrolled at a 4-year comprehensive Midwestern public university in the fall of 2016, and undergraduate faculty with approximately 10 or more years of teaching experience at 4-year public institutions. 


\section{Student Profile}

A total of 13,794 students were originally contacted for participation in the study. However, a review of incoming data indicated an issue with student recruitment. Further investigation revealed that the institution's technology office had accidentally sent the recruitment email to some graduate and doctoral students, and students not within the parameters for birth year. Students not eligible were removed from the list, and the first and second reminder emails were then sent to 10,984 students rather than 13,794 .

Student responses were 1,457. Of that number, 32 responses were removed for missing consent and 164 were removed for a missing birth year or a birth year before 1992. Consent was mandatory for continued participation in the study, but it appeared that a few students copied the survey URL into a new browser window multiple times, thus registering another response. As a precaution, all of those responses were removed. The final number of student responses was 1,261 . Out of the 10,984 possible participants, this was a response rate of $11.4 \%$.

Table 6 shows the frequencies and percentages of selected demographic characteristics of the student participants in the study. Participants were mostly female (73.3\%) and White/Caucasian (79.1\%). The highest percentage of participants was born in 1998 (27.5\%), with the next highest percentage born in 1997 (22.0\%). 
Table 6

Student Participant Demographic Characteristics

\begin{tabular}{|c|c|c|}
\hline Demographic Characteristics & Frequency & Percent \\
\hline \multicolumn{3}{|l|}{ Gender } \\
\hline Male & 332 & 26.3 \\
\hline Female & 924 & 73.3 \\
\hline Transgender & 2 & .2 \\
\hline Another Gender & 1 & .1 \\
\hline Prefer Not to Respond & 2 & .2 \\
\hline \multicolumn{3}{|l|}{ Birth Year } \\
\hline 1992 & 27 & 2.1 \\
\hline 1993 & 48 & 3.8 \\
\hline 1994 & 140 & 11.1 \\
\hline 1995 & 188 & 14.9 \\
\hline 1996 & 233 & 18.5 \\
\hline 1997 & 278 & 22.0 \\
\hline 1998 & 347 & 27.5 \\
\hline \multicolumn{3}{|l|}{ Race/Ethnicity } \\
\hline African American/Black & 66 & 5.2 \\
\hline Asian/Pacific Islander & 49 & 3.9 \\
\hline White/Caucasian & 997 & 79.1 \\
\hline Hispanic/Latino & 87 & 6.9 \\
\hline Multiracial & 38 & 3.0 \\
\hline Native American/American Indian & 1 & .1 \\
\hline Another Racial Identity & 9 & .7 \\
\hline Prefer Not to Respond & 11 & .9 \\
\hline
\end{tabular}

Note. Due to missing data, total may be less than 1,261.

Table 7 shows the frequencies and percentages of selected socioeconomic characteristics of the student participants. Students with family incomes between $\$ 40,000$ $\$ 74,999(20.4 \%), \$ 75,000-\$ 99,000(19.5 \%)$, and $\$ 100,000-\$ 149,900(21.1 \%)$ were almost evenly represented. The highest percentage of participants had a household size of 4 (38.3\%). This number included the student. Most participants were not classified as first-generation students $(68.3 \%)$. As with the pilot study, students with a parent who graduated from college were considered non-first-generation college students. 
Table 7

Student Participant Socioeconomic Characteristics

\begin{tabular}{lrr}
\hline Socioeconomic Characteristics & Frequency & Percent \\
\hline Family Income & & \\
$\quad$ Less than $\$ 20,000$ & 82 & 6.5 \\
$\$ 20,000-\$ 39,999$ & 130 & 10.3 \\
$\$ 40,000-\$ 74,999$ & 257 & 20.4 \\
$\$ 75,000-\$ 99,999$ & 246 & 19.5 \\
$\$ 100,000-\$ 149,999$ & 266 & 21.1 \\
\$150,000 - or More & 101 & 8.0 \\
Do Not Know & 177 & 14.0 \\
Household Size & & \\
1 & 34 & 2.7 \\
2 & 89 & 7.1 \\
3 & 227 & 18.0 \\
4 & 483 & 38.3 \\
5 & 281 & 22.3 \\
$6+$ & 144 & 11.4 \\
First Generation & & \\
Yes & 392 & 31.7 \\
No & 845 & 68.3 \\
\hline Note. Due to missing data, total may
\end{tabular}

Note. Due to missing data, total may be less than 1,261.

Table 8 shows the frequencies and percentages of selected educational characteristics of the student participants. The highest number of participants was represented by the freshmen class (41.2\%). A majority of students reported that they had purchased all of the required materials such as textbooks, online codes, and workbooks for their classes (80.9\%). Only $7.8 \%$ of students reported receiving classroom accommodations for having a disability. Approximately, two-thirds $(66.1 \%)$ indicated that the institution was their first choice. 
Table 8

Student Participant Educational Characteristics

\begin{tabular}{lcc}
\hline Demographic Characteristics & Frequency & Percent \\
\hline Class Year & & \\
$\quad$ Freshman & 520 & 41.2 \\
$\quad$ Sophomore & 170 & 13.5 \\
$\quad$ Junior & 322 & 25.5 \\
$\quad$ Senior & 208 & 16.5 \\
Purchased All Required Classroom Materials & & \\
$\quad$ Yes & 1020 & 80.9 \\
$\quad$ No & 216 & 17.1 \\
Receive Classroom Accommodations & 98 & 7.8 \\
$\quad$ Yes & 1135 & 90.0 \\
$\quad$ No & & \\
This Institution First Choice & 834 & 66.1 \\
$\quad$ Yes & 404 & 32.0 \\
$\quad$ No & & \\
\hline
\end{tabular}

Note. Due to missing data, total may be less than 1,261 .

\section{Faculty Profile}

A total of 1,132 faculty were contacted for participation in the study. Faculty responses were 142 . Of that number, 11 responses were removed for a missing birth year. The final number of faculty responses was 131 , for a response rate of $12.5 \%$. Faculty with approximately 10 years of teaching experience at 4-year public institutions were asked to respond, but the recruitment email was sent to all departmental faculty. There was not a way for the institution's technology office to identify only faculty who taught undergraduate students or had 10 years or more of experience when sending out the recruitment email. As a result, there were 31 faculty who indicated they did not have at least 10 years of experience teaching in a 4-year public institution, and two faculty who did not answer this question. Since these responses represented $25 \%$ of all responses, the researcher decided to include those participants for richer data.

Statistical analysis with those participants removed still resulted in significant findings for all t-tests and similar Cronbach's alpha coefficients for all the scales (see Appendix Q for Tables 
41 through 45, which show these statistics).

Table 9 shows the frequencies and percentages of selected demographic characteristics of the faculty participants in the study. The majority were female (57.3\%) and White/Caucasian (90.1\%). The largest age bracket represented was 35 to $55(56.5 \%)$, or Generation X, and the second largest was 56 to 73 (29.8\%), or Baby Boomers. It was anticipated that the majority of faculty would belong to Generation X, as approximately $49.5 \%$ of faculty were Generation $\mathrm{X}$ in 2015, or the Baby Boomer generation, as approximately $39.5 \%$ of faculty were Baby Boomers or older in 2015 according to data from the Faculty Survey of Student Engagement (A.

BrckaLorenz, personal communication, March 15, 2016). Since the response rate for the faculty survey was only $12.5 \%$, there was no way to know the age distribution of the target population, only the age distribution for the faculty who participated in the study. Still, these percentages were in line with the national average.

Table 9

Faculty Participant Demographic Characteristics

\begin{tabular}{lcc}
\hline Demographic Characteristics & Frequency & Percent \\
\hline Gender & 55 & \\
Male & 75 & 52.0 \\
Female & 1 & .8 \\
Prefer Not to Respond & & \\
Age & 18 & 13.7 \\
25 to 34 & 74 & 56.5 \\
35 to 55 & 39 & 29.8 \\
56 to 73 & & \\
Race/Ethnicity & 1 & .8 \\
African American/Black & 118 & 90.1 \\
White/Caucasian & 5 & 3.8 \\
Asian/Pacific Islander & 1 & .8 \\
Hispanic/Latino & 2 & 1.5 \\
Multiracial & 4 & 3.1 \\
Prefer Not to Respond &
\end{tabular}

Note. Due to missing data, total may be less than 131. 
Table 10 shows the frequencies and percentages of selected institutional characteristics of the faculty participants. The highest number of participants reported having at least 10 years of experience teaching at a 4 -year public institution (74.8\%). There was a mix of academic ranks with the highest number represented by full professors (31.3\%). Most participants were tenured (57.3\%), and the highest percentage came from the College of Arts and Sciences (36.6\%). The highest number of participants reported teaching three courses for the current semester $(38.2 \%)$. A greater percentage of the faculty reported teaching courses required for the major that were not general education versus general education courses and noncredit developmental/remedial courses. Only $16.8 \%$ of participants were not teaching a required major course rather than the $64.9 \%$ not teaching general education or the $90.1 \%$ not teaching noncredit. A small amount, $6.1 \%$, indicated they were teaching at another institution for the current semester.

Table 11 shows the frequencies and percentages of selected pedagogical characteristics of the faculty participants. Most participants updated their course material at least once every year $(71.0 \%)$, and preferred to spend the greatest amount of time on teaching and research. The percentage of time preferred for service was highly represented by the lowest bracket of $0 \%$ $24 \%(73.2 \%)$. This lines up with the lower amount of hours spent participating in service responsibilities in a typical week. A larger majority of participants preferred to do 4 hours or less (58\%). More participants also reported spending four hours or less interacting with students outside of class (69.5\%). 
Table 10

Faculty Participant Institutional Characteristics

\begin{tabular}{|c|c|c|}
\hline Institutional Characteristics & Frequency & Percent \\
\hline \multicolumn{3}{|l|}{ Years of Experience at 4-Year Public } \\
\hline$>10$ Years Experience & 98 & 74.8 \\
\hline$<10$ Years Experience & 31 & 23.7 \\
\hline \multicolumn{3}{|l|}{ Academic Rank } \\
\hline Instructor & 24 & 18.3 \\
\hline Assistant Professor & 22 & 16.8 \\
\hline Associate Professor & 32 & 24.4 \\
\hline Full Professor & 41 & 31.3 \\
\hline Other & 9 & 6.9 \\
\hline \multicolumn{3}{|l|}{ Tenure Status } \\
\hline Tenured & 75 & 57.3 \\
\hline On Tenure Track & 21 & 16.0 \\
\hline Not on Tenure Track & 33 & 25.2 \\
\hline \multicolumn{3}{|l|}{ Academic College } \\
\hline College of Applied Science \& Tech. & 21 & 16.0 \\
\hline College of Arts and Sciences & 48 & 36.6 \\
\hline College of Business & 14 & 10.7 \\
\hline College of Education & 20 & 15.3 \\
\hline College of Fine Arts & 11 & 8.4 \\
\hline Other & 6 & 4.6 \\
\hline \multicolumn{3}{|l|}{ Courses Teaching at Institution } \\
\hline 0 & 5 & 3.8 \\
\hline 1 & 10 & 7.6 \\
\hline 2 & 36 & 27.5 \\
\hline 3 & 50 & 38.2 \\
\hline 4 & 16 & 12.2 \\
\hline $5+$ & 6 & 4.6 \\
\hline \multicolumn{3}{|l|}{ Gen Ed Courses Being Taught } \\
\hline 0 & 85 & 64.9 \\
\hline 1 & 22 & 16.8 \\
\hline 2 & 12 & 9.2 \\
\hline 3 & 2 & 1.5 \\
\hline 4 & 2 & 1.5 \\
\hline \multicolumn{3}{|l|}{ Required Major Courses Being Taught } \\
\hline 0 & 22 & 16.8 \\
\hline 1 & 38 & 29.0 \\
\hline 2 & 34 & 26.0 \\
\hline 3 & 18 & 13.7 \\
\hline 4 & 6 & 4.6 \\
\hline $5+$ & 2 & 1.5 \\
\hline \multicolumn{3}{|l|}{ Noncredit Courses Being Taught } \\
\hline 0 & 118 & 90.1 \\
\hline 1 & 1 & .8 \\
\hline 2 & 1 & .8 \\
\hline 3 & 1 & .8 \\
\hline \multicolumn{3}{|l|}{ Teaching at Another Institution } \\
\hline Yes & 8 & 6.1 \\
\hline No & 114 & 87.0 \\
\hline
\end{tabular}

Note. Due to missing data, total may be less than 131 . 
Table 11

Faculty Participant Pedagogical Characteristics

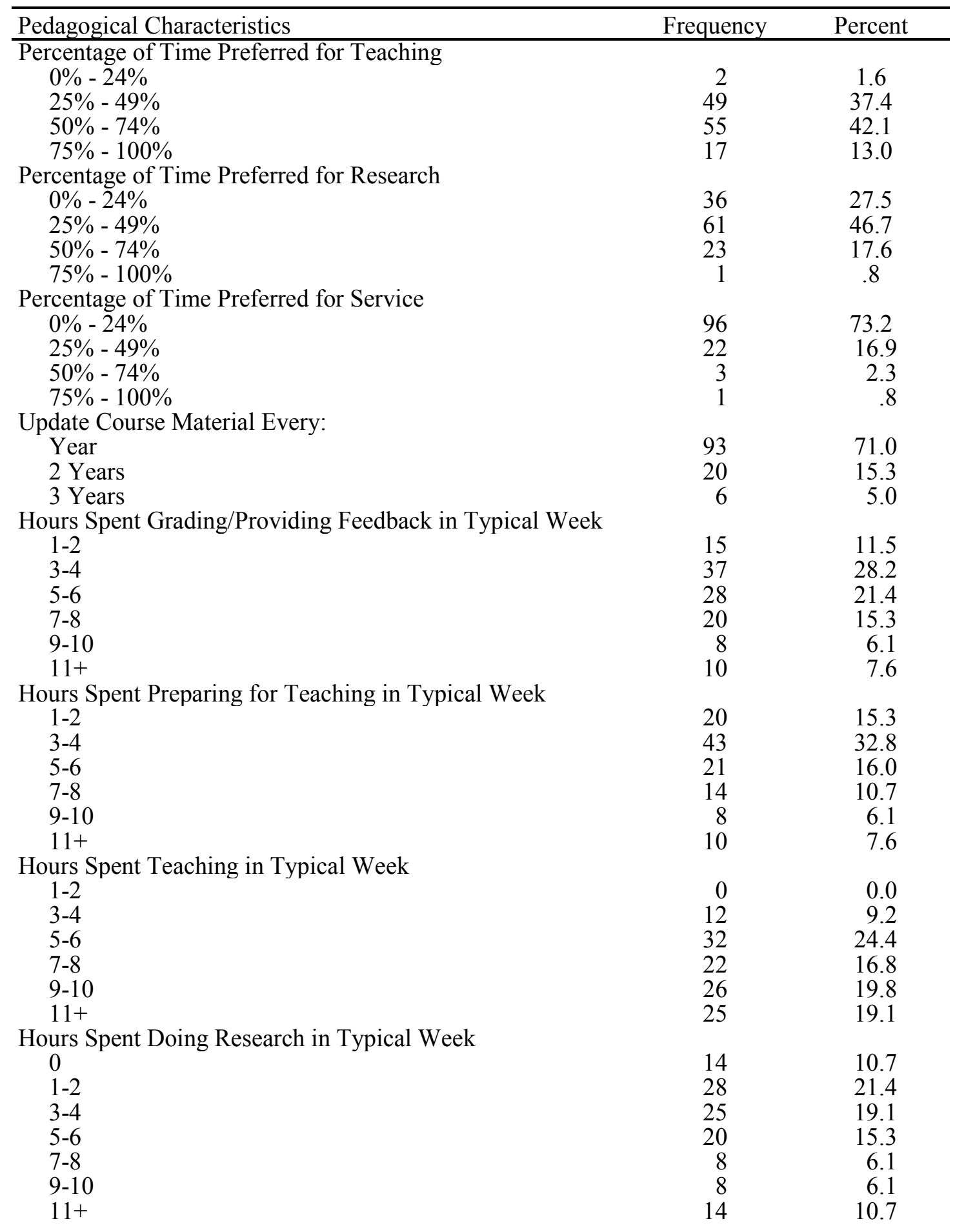

Table continued 


\begin{tabular}{lcc}
\hline Pedagogical Characteristics & Frequency & Percent \\
\hline Hours Spent Participating in Service Responsibilities in & & \\
Typical Week & 8 & 6.1 \\
0 & 38 & 29.0 \\
$1-2$ & 30 & 22.9 \\
$3-4$ & 13 & 9.9 \\
$5-6$ & 9 & 6.9 \\
$7-8$ & 5 & 3.8 \\
$9-10$ & 15 & 11.5 \\
$11+$ & & \\
Hours Spent Interacting With Students Outside Class in & & \\
Typical Week & 1 & 0.8 \\
0 & 53 & 40.5 \\
$1-2$ & 37 & 28.2 \\
$3-4$ & 10 & 7.6 \\
$5-6$ & 7 & 5.3 \\
$7-8$ & 5 & 3.8 \\
$9-10$ & 5 & 3.8 \\
$11+$ & &
\end{tabular}

Note. Due to missing data, total may be less than 131.

Table 12 shows the frequencies and percentages of selected professional development characteristics of the faculty participants. A majority of respondents had participated in professional development opportunities to improve their teaching at the institution $(65.6 \%)$ and would be willing to participate in professional development opportunities about the characteristics of the students in their classes $(67.2 \%)$. If respondents marked that they had participated in professional development opportunities, they were given an open-ended question asking what types of opportunities. Responses ranged from workshops provided by the institution's faculty training center to seminars and conferences.

Table 12

Faculty Participant Professional Development Characteristics

\begin{tabular}{lcc}
\hline Professional Development Characteristics & Frequency & Percent \\
\hline Participated in Professional Development & & \\
Yes & 86 & 65.6 \\
No & 33 & 25.2 \\
Would Participate in Professional Development & 88 & 67.2 \\
Yes & 30 & 22.9 \\
No & &
\end{tabular}

Note. Due to missing data, total may be less than 131. 


\section{Research Question One}

What are students' expectations of instructional activities inside the classroom? On the student survey, 31 items corresponded to this research question. Table 13 lists each of these items and provides a label for quick analysis in subsequent tables.

Table 13

Student Expectations of Instructional Activities Inside the Classroom

\begin{tabular}{|c|c|c|}
\hline Label & Item & Survey Items \\
\hline Reward Efforts & 1 & My instructors should reward me for my efforts in class. \\
\hline Flexible & 2 & My instructors should be flexible to allow for my classroom success. \\
\hline Credit for Trying & 3 & $\begin{array}{l}\text { My instructors should give me credit for trying, regardless of how well I } \\
\text { perform on my coursework. }\end{array}$ \\
\hline Ask Questions & 4 & $\begin{array}{l}\text { I expect to be able to ask questions during class and get answers from my } \\
\text { instructors. }\end{array}$ \\
\hline $\begin{array}{l}\text { Unprepared } \\
\text { Exceptions }\end{array}$ & 5 & If I am unprepared for class, I expect my instructors to make exceptions. \\
\hline Classroom Input & 6 & My instructors should let me have input into classroom decisions. \\
\hline Class Attendance & 7 & Class attendance should not count toward classroom grades. \\
\hline Syllabus & 8 & $\begin{array}{l}\text { The syllabus for a class should detail when every assignment is due for the } \\
\text { semester. }\end{array}$ \\
\hline $\begin{array}{l}\text { Specific Grading } \\
\text { Guidelines }\end{array}$ & 9 & $\begin{array}{l}\text { My instructors should provide specific grading guidelines for each } \\
\text { assignment. }\end{array}$ \\
\hline Classroom Rules & 10 & My instructors should clearly communicate all classroom rules. \\
\hline $\begin{array}{l}\text { Step-by-Step } \\
\text { Instruction }\end{array}$ & 11 & $\begin{array}{l}\text { I would rather have step-by-step instructions for a project than decide on } \\
\text { my own how to accomplish it. }\end{array}$ \\
\hline Structured Classes & 12 & I prefer classes that are very structured. \\
\hline Study Guides & 13 & I expect my instructors to provide study guides. \\
\hline Other Resources & 14 & $\begin{array}{l}\text { My instructors should tell me about tutoring and other resources I can use } \\
\text { on campus to help me be successful. }\end{array}$ \\
\hline Internet Surfing & 15 & I should be allowed to surf the internet or text others while in class. \\
\hline Follow Class & 16 & I can still follow the class while I text or surf the internet. \\
\hline $\begin{array}{l}\text { Technology } \\
\text { Besides PPT }\end{array}$ & 17 & $\begin{array}{l}\text { My instructors should use technology besides PowerPoint presentations in } \\
\text { the classroom, such as interactive whiteboards, music, clickers, and videos. }\end{array}$ \\
\hline Online Resources & 18 & $\begin{array}{l}\text { My instructor should use online resources in class, such as websites and } \\
\text { articles. }\end{array}$ \\
\hline Online Textbooks & 19 & I prefer online textbooks to traditional textbooks. \\
\hline C Grade & 20 & I expect to get at least a $\mathrm{C}$ in a class just for attending. \\
\hline
\end{tabular}

Table continued 


\begin{tabular}{|c|c|c|}
\hline$\underline{\text { Label }}$ & Item & Survey Items \\
\hline Exams & 21 & I prefer to have exams count for the majority of my class grade. \\
\hline $\begin{array}{l}\text { Pass Class w/o } \\
\text { Materials }\end{array}$ & 22 & I can pass my classes without the required textbooks or course materials. \\
\hline $\begin{array}{l}\text { Learning } \\
\text { Objectives }\end{array}$ & 23 & $\begin{array}{l}\text { My instructors should link course assignments with stated course goals or } \\
\text { learning objectives. }\end{array}$ \\
\hline $\begin{array}{l}\text { Instructor } \\
\text { Interaction }\end{array}$ & 24 & I would like more interaction with my instructors in class. \\
\hline Besides Lecture & 25 & $\begin{array}{l}\text { My instructor should do different things in class rather than stand at the } \\
\text { front of the classroom and only explain class content. }\end{array}$ \\
\hline Requires Textbook & 26 & $\begin{array}{l}\text { If my instructor requires a textbook for the class, I expect to use it for my } \\
\text { assignments and tests. }\end{array}$ \\
\hline Material for Exams & 27 & I prefer to cover just the material required for exams. \\
\hline Out-of-Class Work & 28 & I expect to do very little out-of-class work. \\
\hline $\begin{array}{l}\text { Instructional } \\
\text { Strategies }\end{array}$ & 29 & My instructors use more than one way to teach the material. \\
\hline $\begin{array}{l}\text { Generational } \\
\text { Context }\end{array}$ & 30 & $\begin{array}{l}\text { Instructors should meet my generation where it is at academically and } \\
\text { socially. }\end{array}$ \\
\hline $\begin{array}{l}\text { Classroom } \\
\text { Questions }\end{array}$ & 31 & $\begin{array}{l}\text { Instructors should leave enough time in class to go over the material and } \\
\text { have time for my questions. }\end{array}$ \\
\hline
\end{tabular}

Student participants rated their expectations of instructional activities inside the classroom with 5 -point Likert-type items $(1=$ strongly disagree, $2=$ disagree, $3=$ neutral, $4=$ agree, 5 = strongly agree). Descriptive statistics were calculated to determine their expectations. Table 14 lists the frequency and mode for each of the items on this section of the survey. The frequencies are shown as a percentage of the participants who selected each of the Likert-type items. This percentage is the valid percent, which is a percentage that does not include missing responses. Between 56 and 113 students skipped items 1 through 31 from the total 1,261 responses.

As these Likert-type items were designed to reflect the needs of students, it was expected that participants would agree or strongly agree with most of the statements. However, several items received different results. When students were asked if they expected instructors to make exceptions if they were unprepared for class, $52.7 \%$ disagreed with that statement and 
$18.5 \%$ strongly disagreed. For expecting to get at least a $\mathrm{C}$ grade just for attending class, $38 \%$ disagreed and $15.2 \%$ strongly disagreed. When students were asked if they expected to do very little out-of-class work, $49.6 \%$ disagreed and $16.3 \%$ strongly disagreed. As this generation is technologically savvy, it was anticipated they would be more open to online textbooks, but when asked if they preferred online textbooks to traditional textbooks, $31.2 \%$ disagreed and $26.4 \%$ strongly disagreed.

The highest level of agreement was found for item 4 . When students were asked if they expected to be able to ask questions during class and get answers from their instructors, $95.7 \%$ agreed or strongly agreed. When combining agree and strongly agree for other items, high levels of agreement were found for instructors being flexible for students' classroom success (81.2\%), a syllabus listing due dates for every assignment (83.7\%), instructors providing specific grading guidelines for each assignment (89.2\%), and instructors clearly communicating classroom rules (91.3\%). Students also agreed that instructors should leave enough time in class to go over the material and answer their questions (82.7\%), and use more than one way to teach the material (84\%). Students expected their instructors to tell them about tutoring and other resources on campus to help them be successful (80.5\%), and expected to use the textbook for assignments and tests if the textbook was required for the class $(87.9 \%)$. 
Table 14

Student Frequencies and Modes for Expectations of Instructional Activities Inside the Classroom

\begin{tabular}{|c|c|c|c|c|c|c|c|}
\hline Survey Item Label & Item & $\mathrm{SD}(\%)$ & $\mathrm{D}(\%)$ & $\mathrm{N}(\%)$ & $\mathrm{A}(\%)$ & SA $(\%)$ & Mode \\
\hline Reward Efforts & 1 & 1.0 & 7.2 & 28.9 & 46.4 & 16.5 & 4 \\
\hline Flexible & 2 & 0.3 & 2.6 & 15.8 & 58.5 & 22.7 & 4 \\
\hline Credit for Trying & 3 & 3.6 & 18.8 & 30.3 & 35.2 & 12.2 & 4 \\
\hline Ask Questions & 4 & 0.2 & 0.6 & 3.6 & 35.8 & 59.9 & 5 \\
\hline Unprepared Exceptions & 5 & 18.5 & 52.7 & 21.8 & 5.2 & 1.7 & 2 \\
\hline Classroom Input & 6 & 1.1 & 7.3 & 33.1 & 46.0 & 12.5 & 4 \\
\hline Class Attendance & 7 & 10.9 & 24.5 & 26.8 & 20.6 & 17.3 & 3 \\
\hline Syllabus & 8 & 0.4 & 4.3 & 11.5 & 38.9 & 44.8 & 5 \\
\hline $\begin{array}{l}\text { Specific Grading } \\
\text { Guidelines }\end{array}$ & 9 & 0.2 & 2.5 & 8.1 & 47.1 & 42.1 & 4 \\
\hline Classroom Rules & 10 & 0.5 & 1.0 & 7.2 & 45.1 & 46.2 & 5 \\
\hline Step-by-Step Instruction & 11 & 1.8 & 9.4 & 27.0 & 35.1 & 26.7 & 4 \\
\hline Structured Classes & 12 & 0.4 & 3.3 & 20.9 & 47.5 & 27.8 & 4 \\
\hline Study Guides & 13 & 1.8 & 9.9 & 23.1 & 38.0 & 27.2 & 4 \\
\hline Other Resources & 14 & 0.5 & 3.8 & 15.2 & 49.2 & 31.3 & 4 \\
\hline Internet Surfing & 15 & 13.5 & 29.1 & 36.1 & 16.8 & 4.5 & 3 \\
\hline Follow Class & 16 & 12.6 & 23.7 & 20.0 & 32.2 & 11.6 & 4 \\
\hline $\begin{array}{l}\text { Technology Besides } \\
\text { PPT }\end{array}$ & 17 & 1.3 & 4.8 & 28.3 & 41.7 & 24.0 & 4 \\
\hline Online Resources & 18 & 0.5 & 3.9 & 27.9 & 48.0 & 19.6 & 4 \\
\hline Online Textbooks & 19 & 26.4 & 31.2 & 23.2 & 12.0 & 7.2 & 2 \\
\hline C Grade & 20 & 15.2 & 38.0 & 25.0 & 16.0 & 5.9 & 2 \\
\hline Exams & 21 & 20.4 & 39.5 & 23.6 & 13.4 & 3.2 & 2 \\
\hline $\begin{array}{l}\text { Pass Class w/o } \\
\text { Materials }\end{array}$ & 22 & 8.3 & 28.6 & 30.9 & 25.4 & 6.9 & 3 \\
\hline Learning Objectives & 23 & 0.3 & 5.1 & 27.2 & 51.0 & 16.4 & 4 \\
\hline Instructor Interaction & 24 & 0.3 & 6.5 & 33.8 & 43.5 & 15.9 & 4 \\
\hline Besides Lecture & 25 & 0.3 & 6.7 & 23.3 & 43.2 & 26.4 & 4 \\
\hline Requires Textbook & 26 & 0.7 & 2.2 & 9.2 & 43.7 & 44.2 & 5 \\
\hline Material for Exams & 27 & 2.4 & 18.7 & 24.0 & 36.6 & 18.4 & 4 \\
\hline Out-of-Class Work & 28 & 16.3 & 49.6 & 23.9 & 7.8 & 2.3 & 2 \\
\hline Instructional Strategies & 29 & 0.1 & 1.0 & 14.9 & 56.5 & 27.5 & 4 \\
\hline Generational Context & 30 & 1.2 & 8.6 & 29.6 & 46.1 & 14.4 & 4 \\
\hline Classroom Questions & 31 & 0.3 & 2.6 & 14.4 & 56.3 & 26.4 & 4 \\
\hline
\end{tabular}




\section{Research Question Two}

What are students' expectations of instructional activities outside the classroom? On the student survey, 13 items corresponded to this research question. Table 15 lists each of these items and provides a label for quick analysis in subsequent tables.

Table 15

Student Expectations of Instructional Activities Outside the Classroom

\begin{tabular}{|c|c|c|}
\hline Label & Item & Survey Items \\
\hline $\begin{array}{l}\text { Individualized } \\
\text { Attention }\end{array}$ & 32 & $\begin{array}{l}\text { My instructors should be available to provide individualized attention if I } \\
\text { need it. }\end{array}$ \\
\hline $\begin{array}{l}\text { 24-Hour Email } \\
\text { Response }\end{array}$ & 33 & I expect my instructors to answer my emails within 24 hours or sooner. \\
\hline Special Treatment & 34 & It is fine to ask instructors for special treatment. \\
\hline CMS & 35 & $\begin{array}{l}\text { My instructors should use the online course management system to post } \\
\text { grades, assignments, and classroom study materials. }\end{array}$ \\
\hline $\begin{array}{l}\text { Grade } \\
\text { Assignments }\end{array}$ & 36 & $\begin{array}{l}\text { My instructors should have assignments graded and returned within two } \\
\text { weeks of the due date or sooner. }\end{array}$ \\
\hline Detailed Feedback & 37 & I expect detailed feedback from my instructors on my coursework. \\
\hline Use Feedback & 38 & I use instructor feedback from assignments to prepare future assignments. \\
\hline $\begin{array}{l}\text { Outside } \\
\text { Interactions }\end{array}$ & 39 & $\begin{array}{l}\text { My interactions with instructors outside the classroom have had a positive } \\
\text { influence on my personal growth at this institution. }\end{array}$ \\
\hline $\begin{array}{l}\text { Outside Class- } \\
\text { Related Issues }\end{array}$ & 40 & I contact my instructors outside of class about class-related issues. \\
\hline $\begin{array}{l}\text { Informal } \\
\text { Interaction }\end{array}$ & 41 & $\begin{array}{l}\text { I am satisfied with the opportunities to meet and interact informally with } \\
\text { instructors. }\end{array}$ \\
\hline Instructor Interest & 42 & $\begin{array}{l}\text { It is important that my instructors get to know me and show an interest in } \\
\text { me. }\end{array}$ \\
\hline $\begin{array}{l}\text { More Outside } \\
\text { Interaction }\end{array}$ & 43 & I would like more interaction with my instructors outside of class. \\
\hline $\begin{array}{l}\text { Outside Nonclass- } \\
\text { Related Issues }\end{array}$ & 44 & I contact my instructors outside of class about non-class-related issues. \\
\hline
\end{tabular}

Student participants rated their expectations of instructional activities outside the classroom with 5-point Likert-type items $(1=$ strongly disagree, $2=$ disagree, $3=$ neutral, $4=$ agree, 5 = strongly agree). Descriptive statistics were calculated to determine their expectations. Table 16 lists the frequency and mode for each of the items on this section of the 
survey. The frequencies are shown as a percentage of the participants who selected each of the Likert-type items. This percentage is the valid percent, which is a percentage that does not include missing responses. Between 101 and 116 students skipped items 32 through 44 from the total 1,261 responses.

As these Likert-type items were also designed to reflect the needs of students, it was expected that participants would agree or strongly agree with most of the statements. Similar to the instructional activities inside the classroom section, a few items received different results. When students were asked if it was fine to ask instructors for special treatment, $44.9 \%$ disagreed with that statement and $17.4 \%$ strongly disagreed. For wanting more interaction with instructors outside of class, $40.9 \%$ were neutral and $11.9 \%$ disagreed. When students were asked if they contacted instructors outside of class about nonclass-related issues, $44.3 \%$ disagreed and $25 \%$ strongly disagreed.

The highest level of agreement was found for item 35 . When students were asked if instructors should use the online course management system to post grades, assignments, and classroom study materials, 92.7\% agreed or strongly agreed. When combining agree and strongly agree for other items, high levels of agreement were found for instructors being available to provide individualized attention (84.9\%), instructors answering emails within 24 hours or sooner $(82.5 \%)$, and instructors having assignments graded and returned within two weeks of the due date or sooner $(90.8 \%)$. Students also agreed that they used their instructor feedback from assignments to prepare future assignments (88.8\%). 
Table 16

Student Frequencies and Modes for Expectations of Instructional Activities Outside the Classroom

\begin{tabular}{lccccccc}
\hline Survey Item Label & Item & $\mathrm{SD}(\%)$ & $\mathrm{D}(\%)$ & $\mathrm{N}(\%)$ & $\mathrm{A}(\%)$ & $\mathrm{SA}(\%)$ & Mode \\
\hline Individualized Attention & 32 & 0.2 & 1.6 & 13.4 & 54.9 & 30.0 & 4 \\
24-Hour Email & 33 & 0.2 & 3.5 & 13.8 & 48.4 & 34.1 & 4 \\
Response & 34 & 17.4 & 44.9 & 26.3 & 8.7 & 2.7 & 2 \\
Special Treatment & 35 & 0.3 & 1.2 & 5.8 & 38.2 & 54.5 & 5 \\
CMS & 36 & 0.2 & 0.5 & 8.5 & 35.7 & 55.1 & 5 \\
Graded Assignments & 37 & 0.2 & 3.3 & 22.4 & 48.5 & 25.6 & 4 \\
Detailed Feedback & 38 & 0.2 & 2.0 & 9.0 & 48.7 & 40.1 & 4 \\
Use Feedback & 39 & 0.8 & 4.2 & 24.8 & 45.2 & 25.1 & 4 \\
Outside Interactions & 40 & 1.3 & 8.0 & 18.5 & 51.5 & 20.7 & 4 \\
Outside Class-Related & & & & & & & \\
Issues & 41 & 0.8 & 7.8 & 28.9 & 48.6 & 13.9 & 4 \\
Informal Interaction & 42 & 0.4 & 6.3 & 26.4 & 49.7 & 17.2 & 4 \\
Instructor Interest & 43 & 1.2 & 11.9 & 40.9 & 34.2 & 11.8 & 3 \\
More Outside & 44 & 25.0 & 44.3 & 16.3 & 10.9 & 3.5 & 2 \\
Interaction & & & & & & \\
Outside Nonclass- & Related Issues & & & & & & \\
\hline Note. 1=Strongly Disagree (SD), 2=Disagree (D), 3=Neutral (N), $4=$ Agree (A), 5=Strongly Agree (SA)
\end{tabular}

\section{Research Question Three}

What are faculty approaches to instructional activities inside the classroom? On the faculty survey, 31 items corresponded to this research question. Table 17 lists each of these items and provides a label for quick analysis in subsequent tables. 
Table 17

Faculty Approaches to Instructional Activities Inside the Classroom

\begin{tabular}{|c|c|c|}
\hline Label & Item & Survey Items \\
\hline Reward Efforts & 1 & I reward students for their efforts in class. \\
\hline Flexible & 2 & I am flexible to allow for students' classroom success. \\
\hline Credit for Trying & 3 & $\begin{array}{l}\text { I give students credit for trying, regardless of how well they perform on } \\
\text { their coursework. }\end{array}$ \\
\hline Ask Questions & 4 & $\begin{array}{l}\text { Students are encouraged to ask questions during class so I can clarify the } \\
\text { material. }\end{array}$ \\
\hline $\begin{array}{l}\text { Unprepared } \\
\text { Exceptions }\end{array}$ & 5 & If students are unprepared for class, I make exceptions. \\
\hline Classroom Input & 6 & I let students have input into classroom decisions. \\
\hline Class Attendance & 7 & I do not count class attendance toward classroom grades. \\
\hline Syllabus & 8 & $\begin{array}{l}\text { The syllabi for my classes detail when every assignment is due for the } \\
\text { semester. }\end{array}$ \\
\hline $\begin{array}{l}\text { Specific Grading } \\
\text { Guidelines }\end{array}$ & 9 & I provide specific grading guidelines for each assignment. \\
\hline Classroom Rules & 10 & I clearly communicate all classroom rules. \\
\hline $\begin{array}{l}\text { Step-by-Step } \\
\text { Instruction }\end{array}$ & 11 & $\begin{array}{l}\text { I provide step-by-step instructions for a project rather than let students } \\
\text { decide on their own how to accomplish it. }\end{array}$ \\
\hline Structured Classes & 12 & My classes are very structured. \\
\hline Study Guides & 13 & I provide study guides. \\
\hline Other Resources & 14 & $\begin{array}{l}\text { I tell students about tutoring and other resources they can use on campus to } \\
\text { help them be successful. }\end{array}$ \\
\hline Internet Surfing & 15 & I allow students to surf the internet or text others while in class. \\
\hline Follow Class & 16 & Students can still follow the class while they text or surf the internet. \\
\hline $\begin{array}{l}\text { Technology Besides } \\
\text { PPT }\end{array}$ & 17 & $\begin{array}{l}\text { I use technology besides PowerPoint presentations in the classroom, such } \\
\text { as interactive whiteboards, music, clickers, and videos. }\end{array}$ \\
\hline Online Resources & 18 & I use online resources in my classes, such as websites and articles. \\
\hline Online Textbooks & 19 & I prefer using online textbooks to traditional textbooks. \\
\hline C Grade & 20 & I give students at least a $\mathrm{C}$ in a class just for attending. \\
\hline Exams & 21 & Exams count for the majority of the class grade. \\
\hline $\begin{array}{l}\text { Pass Class w/o } \\
\text { Materials }\end{array}$ & 22 & $\begin{array}{l}\text { Students can pass my classes without the required textbooks or course } \\
\text { materials. }\end{array}$ \\
\hline Learning Objectives & 23 & I link course assignments with stated course goals or learning objectives. \\
\hline $\begin{array}{l}\text { Instructor } \\
\text { Interaction }\end{array}$ & 24 & I would like more interaction with my students in class. \\
\hline Besides Lecture & 25 & $\begin{array}{l}\text { I do different things in class rather than stand at the front of the classroom } \\
\text { and only explain class content. }\end{array}$ \\
\hline Requires Textbook & 26 & If I require a textbook for the class, I use it for assignments and tests. \\
\hline Material for Exams & 27 & I cover just the material required for exams. \\
\hline
\end{tabular}

Table continued 


\begin{tabular}{lcl}
\hline Label & Item & \multicolumn{1}{c}{ Survey Items } \\
\hline $\begin{array}{l}\text { Out-of-Class Work } \\
\text { Instructional }\end{array}$ & 28 & $\begin{array}{l}\text { Students are expected to do very little out-of-class work. } \\
\text { Strategies }\end{array}$ \\
$\begin{array}{l}\text { Generational } \\
\text { Context }\end{array}$ & 29 & I use more than one way to teach the material. \\
$\begin{array}{l}\text { Classroom } \\
\text { Questions }\end{array}$ & 31 & $\begin{array}{l}\text { I am meeting this generation of students where it is at academically and } \\
\text { socially. }\end{array}$ \\
\hline
\end{tabular}

Faculty participants rated their approaches to instructional activities inside the classroom with 5-point Likert-type items $(1=$ strongly disagree, $2=$ disagree, $3=$ neutral, $4=$ agree, $5=$ strongly agree). Descriptive statistics were calculated to determine their expectations. Table 18 lists the frequency and mode for each of the items on this section of the survey. The frequencies are shown as a percentage of the participants who selected each of the Likert-type items. This percentage is the valid percent, which is a percentage that does not include missing responses. Between 14 and 20 faculty skipped items 1 through 31 from the total 131 responses.

For items 19, 21, 26, and 27, faculty could also pick N/A as an option. Items 19 and 26 were about textbooks, and 21 and 27 were about exams. In the pilot study, comments from participants indicated a need for an N/A option as not all faculty used textbooks or gave exams. The frequencies for N/A for items $19,21,26$, and 27 , in order, were $6.1 \%, 6.1 \%, 4.4 \%$, and $6.2 \%$

As these Likert-type items were designed to reflect the needs of students, and the majority of faculty who responded to the survey were either Generation X (56.5\%) or Baby Boomers (29.8\%), it was expected that participants would disagree or strongly disagree with some of the statements. However, several items received different results. When faculty were asked if they gave students credit for trying, regardless of how well students performed on their 
coursework, $33.6 \%$ agreed with that statement and $6 \%$ strongly agreed. For making exceptions when students were unprepared for class, $34.2 \%$ were neutral and $17.5 \%$ agreed. When asked if they allowed students to surf the internet or text others while in class, $23.7 \%$ were neutral and $15.8 \%$ agreed. For the statement about meeting this generation of students where it was at academically and socially, $41.4 \%$ were neutral.

It was anticipated that faculty would have strong opinions on a few statements. When asked if they gave students at least a $\mathrm{C}$ in the class just for attending, $41.2 \%$ disagreed and $50 \%$ strongly disagreed. For a supplemental item to the internet surfing item indicating that students could still follow class while they texted or surfed the internet, $27.8 \%$ disagreed and $48.7 \%$ strong disagreed.

The highest level of agreement was found for item 4 . When faculty were asked if students were encouraged to ask questions during class so faculty could clarify the material, $99.1 \%$ agreed or strongly agreed. When combining agree and strongly agree for other items, high levels of agreement were found for instructors rewarding students for their efforts in class (88.9\%), instructors being flexible for students' classroom success (87.9\%), a syllabus listing due dates for every assignment $(82.7 \%)$, instructors providing specific grading guidelines for each assignment (85.3\%), and instructors clearly communicating classroom rules (86.8\%). Instructors also agreed that they used online resources in their classes such as websites and articles (94.6\%), and did different things in the class rather than stand at the front of the classroom and only explain class content $(88.5 \%)$. They left enough time in class to go over the material and answer students' questions (84.1\%), and used more than one way to teach the material (91.2\%). If instructors required a textbook for class, they agreed they used it for assignments and tests $(82.3 \%)$. 
Table 18

Faculty Frequencies and Modes for Approaches to Instructional Activities Inside the Classroom

\begin{tabular}{|c|c|c|c|c|c|c|c|}
\hline Survey Item Label & Item & $\mathrm{SD}(\%)$ & $\mathrm{D}(\%)$ & $\mathrm{N}(\%)$ & $\mathrm{A}(\%)$ & SA $(\%)$ & Mode \\
\hline Reward Efforts & 1 & 2.6 & 1.7 & 6.8 & 57.3 & 31.6 & 4 \\
\hline Flexible & 2 & 0.9 & 2.6 & 8.7 & 49.6 & 38.3 & 4 \\
\hline Credit for Trying & 3 & 2.6 & 26.7 & 31.0 & 33.6 & 6.0 & 4 \\
\hline Ask Questions & 4 & 0.0 & 0.0 & 0.9 & 20.7 & 78.4 & 5 \\
\hline Unprepared Exceptions & 5 & 14.9 & 30.7 & 34.2 & 17.5 & 2.6 & 3 \\
\hline Classroom Input & 6 & 1.7 & 6.9 & 19.0 & 48.3 & 24.1 & 4 \\
\hline Class Attendance & 7 & 23.3 & 37.1 & 5.2 & 19.8 & 14.7 & 2 \\
\hline Syllabus & 8 & 1.7 & 8.6 & 6.9 & 28.4 & 54.3 & 5 \\
\hline $\begin{array}{l}\text { Specific Grading } \\
\text { Guidelines }\end{array}$ & 9 & 0.0 & 5.2 & 9.6 & 47.0 & 38.3 & 4 \\
\hline Classroom Rules & 10 & 0.0 & 2.6 & 10.5 & 48.2 & 38.6 & 4 \\
\hline $\begin{array}{l}\text { Step-by-Step } \\
\text { Instruction }\end{array}$ & 11 & 1.7 & 19.1 & 21.7 & 35.7 & 21.7 & 4 \\
\hline Structured Classes & 12 & 0.9 & 15.8 & 21.1 & 48.2 & 14.0 & 4 \\
\hline Study Guides & 13 & 10.4 & 15.7 & 15.7 & 37.4 & 20.9 & 4 \\
\hline Other Resources & 14 & 3.5 & 11.4 & 16.7 & 41.2 & 27.2 & 4 \\
\hline Internet Surfing & 15 & 31.6 & 27.2 & 23.7 & 15.8 & 1.8 & 1 \\
\hline Follow Class & 16 & 48.7 & 27.8 & 17.4 & 5.2 & 0.9 & 1 \\
\hline $\begin{array}{l}\text { Technology Besides } \\
\text { PPT }\end{array}$ & 17 & 4.4 & 13.3 & 6.2 & 45.1 & 31.0 & 4 \\
\hline Online Resources & 18 & 0.0 & 4.5 & 0.9 & 47.3 & 47.3 & 4,5 \\
\hline Online Textbooks & 19 & 16.7 & 21.9 & 35.1 & 11.4 & 8.8 & 3 \\
\hline C Grade & 20 & 50.0 & 41.2 & 7.0 & 0.9 & 0.9 & 1 \\
\hline Exams & 21 & 20.2 & 25.4 & 14.9 & 20.2 & 13.2 & 2 \\
\hline $\begin{array}{l}\text { Pass Class w/o } \\
\text { Materials }\end{array}$ & 22 & 33.3 & 44.7 & 11.4 & 9.6 & 0.9 & 2 \\
\hline Learning Objectives & 23 & 0.0 & 9.7 & 15.9 & 49.6 & 24.8 & 4 \\
\hline Instructor Interaction & 24 & 0.0 & 8.8 & 28.1 & 52.6 & 10.5 & 4 \\
\hline Besides Lecture & 25 & 0.0 & 6.2 & 5.3 & 43.4 & 45.1 & 5 \\
\hline Requires Textbook & 26 & 0.9 & 6.2 & 6.2 & 43.4 & 38.9 & 4 \\
\hline Material for Exams & 27 & 33.6 & 46.0 & 7.1 & 1.8 & 5.3 & 2 \\
\hline Out-of-Class Work & 28 & 44.2 & 44.2 & 8.8 & 2.7 & 0.0 & 1,2 \\
\hline Instructional Strategies & 29 & 1.8 & 0.9 & 6.2 & 54.9 & 36.3 & 4 \\
\hline Generational Context & 30 & 0.0 & 9.9 & 41.4 & 39.6 & 9.0 & 3 \\
\hline Classroom Questions & 31 & 0.0 & 4.4 & 11.5 & 59.3 & 24.8 & 4 \\
\hline
\end{tabular}




\section{Research Question Four}

What are faculty approaches to instructional activities outside the classroom? On the faculty survey, 13 items corresponded to this research question. Table 19 lists each of these items and provides a label for quick analysis in subsequent tables.

Table 19

Faculty Approaches to Instructional Activities Outside the Classroom

\begin{tabular}{|c|c|c|}
\hline Label & Item & Survey Items \\
\hline $\begin{array}{l}\text { Individualized } \\
\text { Attention }\end{array}$ & 32 & I am available to provide individualized attention if students need it. \\
\hline $\begin{array}{l}\text { 24-Hour Email } \\
\text { Response }\end{array}$ & 33 & I answer students' emails within 24 hours or sooner. \\
\hline Special Treatment & 34 & It is fine for students to ask me for special treatment. \\
\hline CMS & 35 & $\begin{array}{l}\text { I use the online course management system to post grades, assignments, } \\
\text { and classroom study materials. }\end{array}$ \\
\hline Grade Assignments & 36 & $\begin{array}{l}\text { I have assignments graded and returned within two weeks of the due date } \\
\text { or sooner. }\end{array}$ \\
\hline Detailed Feedback & 37 & I give detailed feedback on students' coursework. \\
\hline Use Feedback & 38 & Students use my feedback from assignments to prepare future assignments. \\
\hline Outside Interactions & 39 & $\begin{array}{l}\text { My interactions with students outside the classroom have had a positive } \\
\text { influence on their personal growth at this institution. }\end{array}$ \\
\hline $\begin{array}{l}\text { Outside Class- } \\
\text { Related Issues }\end{array}$ & 40 & Students contact me outside of class about class-related issues. \\
\hline Informal Interaction & 41 & $\begin{array}{l}\text { I am satisfied with the opportunities to meet and interact informally with } \\
\text { students. }\end{array}$ \\
\hline Instructor Interest & 42 & It is important I get to know my students and show an interest in them. \\
\hline $\begin{array}{l}\text { More Outside } \\
\text { Interaction }\end{array}$ & 43 & I would like more interaction with my students outside of class. \\
\hline $\begin{array}{l}\text { Outside Nonclass- } \\
\text { Related Issues }\end{array}$ & 44 & Students contact me outside of class about non-class-related issues. \\
\hline
\end{tabular}

Faculty participants rated their approaches to instructional activities outside the classroom with 5-point Likert-type items $(1=$ strongly disagree, $2=$ disagree, $3=$ neutral, $4=$ agree, 5 = strongly agree). Descriptive statistics were calculated to determine their 
expectations. Table 20 lists the frequency and mode for each of the items on this section of the survey. The frequencies are shown as a percentage of the participants who selected each of the Likert-type items. This percentage is the valid percent, which is a percentage that does not include missing responses. Between 18 and 20 faculty skipped items 32 through 44 from the total 131 responses.

As these Likert-type items were also designed to reflect the needs of students, and the majority of faculty who responded to the survey were either Generation X (56.5\%) or Baby Boomers (29.8\%), it was expected that participants would disagree or strongly disagree with some of the statements. Similar to the instructional activities inside the classroom section, a couple of statements received different results. When faculty were asked if it was fine for students to seek special treatment, $38.9 \%$ were neutral and $17.7 \%$ agreed. For wanting more interaction with students outside of class, $38.7 \%$ were neutral and $35.1 \%$ agreed.

The highest level of agreement was found for item 40. When faculty were asked if students contacted them outside of class about class-related issues, 97.4\% agreed or strongly agreed. When combining agree and strongly agree for other items, high levels of agreement were found for instructors being available to provide individualized attention $(97.3 \%)$, instructors answering emails within 24 hours or sooner $(81.9 \%)$, and instructors having assignments graded and returned within 2 weeks of the due date or sooner $(89.3 \%)$. Faculty also agreed that they gave detailed feedback on students' coursework (85.7\%), and used the online course management system to post grades, assignments, and classroom study materials $(87.6 \%)$ 
Table 20

Faculty Frequencies and Modes for Approaches to Instructional Activities Outside the Classroom

\begin{tabular}{|c|c|c|c|c|c|c|c|}
\hline Survey Item Label & Item & $\mathrm{SD}(\%)$ & $\mathrm{D}(\%)$ & $\mathrm{N}(\%)$ & $\mathrm{A}(\%)$ & SA $(\%)$ & Mode \\
\hline $\begin{array}{l}\text { Individualized } \\
\text { Attention }\end{array}$ & 32 & 0.0 & 0.9 & 1.8 & 46.0 & 51.3 & 5 \\
\hline $\begin{array}{l}\text { 24-Hour Email } \\
\text { Response }\end{array}$ & 33 & 0.0 & 5.4 & 12.6 & 42.3 & 39.6 & 4 \\
\hline Special Treatment & 34 & 14.2 & 26.5 & 38.9 & 17.7 & 2.7 & 3 \\
\hline CMS & 35 & 1.8 & 4.4 & 6.2 & 23.0 & 64.6 & 5 \\
\hline Grade Assignments & 36 & 0.0 & 4.5 & 6.3 & 34.8 & 54.5 & 5 \\
\hline Detailed Feedback & 37 & 0.0 & 6.3 & 8.0 & 48.2 & 37.5 & 4 \\
\hline Use Feedback & 38 & 3.5 & 8.8 & 21.2 & 42.5 & 23.9 & 4 \\
\hline Outside Interactions & 39 & 0.0 & 1.8 & 15.2 & 50.0 & 33.0 & 4 \\
\hline $\begin{array}{l}\text { Outside Class-Related } \\
\text { Issues }\end{array}$ & 40 & 0.0 & 0.0 & 2.7 & 60.2 & 37.2 & 4 \\
\hline Informal Interaction & 41 & 2.7 & 7.1 & 22.1 & 54.0 & 14.2 & 4 \\
\hline Instructor Interest & 42 & 0.0 & 3.5 & 7.1 & 53.1 & 36.3 & 4 \\
\hline $\begin{array}{l}\text { More Outside } \\
\text { Interaction }\end{array}$ & 43 & 0.9 & 15.3 & 38.7 & 35.1 & 9.9 & 3 \\
\hline $\begin{array}{l}\text { Outside Nonclass- } \\
\text { Related Issues }\end{array}$ & 44 & 0.9 & 22.1 & 25.7 & 36.3 & 15.0 & 4 \\
\hline
\end{tabular}

Note. 1=Strongly Disagree (SD), 2=Disagree (D), 3=Neutral (N), 4=Agree (A), 5=Strongly Agree (SA)

\section{Research Question Five}

To what extent do faculty approaches to instructional activities inside the classroom differ from students' expectations of those instructional activities? To answer this research question, an independent samples t-test was conducted to compare the expectations of students and the approaches of faculty toward instructional activities inside the classroom. A variable that represented a mean score for each participant was calculated using the compute variable function in SPSS for the 31 Likert-type items in this section to create the scale.

Table 21 lists the results of the t-test. There was a statistically significant difference between faculty $(\mathrm{M}=3.43, \mathrm{SD}=.31)$ and students $(\mathrm{M}=3.55, \mathrm{SD}=.37), \mathrm{t}(1320)=-3.26, p \leq$ 
.05 , CI.95 -.18, -.05) when comparing responses of faculty and students for instructional activities inside the classroom. The null hypothesis of no significant difference between students' expectations of instructional activities inside the classroom and faculty approaches to instructional activities inside the classroom was rejected. Further, Cohen's effect size value (d $=.33)$ suggests a small to moderate practical significance.

\section{Table 21}

Results from t-test Comparing Responses of Faculty and Students for Instructional Activities Inside the Classroom

\begin{tabular}{lccccccc}
\hline Group & $\mathrm{n}$ & Mean & $\mathrm{SD}$ & $\mathrm{t}$ & $\mathrm{df}$ & $\mathrm{p}$ & Decision \\
\hline Students & 1205 & 3.5495 & .37047 & -3.258 & 1320 & .001 & Reject \\
Faculty & 117 & 3.4342 & .31076 & & & & \\
\hline
\end{tabular}

Table 22 lists notable differences between students and faculty in responses to items 1 , $7,15,16,20,22,27$, and 28 . A higher percentage of faculty (31.6\%) strongly agreed that it rewarded students for efforts in class versus students expecting their faculty to reward them for those efforts (16.5\%). Faculty and students also differed on whether class attendance should count toward classroom grades. When asked if class attendance should not count toward classroom grades, $20.6 \%$ of students agreed and $17.3 \%$ strongly agreed. When asked if they did not count class attendance toward classroom grades, $37.1 \%$ of faculty disagreed and $23.3 \%$ strongly disagreed.

It was expected that faculty would not agree that students could still follow class while surfing the internet or texting; $27.8 \%$ disagreed and $48.7 \%$ strongly disagreed. For the students, however, $32.2 \%$ agreed and $11.6 \%$ strongly agreed that they could still follow along with the class. For passing classes without the required textbooks or course materials, $25.4 \%$ of students 
agreed and $6.9 \%$ strongly agreed that it was possible versus $9.6 \%$ for agreed and $0.9 \%$ for strongly agreed for faculty. Students agreed they preferred to cover just the material for exams at $36.6 \%$ and strongly agreed at $18.4 \%$, while only $1.8 \%$ of faculty agreed they covered just that material and 5.3\% strongly agreed.

Table 22

Frequencies and Modes for Instructional Activities Inside the Classroom

\begin{tabular}{lcrrrrrrr}
\hline Survey Item Label & $\mathrm{G}^{\mathrm{a}}$ & $\mathrm{Q} \#$ & $\mathrm{SD}(\%)$ & $\mathrm{D}(\%)$ & $\mathrm{N}(\%)$ & $\mathrm{A}(\%)$ & $\mathrm{SA}(\%)$ & Mode $^{\mathrm{b}}$ \\
\hline Reward Efforts & $\mathrm{S}$ & 1 & 1.0 & 7.2 & 28.9 & 46.4 & 16.5 & 4 \\
& $\mathrm{~F}$ & 1 & 2.6 & 1.7 & 6.8 & 57.3 & 31.6 & 4 \\
Class Attendance & $\mathrm{S}$ & 7 & 10.9 & 24.5 & 26.8 & 20.6 & 17.3 & 3 \\
& $\mathrm{~F}$ & 7 & 23.3 & 37.1 & 5.2 & 19.8 & 14.7 & 2 \\
Internet Surfing & $\mathrm{S}$ & 15 & 13.5 & 29.1 & 36.1 & 16.8 & 4.5 & 3 \\
& $\mathrm{~F}$ & 15 & 31.6 & 27.2 & 23.7 & 15.8 & 1.8 & 1 \\
Follow Class & $\mathrm{S}$ & 16 & 12.6 & 23.7 & 20.0 & 32.2 & 11.6 & 4 \\
& $\mathrm{~F}$ & 16 & 48.7 & 27.8 & 17.4 & 5.2 & 0.9 & 1 \\
C Grade & $\mathrm{S}$ & 20 & 15.2 & 38.0 & 25.0 & 16.0 & 5.9 & 2 \\
& $\mathrm{~F}$ & 20 & 50.0 & 41.2 & 7.0 & 0.9 & 0.9 & 1 \\
Pass Class w/o Materials & $\mathrm{S}$ & 22 & 8.3 & 28.6 & 30.9 & 25.4 & 6.9 & 3 \\
& $\mathrm{~F}$ & 22 & 33.3 & 44.7 & 11.4 & 9.6 & 0.9 & 2 \\
Material for Exams & $\mathrm{S}$ & 27 & 2.4 & 18.7 & 24.0 & 36.6 & 18.4 & 4 \\
& $\mathrm{~F}$ & 27 & 33.6 & 46.0 & 7.1 & 1.8 & 5.3 & 2 \\
Out-of-Class Work & $\mathrm{S}$ & 28 & 16.3 & 49.6 & 23.9 & 7.8 & 2.3 & 2 \\
& $\mathrm{~F}$ & 28 & 44.2 & 44.2 & 8.8 & 2.7 & 0.0 & 1,2
\end{tabular}

Note. ${ }^{\mathrm{a}} 1=$ Strongly Disagree (SD), 2=Disagree (D), 3=Neutral (N), 4=Agree (A), $5=$ Strongly Agree (SA) ${ }^{\mathrm{b}} \mathrm{S}=$ Students, $\mathrm{F}=$ Faculty

\section{Instructional Activities Inside the Classroom Subscales}

To further identify differences between faculty and students and to take a closer look at the Millennial typology, the instructional activities inside the classroom scale of 31-Likert type items was broken into two subscales: Millennial characteristics and pedagogical characteristics. The Millennial subscale consisted of 16 Likert-type items and the pedagogical subscale 
consisted of 15 Likert-type items. Tables 23 and 24 list each of these items from the student survey and provide a label for quick analysis. Tables 25 and 26 list each of these items from the faculty survey and also provide a label for quick analysis.

Table 23

Student Instrument-Millennial Characteristics Subscale

\begin{tabular}{|c|c|c|}
\hline$\underline{\text { Label }}$ & Item & Survey Items \\
\hline Reward Efforts & 1 & My instructors should reward me for my efforts in class. \\
\hline Flexible & 2 & My instructors should be flexible to allow for my classroom success. \\
\hline Credit for Trying & 3 & $\begin{array}{l}\text { My instructors should give me credit for trying, regardless of how well I } \\
\text { perform on my coursework. }\end{array}$ \\
\hline Ask Questions & 4 & $\begin{array}{l}\text { I expect to be able to ask questions during class and get answers from my } \\
\text { instructors. }\end{array}$ \\
\hline $\begin{array}{l}\text { Unprepared } \\
\text { Exceptions }\end{array}$ & 5 & If I am unprepared for class, I expect my instructors to make exceptions. \\
\hline Classroom Input & 6 & My instructors should let me have input into classroom decisions. \\
\hline Other Resources & 14 & $\begin{array}{l}\text { My instructors should tell me about tutoring and other resources I can use } \\
\text { on campus to help me be successful. }\end{array}$ \\
\hline Internet Surfing & 15 & I should be allowed to surf the internet or text others while in class. \\
\hline Follow Class & 16 & I can still follow the class while I text or surf the internet. \\
\hline Online Textbooks & 19 & I prefer online textbooks to traditional textbooks. \\
\hline C Grade & 20 & I expect to get at least a $\mathrm{C}$ in a class just for attending. \\
\hline $\begin{array}{l}\text { Pass Class w/o } \\
\text { Materials }\end{array}$ & 22 & I can pass my classes without the required textbooks or course materials. \\
\hline $\begin{array}{l}\text { Instructor } \\
\text { Interaction }\end{array}$ & 24 & I would like more interaction with my instructors in class. \\
\hline Out-of-Class Work & 28 & I expect to do very little out-of-class work. \\
\hline $\begin{array}{l}\text { Generational } \\
\text { Context }\end{array}$ & 30 & $\begin{array}{l}\text { Instructors should meet my generation where it is at academically and } \\
\text { socially. }\end{array}$ \\
\hline $\begin{array}{l}\text { Classroom } \\
\text { Questions }\end{array}$ & 31 & $\begin{array}{l}\text { Instructors should leave enough time in class to go over the material and } \\
\text { have time for my questions. }\end{array}$ \\
\hline
\end{tabular}


Table 24

Student Instrument-Pedagogical Characteristics Subscale

\begin{tabular}{|c|c|c|}
\hline Label & Item & Survey Items \\
\hline Class Attendance & 7 & Class attendance should not count toward classroom grades. \\
\hline Syllabus & 8 & $\begin{array}{l}\text { The syllabus for a class should detail when every assignment is due for the } \\
\text { semester. }\end{array}$ \\
\hline $\begin{array}{l}\text { Specific Grading } \\
\text { Guidelines }\end{array}$ & 9 & $\begin{array}{l}\text { My instructors should provide specific grading guidelines for each } \\
\text { assignment. }\end{array}$ \\
\hline Classroom Rules & 10 & My instructors should clearly communicate all classroom rules. \\
\hline $\begin{array}{l}\text { Step-by-Step } \\
\text { Instruction }\end{array}$ & 11 & $\begin{array}{l}\text { I would rather have step-by-step instructions for a project than decide on } \\
\text { my own how to accomplish it. }\end{array}$ \\
\hline Structured Classes & 12 & I prefer classes that are very structured. \\
\hline Study Guides & 13 & I expect my instructors to provide study guides. \\
\hline $\begin{array}{l}\text { Technology } \\
\text { Besides PPT }\end{array}$ & 17 & $\begin{array}{l}\text { My instructors should use technology besides PowerPoint presentations in } \\
\text { the classroom, such as interactive whiteboards, music, clickers, and videos. }\end{array}$ \\
\hline Online Resources & 18 & $\begin{array}{l}\text { My instructor should use online resources in class, such as websites and } \\
\text { articles. }\end{array}$ \\
\hline Exams & 21 & I prefer to have exams count for the majority of my class grade. \\
\hline $\begin{array}{l}\text { Learning } \\
\text { Objectives }\end{array}$ & 23 & $\begin{array}{l}\text { My instructors should link course assignments with stated course goals or } \\
\text { learning objectives. }\end{array}$ \\
\hline Besides Lecture & 25 & $\begin{array}{l}\text { My instructor should do different things in class rather than stand at the } \\
\text { front of the classroom and only explain class content. }\end{array}$ \\
\hline Requires Textbook & 26 & $\begin{array}{l}\text { If my instructor requires a textbook for the class, I expect to use it for my } \\
\text { assignments and tests. }\end{array}$ \\
\hline Material for Exams & 27 & I prefer to cover just the material required for exams. \\
\hline $\begin{array}{l}\text { Instructional } \\
\text { Strategies }\end{array}$ & 29 & My instructors use more than one way to teach the material. \\
\hline
\end{tabular}


Table 25

Faculty Instrument-Millennial Characteristics Subscale

\begin{tabular}{|c|c|c|}
\hline Label & Item & Survey Items \\
\hline Reward Efforts & 1 & I reward students for their efforts in class. \\
\hline Flexible & 2 & I am flexible to allow for students' classroom success. \\
\hline Credit for Trying & 3 & $\begin{array}{l}\text { I give students credit for trying, regardless of how well they perform on } \\
\text { their coursework. }\end{array}$ \\
\hline Ask Questions & 4 & $\begin{array}{l}\text { Students are encouraged to ask questions during class so I can clarify the } \\
\text { material. }\end{array}$ \\
\hline $\begin{array}{l}\text { Unprepared } \\
\text { Exceptions }\end{array}$ & 5 & If students are unprepared for class, I make exceptions. \\
\hline Classroom Input & 6 & I let students have input into classroom decisions. \\
\hline Other Resources & 14 & $\begin{array}{l}\text { I tell students about tutoring and other resources they can use on campus to } \\
\text { help them be successful. }\end{array}$ \\
\hline Internet Surfing & 15 & I allow students to surf the internet or text others while in class. \\
\hline Follow Class & 16 & Students can still follow the class while they text or surf the internet. \\
\hline Online Textbooks & 19 & I prefer using online textbooks to traditional textbooks. \\
\hline C Grade & 20 & I give students at least a $\mathrm{C}$ in a class just for attending. \\
\hline $\begin{array}{l}\text { Pass Class w/o } \\
\text { Materials }\end{array}$ & 22 & $\begin{array}{l}\text { Students can pass my classes without the required textbooks or course } \\
\text { materials. }\end{array}$ \\
\hline $\begin{array}{l}\text { Instructor } \\
\text { Interaction }\end{array}$ & 24 & I would like more interaction with my students in class. \\
\hline Out-of-Class Work & 28 & Students are expected to do very little out-of-class work. \\
\hline $\begin{array}{l}\text { Generational } \\
\text { Context }\end{array}$ & 30 & $\begin{array}{l}\text { I am meeting this generation of students where it is at academically and } \\
\text { socially. }\end{array}$ \\
\hline $\begin{array}{l}\text { Classroom } \\
\text { Questions }\end{array}$ & 31 & $\begin{array}{l}\text { I leave enough time in my class to go over the material and have time for } \\
\text { students' questions. }\end{array}$ \\
\hline
\end{tabular}


Table 26

Faculty Instrument-Pedagogical Characteristics Subscale

\begin{tabular}{|c|c|c|}
\hline Label & Item & Survey Statement \\
\hline Class Attendance & 7 & I do not count class attendance toward classroom grades. \\
\hline Syllabus & 8 & $\begin{array}{l}\text { The syllabi for my classes detail when every assignment is due for the } \\
\text { semester. }\end{array}$ \\
\hline $\begin{array}{l}\text { Specific Grading } \\
\text { Guidelines }\end{array}$ & 9 & I provide specific grading guidelines for each assignment. \\
\hline Classroom Rules & 10 & I clearly communicate all classroom rules. \\
\hline $\begin{array}{l}\text { Step-by-Step } \\
\text { Instruction }\end{array}$ & 11 & $\begin{array}{l}\text { I provide step-by-step instructions for a project rather than let students } \\
\text { decide on their own how to accomplish it. }\end{array}$ \\
\hline Structured Classes & 12 & My classes are very structured. \\
\hline Study Guides & 13 & I provide study guides. \\
\hline $\begin{array}{l}\text { Technology Besides } \\
\text { PPT }\end{array}$ & 17 & $\begin{array}{l}\text { I use technology besides PowerPoint presentations in the classroom, such } \\
\text { as interactive whiteboards, music, clickers, and videos. }\end{array}$ \\
\hline Online Resources & 18 & I use online resources in my classes, such as websites and articles. \\
\hline Exams & 21 & Exams count for the majority of the class grade. \\
\hline Learning Objectives & 23 & I link course assignments with stated course goals or learning objectives. \\
\hline Besides Lecture & 25 & $\begin{array}{l}\text { I do different things in class rather than stand at the front of the classroom } \\
\text { and only explain class content. }\end{array}$ \\
\hline Requires Textbook & 26 & If I require a textbook for the class, I use it for assignments and tests. \\
\hline Material for Exams & 27 & I cover just the material required for exams. \\
\hline $\begin{array}{l}\text { Instructional } \\
\text { Strategies }\end{array}$ & 29 & I use more than one way to teach the material. \\
\hline
\end{tabular}

An independent samples t-test was conducted to compare student and faculty responses to the Likert-type items on the Millennial subscale. A variable that represented a mean score for each participant was calculated using the compute variable function in SPSS for the 16 items in this section to create the subscale. Table 27 lists the results of the t-test. There was a statistically significant difference between faculty $(\mathrm{M}=3.15, \mathrm{SD}=.39)$ and students $(\mathrm{M}=$ $3.31, \mathrm{SD}=.43), \mathrm{t}(1320)=-3.866, p \leq .05, \mathrm{CI} .95-.24,-.07)$ when comparing responses of faculty and students for Millennial characteristics inside the classroom. This further supports the rejection of the null hypothesis that there is no significant difference between students' expectations of instructional activities inside the classroom and faculty approaches to 
instructional activities inside the classroom. Further, Cohen's effect size value $(d=.39)$

suggests a small to moderate practical significance.

Table 27

Results from t-test Comparing Responses of Faculty and Students for Millennial Characteristics Subscale

\begin{tabular}{lrcccccc}
\hline Group & $\mathrm{n}$ & Mean & $\mathrm{SD}$ & $\mathrm{t}$ & $\mathrm{df}$ & $\mathrm{p}$ & Decision \\
\hline Students & 1205 & 3.3111 & .43201 & -3.857 & 1320 & .000 & Reject \\
Faculty & 117 & 3.1511 & .39135 & & & & \\
\hline
\end{tabular}

An independent samples t-test was conducted to compare student and faculty responses to the Likert-type items on the pedagogical subscale. A variable that represented a mean score for each participant was calculated using the compute variable function in SPSS for the 15 items in this section to create the subscale. Table 28 lists the results of the t-test. There was a statistically significant difference between faculty $(\mathrm{M}=3.73, \mathrm{SD}=.38)$ and students $(\mathrm{M}=$ $3.80, \mathrm{SD}=.41), \mathrm{t}(1319)=-1.964, p \leq .05, \mathrm{CI} .95-.16,-.00)$ when comparing responses of faculty and students for pedagogical characteristics inside the classroom. As with the Millennial characteristics subscale, this further supports the rejection of the null hypothesis that there is no significant difference between students' expectations of instructional activities inside the classroom and faculty approaches to instructional activities inside the classroom. Further, Cohen's effect size value $(\mathrm{d}=.20)$ suggests a small practical significance.

Table 28

Results from t-test Comparing Responses of Faculty and Students for Pedagogical Characteristics Subscale

\begin{tabular}{lccccccc}
\hline Group & $\mathrm{n}$ & Mean & $\mathrm{SD}$ & $\mathrm{t}$ & $\mathrm{df}$ & $\mathrm{p}$ & Decision \\
\hline Students & 1205 & 3.8034 & .40955 & -1.964 & 1319 & .050 & Reject \\
Faculty & 116 & 3.7256 & .38078 & & & & \\
\hline
\end{tabular}




\section{Research Question Six}

To what extent do faculty approaches to instructional activities outside the classroom differ from students' expectations of those instructional activities? To answer this research question, an independent samples t-test was conducted to compare the expectations of students and the approaches of faculty toward instructional activities outside the classroom. A variable that represented a mean score for each participant was calculated using the compute variable function in SPSS for the 13 Likert-type items in this section to create the scale.

Table 29 lists the results of the t-test. There was a statistically significant difference between faculty $(\mathrm{M}=3.94, \mathrm{SD}=.34)$ and students $(\mathrm{M}=3.74, \mathrm{SD}=.40), \mathrm{t}(1275)=5.25, p \leq$ .05 , CI.95 .13, .28) when comparing responses of faculty and students for instructional activities outside the classroom. Therefore, the null hypothesis of there not being a significant difference between students' expectations of instructional activities outside the classroom and faculty approaches to instructional activities outside the classroom was rejected. Further, Cohen's effect size value $(\mathrm{d}=.55)$ suggests a moderate to high practical significance.

Table 29

Results from t-test Comparing Responses of Faculty and Students for Instructional Activities Outside the Classroom

\begin{tabular}{lrcccccc}
\hline Group & $\mathrm{n}$ & Mean & $\mathrm{SD}$ & $\mathrm{t}$ & $\mathrm{df}$ & $\mathrm{p}$ & Decision \\
\hline Students & 1163 & 3.7400 & .40336 & 5.245 & 1275 & .000 & Reject \\
Faculty & 114 & 3.9949 & .33717 & & & & \\
\hline
\end{tabular}

Table 30 lists notable differences between students and faculty in responses to items 38, 40, 42, and 44. A lower percentage of faculty (23.9\%) strongly agreed that students were using feedback from assignments to prepare future assignments versus students who strongly agreed (40.1\%). Faculty and students also differed on whether students contacted them outside of class 
about class-related issues; $51.5 \%$ of students agreed and $20.7 \%$ strongly agreed, while $60.2 \%$ of faculty agreed and $37.2 \%$ strongly agreed. When asked if it was important for instructors to get to know students and show an interest in them, $17.2 \%$ of students strongly agreed, while $36.3 \%$ of faculty strong agreed. The largest differences in responses were seen in the statement about contacting instructors outside of class regarding nonclass-related issues; $36.3 \%$ of faculty agreed that students do this while only $10.9 \%$ of students agreed.

Table 30

Frequencies and Modes for Instructional Activities Outside the Classroom

\begin{tabular}{lcccccccc}
\hline Survey Statement Label & $\mathrm{G}^{\mathrm{a}}$ & $\mathrm{Q} \#$ & $\mathrm{SD}(\%)$ & $\mathrm{D}(\%)$ & $\mathrm{N}(\%)$ & $\mathrm{A}(\%)$ & $\mathrm{SA}(\%)$ & Mode $^{\mathrm{b}}$ \\
\hline Use Feedback & $\mathrm{S}$ & 38 & 0.2 & 2.0 & 9.0 & 48.7 & 40.1 & 4 \\
& $\mathrm{~F}$ & 38 & 3.5 & 8.8 & 21.2 & 42.5 & 23.9 & 4 \\
Outside Class-Related & $\mathrm{S}$ & 40 & 1.3 & 8.0 & 18.5 & 51.5 & 20.7 & 4 \\
Issues & $\mathrm{F}$ & 40 & 0.0 & 0.0 & 2.7 & 60.2 & 37.2 & 4 \\
Instructor Interest & $\mathrm{S}$ & 42 & 0.4 & 6.3 & 26.4 & 49.7 & 17.2 & 4 \\
& $\mathrm{~F}$ & 42 & 0.0 & 3.5 & 7.1 & 53.1 & 36.3 & 4 \\
Outside Nonclass- & $\mathrm{S}$ & 44 & 25.0 & 44.3 & 16.3 & 10.9 & 3.5 & 2 \\
Related Issues & $\mathrm{F}$ & 44 & 0.9 & 22.1 & 25.7 & 36.3 & 15.0 & 4
\end{tabular}

Note. ${ }^{\mathrm{a}} 1=$ Strongly Disagree (SD), 2=Disagree (D), 3=Neutral (N), 4=Agree (A), 5=Strongly Agree (SA) ${ }^{\mathrm{b}} \mathrm{S}=$ Students, $\mathrm{F}=$ Faculty

Unlike with the instructional activities inside the classroom scale, none of the items on the instructional activities outside the classroom scale needed to be broken down into subscales for further analysis to answer research question six. All items were grouped together accordingly.

\section{Other Data-Qualitative}

In addition to the characteristic questions and Likert-type items asked of each group, participants were also asked three open-ended questions at the end of the surveys. The data collected from these questions were reviewed through the exploratory qualitative data analysis 
method of word clouds, also referred to as content clouds or semantic clouds (Cidell, 2010; McNaught \& Lam 2010). Answers to each question were entered into the word cloud generator TagCrowd, from ethnographer Dr. Daniel Steinbock, which broke down the text into component words and counted their frequency in the text. The larger the font of the word, the more often the word appeared in the answers to the open-ended questions (TagCrowd, n.d.).

TagCrowd offers several options for users creating content clouds. This includes choosing a maximum number of words to show; the minimum number of times a word can show up before being counted; showing the word count next to the word; grouping similar words such as learn, learned, and learning; and excluding unwanted words. The program automatically filters the text through a stop list. These words, such as the, their, and you're, are automatically excluded unless you turn off that option. The text entered into the generator is not stored anywhere, nor shared (TagCrowd, n.d.).

\section{Student Responses}

Student respondents were asked three questions about their instructors. Table 31 lists the questions and number of responses. The frequency does not include missing responses or when respondents answered with some form of not applicable.

Table 31

Student Open-Ended Questions

\begin{tabular}{llc}
\hline Label & \multicolumn{1}{c}{ Survey Question } & Frequency \\
\hline $\begin{array}{ll}\text { Instructors Meeting } & \text { How are your instructors meeting your needs } \\
\text { Needs } & \text { inside and outside the classroom? }\end{array}$ & 852 \\
$\begin{array}{l}\text { Instructors Not Meeting } \\
\text { Needs }\end{array}$ & $\begin{array}{l}\text { How are your instructors not meeting your needs inside } \\
\text { and outside the classroom? }\end{array}$ & 739 \\
$\begin{array}{l}\text { Open Comments About } \\
\text { Instructors }\end{array}$ & $\begin{array}{l}\text { Is there anything else you want to share about what you } \\
\text { expect of your instructors? }\end{array}$ & 548 \\
\hline
\end{tabular}


Figure 1 shows a word cloud for responses to the first open-ended question (see Appendix S for a larger version of the word cloud). In addition to the stop list of words that TagCrowd automatically excluded, the researcher chose to exclude words that did not appear to offer any real context (see Appendix R for the list of excluded words for Figures 1-6). Figure 1 contains 151 words. The minimum frequency for words to appear in the cloud was six. A total of 860 words was available, but only 151 showed up a minimum of six times.

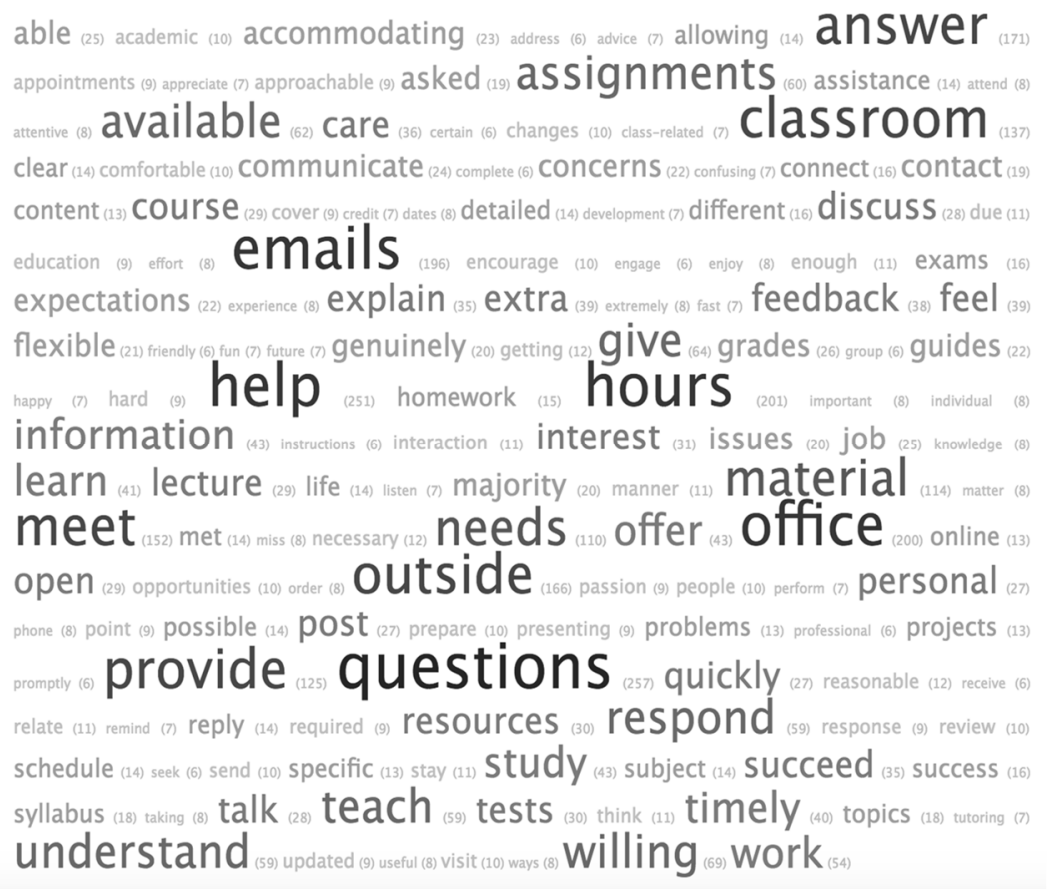

Figure 1. Word Cloud for Instructors Meeting Needs

Table 32 lists the words used most frequently in Figure 1. Students were asked about ways their instructors were meeting their needs inside and outside the classroom. Here are a few statements with the highly used words identified in bold:

- 3 out of 4 of my instructors reply within hours to my emails. Outside of the classroom, they always send emails with assignments and then say have a good weekend and that, to me, is personal and very awesome. 
- All around, everything you can think of. They email me back as soon as possible, they post grades as soon as they can, etc.

- All if my instructors stay for a bit after class where we can go up to them and ask questions or express concerns. They all have flexible office hours allowing for appointments if we cannot make their typical availability.

- I have a professor that never replies to emails. As a stressed out college student, it's important for me to get answers about problems before coming to the next class period.

- All of my instructors answer any questions I have within a reasonable time and are almost always willing to help.

Table 32

Student Frequencies for Words from Instructors Meeting Needs

\begin{tabular}{lclc}
\hline Word & Frequency & Word & Frequency \\
\hline Answer & 171 & Meet & 152 \\
Classroom & 137 & Needs & 110 \\
Emails & 196 & Office & 200 \\
Help & 251 & Outside & 166 \\
Hours & 201 & Provide & 125 \\
Material & 114 & Questions & 257 \\
\hline
\end{tabular}

Figure 2 shows a word cloud for responses to the second open-ended question (see Appendix $\mathrm{T}$ for a larger version of the word cloud). It contains 172 words. The minimum frequency for words to appear in the cloud was six. A total of 1,073 words was available but only 172 showed up a minimum of six times. 


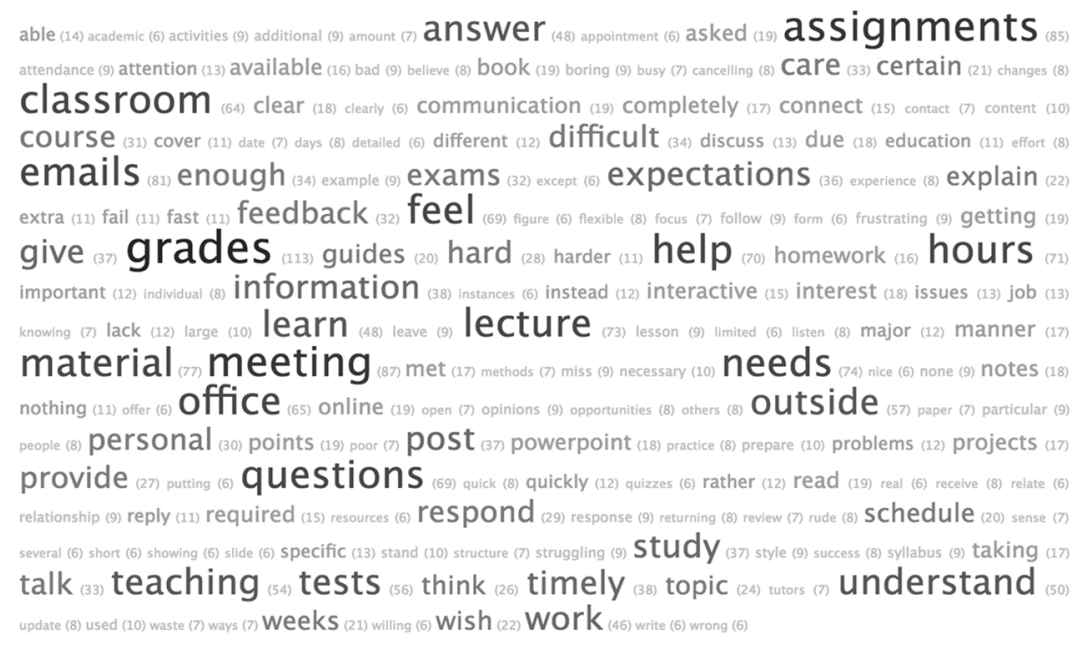

Figure 2. Word Cloud for Instructors Not Meeting Needs

Table 33 lists the words used most frequently in Figure 2. Students were asked about ways their instructors were not meeting their needs inside and outside the classroom. Here are a few statements with the highly used words identified in bold:

- Returning grades quick enough, or emailing back in a prompt manner.

- Some professors do not post grades. I am the type of person who likes to know how I am doing in the class throughout the semester.

- When reviews and study guides are provided, I feel it is not what we learned in lecture.

- Sometimes they take forever to reply back to emails.

- I would like more instructions for out of class assignments. 
Table 33

Student Frequencies for Words from Instructors Not Meeting Needs

\begin{tabular}{lclc}
\hline Word & Frequency & Word & Frequency \\
\hline Assignments & 85 & Material & 77 \\
Classroom & 64 & Meeting & 87 \\
Emails & 81 & Needs & 74 \\
Feel & 69 & Office & 65 \\
Grades & 113 & Outside & 57 \\
Help & 70 & Questions & 69 \\
Hours & 71 & Tests & 56 \\
Lecture & 73 & & \\
\hline
\end{tabular}

Figure 3 shows a word cloud for responses to the third open-ended question (see Appendix U for a larger version of the word cloud). It contains 108 words. The minimum frequency for words to appear in the cloud was six. A total of 866 words was available, but only 108 showed up a minimum of six times.

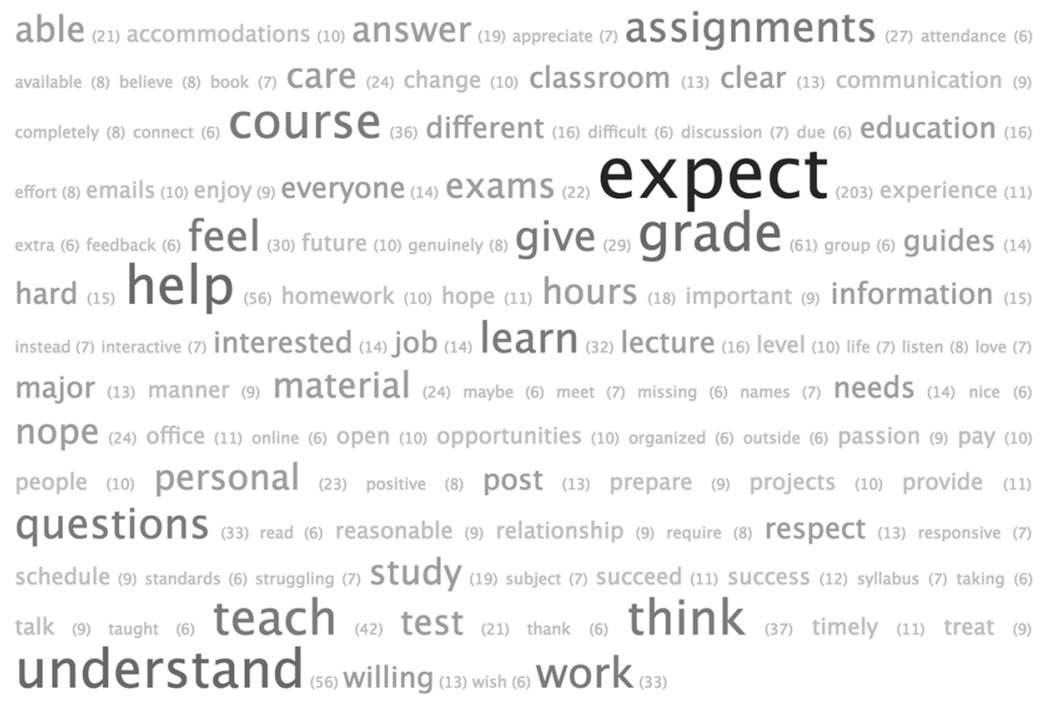

Figure 3. Word Cloud for Open Comments About Instructors 
Table 34 lists the words used most frequently in Figure 3. Students were asked if there was anything else they wanted to share about what they expected of their instructors. Here are a few statements with the highly used words identified in bold:

- I expect good communication and clear expectations.

- I expect them to be friendly, easy to talk to, organized, and caring towards me as a person.

- I expect my instructors to follow a strict syllabus, reply promptly to emails, and grade exams and assignments in a timely manner.

- Some of my instructors do not post grades. This is something I expect all instructors to do to help me succeed.

Table 34

Student Frequencies for Words from Open Comments About Instructors

\begin{tabular}{lclc}
\hline Word & Frequency & Word & Frequency \\
\hline Course & 36 & Questions & 33 \\
Expect & 203 & Teach & 42 \\
Feel & 30 & Think & 37 \\
Grade & 61 & Understand & 56 \\
Help & 56 & Work & 33 \\
Learn & 32 & & \\
\hline
\end{tabular}

\section{Faculty Responses}

Faculty respondents were asked three questions about their interactions with students. Table 35 lists the questions and number of responses. The frequency does not include missing responses or when respondents answered with some form of not applicable. 
Table 35

Faculty Open-Ended Questions

\begin{tabular}{llc}
\hline Label & \multicolumn{1}{c}{ Survey Question } & Frequency \\
\hline Needs of Generation & $\begin{array}{l}\text { How could faculty better meet the needs of this } \\
\text { generation of students? }\end{array}$ & 82 \\
Develop Relationships & How do you develop relationships with students? & 85 \\
Open Comments About & Is there anything else you want to share about & 67 \\
Students & teaching this generation of students? & \\
\hline
\end{tabular}

Figure 4 shows a word cloud for responses to the first open-ended question (see Appendix $\mathrm{V}$ for a larger version of the word cloud). It contains 75 words. The minimum frequency for words to appear in the cloud was three. A total of 482 words was available, but only 75 showed up a minimum of three times.

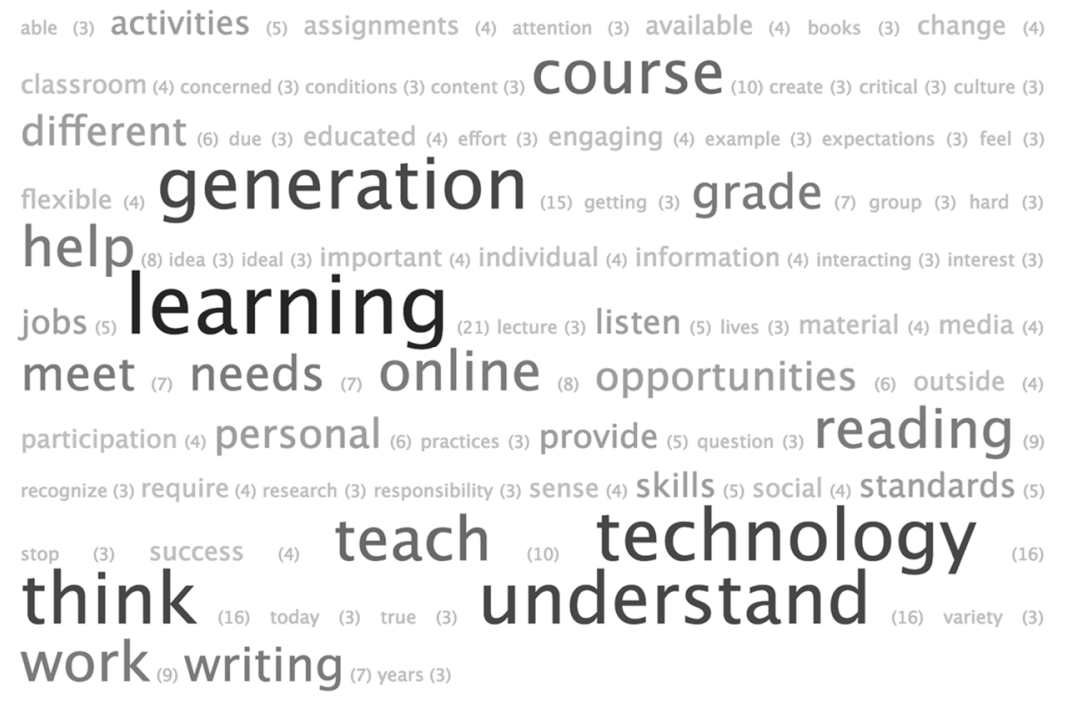

Figure 4. Word Cloud for Needs of Generation

Table 36 lists the words used most frequently in Figure 4. Faculty were asked about ways they could better meet the needs of this generation of students. Here are a few statements with the highly used words identified in bold: 
- For us older professors, I think our greatest challenge is keeping up with all of the technology and resultant opportunities available to the students and to us.

- More technology uses in class that allow for learning of the material in a variety of ways

- The university should provide social science research relevant to this generation and opportunities for faculty discussion.

- We need to understand the things they are dealing with in their personal lives that pull them away from schoolwork.

Table 36

Faculty Frequencies for Words from Needs of Generation

\begin{tabular}{lclc}
\hline Word & Frequency & Word & Frequency \\
\hline Course & 10 & Teach & 10 \\
Generation & 15 & Technology & 16 \\
Help & 8 & Think & 16 \\
Learning & 21 & Understand & 16 \\
Online & 8 & Work & 9 \\
Reading & 9 & & \\
\hline
\end{tabular}

Figure 5 shows a word cloud for responses to the second open-ended question (see Appendix $\mathrm{W}$ for a larger version of the word cloud). It contains 76 words. The minimum frequency for words to appear in the cloud was three. A total of 429 words was available, but only 76 showed up a minimum of three times. 


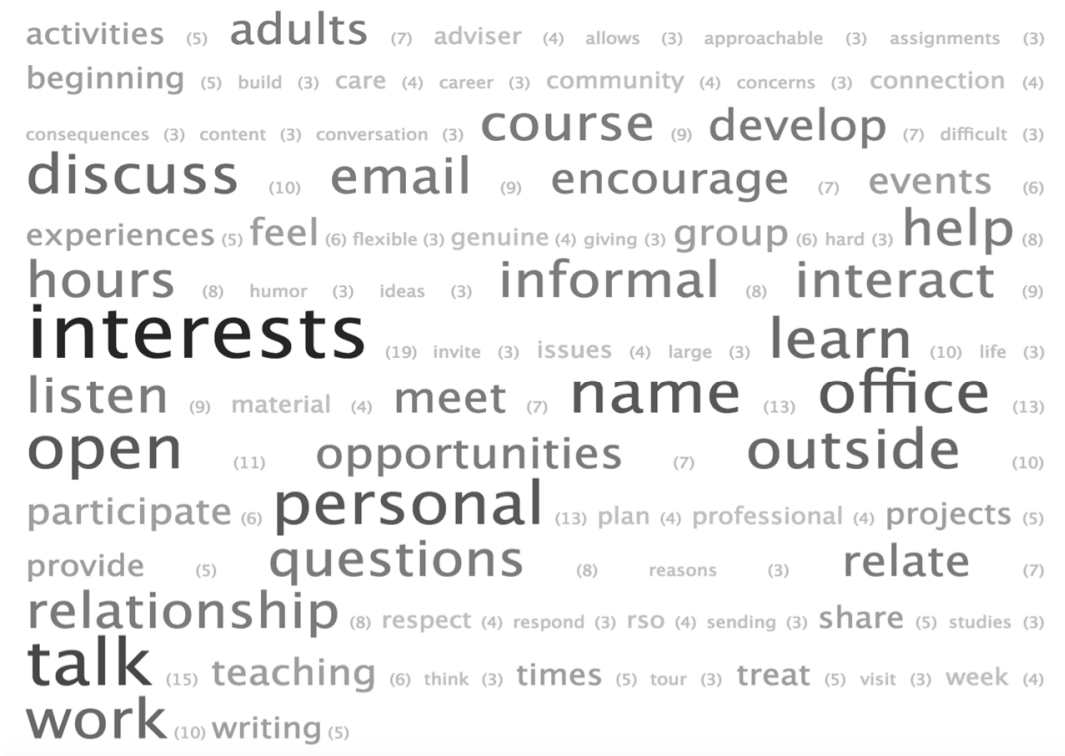

Figure 5. Word Cloud for Develop Relationships

Table 37 lists the words used most frequently in Figure 5. Faculty were asked about ways they developed relationships with students. Here are a few statements with the highly used words identified in bold:

- Learn about their background and interests starting day 1.

- I like to interact with them as much as I can about their interests outside of the course content. When they come to my office, we often get into discussions about their future plans, current events, and personal interests.

- If they have life challenges or other problems that are preventing them from doing their best in my class, they need to talk to me about it.

- Try to talk to them about life outside of class. 
Table 37

Faculty Frequencies for Words from Develop Relationships

\begin{tabular}{lclc}
\hline Word & Frequency & Word & Frequency \\
\hline Discuss & 10 & Open & 11 \\
Interests & 19 & Outside & 10 \\
Learn & 10 & Personal & 13 \\
Name & 13 & Talk & 15 \\
Office & 13 & Work & 10 \\
\hline
\end{tabular}

Figure 6 shows a word cloud for responses to the third open-ended question (see Appendix X for a larger version of the word cloud). It contains 75 words. The minimum frequency for words to appear in the cloud was three. A total of 560 words was available but only 75 showed up a minimum of three times.

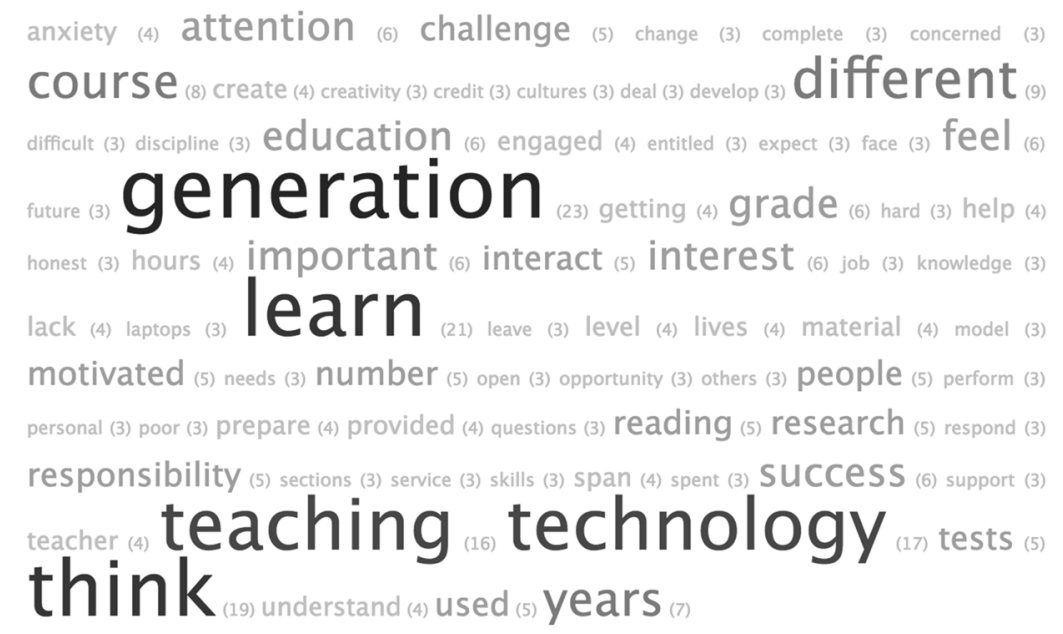

Figure 6. Word Cloud for Open Comments About Students

Table 38 lists the words used most frequently in Figure 6. Faculty were asked if there was anything else they wanted to share about teaching this generation of students. Here are a few statements with the highly used words identified in bold: 
- They are far more technologically adept than I am.

- Technology, technology, technology! :) Get used to it and use it in your instruction.

- Really not that different than other generations. Too much is made of the small differences.

- Create generational bridges instead of arbitrary rhetorical divides.

- We as educators must be vigilant and unyielding in maintaining high expectations and creating learning environments that are conducive for students' own selfdiscovery.

Table 38

Faculty Frequencies for Words from Open Comments About Students

\begin{tabular}{|c|c|c|c|}
\hline Word & Frequency & Word & Frequency \\
\hline Course & & Teaching & \\
\hline Different & & Technology & \\
\hline Generation & & Think & \\
\hline Learn & & Years & \\
\hline
\end{tabular}

\section{Other Data-Institutional and Goal Commitment}

The final section of Likert-type items on the student survey was not used for comparison against the faculty group. This section was adapted from Pascarella and Terenizini's (1980) Institutional Integration Scale. Table 39 lists each of these 11 items and provides a label for quick analysis in subsequent tables. 
Table 39

Student Institutional and Goal Commitment

\begin{tabular}{|c|c|c|}
\hline Label & Item & Survey Items \\
\hline College Graduation & 45 & It is important for me to graduate from college. \\
\hline $\begin{array}{l}\text { On-Time } \\
\text { Graduation }\end{array}$ & 46 & I plan to graduate within the time allotted for my degree program. \\
\hline College Decision & 47 & I am confident I made the right decision in choosing this university. \\
\hline Class Registration & 48 & It is likely I will register for classes next semester. \\
\hline $\begin{array}{l}\text { Institutional } \\
\text { Commitment }\end{array}$ & 49 & It is important to me to graduate from this university. \\
\hline $\begin{array}{l}\text { Academic } \\
\text { Performance }\end{array}$ & 50 & I am performing academically as well as I anticipated I would. \\
\hline $\begin{array}{l}\text { Academic } \\
\text { Experience } \\
\text { Satisfaction }\end{array}$ & 51 & I am satisfied with my academic experience at this university. \\
\hline $\begin{array}{l}\text { Instructor } \\
\text { Connection }\end{array}$ & 52 & I feel connected to my instructors. \\
\hline Instructor Interest & 53 & $\begin{array}{l}\text { Most instructors I have had contact with are genuinely interested in } \\
\text { students. }\end{array}$ \\
\hline $\begin{array}{l}\text { Instructor } \\
\text { Relationships }\end{array}$ & 54 & $\begin{array}{l}\text { My relationships with instructors are an important part of my college } \\
\text { experience. }\end{array}$ \\
\hline Instructor Mentor & 55 & $\begin{array}{l}\text { Since coming to this university, I have started to develop a close } \\
\text { relationship with at least one instructor who I can see as a possible mentor. }\end{array}$ \\
\hline
\end{tabular}

Student participants rated their attitudes of institutional and goal commitment with 5point Likert-type items $(1=$ strongly disagree, $2=$ disagree, $3=$ neutral, $4=$ agree, $5=$ strongly agree). Descriptive statistics were calculated to determine their attitudes. Table 40 lists the frequency and mode for each of the items on this section of the survey. The frequencies are shown as a percentage of the participants who selected each of the Likert-type items. This percentage is the valid percent, which is a percentage that does not include missing responses. Between 112 and 119 students skipped items 45 through 55 from the total 1,261 responses. For item 48 about registering for classes next semester, students could also pick N/A - Graduating; $3.1 \%$ of participants chose that option. 
As these Likert-type items were designed to measure institutional and goal commitment, it was expected that participants would agree or strongly agree with most of the statements. A few items received different results. When participants were asked if most instructors they have had contact with were genuinely interested in students, $38.1 \%$ were neutral and $17.5 \%$ disagreed. However, most agreed (45.4\%) or strongly agreed $(24.6 \%)$ that relationships with instructors were an important part of their college experience. Since the majority of participants were freshmen (41.2\%), a lower percentage of students who agreed they had started to develop a close relationship with at least one instructor they could see as a possible mentor ( $45 \%$ when combining agree and strongly agree) was not unexpected.

Table 40

Student Frequencies and Modes for Institutional and Goal Commitment

\begin{tabular}{lccrrrrr}
\hline Survey Item Label & Item & $\mathrm{SD}(\%)$ & $\mathrm{D}(\%)$ & $\mathrm{N}(\%)$ & $\mathrm{A}(\%)$ & $\mathrm{SA}(\%)$ & Mode \\
\hline College Graduation & 45 & 0.0 & .3 & 2.8 & 7.0 & 89.9 & 5 \\
On-Time Graduation & 46 & .1 & 2.5 & 5.4 & 17.9 & 74.0 & 5 \\
College Decision & 47 & 1.0 & 3.8 & 12.4 & 29.9 & 53.0 & 5 \\
Class Registration & 48 & 1.4 & .7 & 1.7 & 7.8 & 85.4 & 5 \\
Institutional & 49 & .5 & 1.7 & 6.6 & 16.5 & 74.7 & 5 \\
Commitment & & & & & & & \\
Academic Performance & 50 & 1.3 & 13.1 & 15.5 & 43.3 & 26.8 & 4 \\
Academic Experience & 51 & 1.2 & 7.4 & 17.8 & 46.3 & 27.2 & 4 \\
Satisfaction & & & & & & & \\
Instructor Connection & 52 & 3.7 & 17.5 & 38.1 & 31.0 & 9.7 & 3 \\
Instructor Interest & 53 & 1.1 & 7.2 & 19.7 & 50.4 & 21.6 & 4 \\
Instructor Relationships & 54 & 1.0 & 5.7 & 23.4 & 45.4 & 24.6 & 4 \\
Instructor Mentor & 55 & 7.0 & 24.8 & 23.2 & 26.8 & 18.2 & 4 \\
\hline
\end{tabular}

Note. 1=Strongly Disagree (SD), 2=Disagree (D), 3=Neutral (N), 4=Agree (A), 5=Strongly Agree (SA)

\section{Summary}

Findings from this study revealed that students' expectations of instructional activities both inside and outside the classroom are significantly different from faculty approaches to 
instructional activities both inside and outside the classroom, and provide more insight into the student-faculty relationship. Variables examined on the student survey and faculty survey were class structure, feedback and assessment, technology use, faculty/student interaction, personal regard, class planning, use of resources, pedagogy, Millennial characteristics, and institutional and goal commitment.

Inside the classroom, faculty and students differed in their responses to whether students could still follow along in class while texting or surfing the internet, if students should get a $\mathrm{C}$ just for attending class, if students should be able to pass a class without the required textbooks or course materials, whether faculty should only cover the material for exams, whether exams should count for the majority of the class grade, and student input into classroom decisions. Outside the classroom, faculty and students differed in their responses to whether students used instructor feedback from assignments to prepare future assignments, whether students contacted instructors outside of class about class-related issues, whether it was important for faculty to get to know students and show an interest in them, and whether students contacted instructors outside of class about nonclass-related issues. The implications of these findings and how they may affect persistence, as well as recommendations for practice and future research, will be discussed in the following chapter. 


\section{CHAPTER V \\ SUMMARY, DISCUSSION, IMPLICATIONS, AND RECOMMENDATIONS}

\section{Introduction}

This chapter provides a summary of the study, which includes a recap of the purpose of the study, the participants, the research design and methodology, and the findings. The findings of the study will be reviewed relative to the literature on persistence, generational characteristics, and pedagogy. Implications of the research and strategies for successful persistence practices and target areas for faculty and staff development will also be considered. The chapter will close with recommendations for future research.

\section{Purpose of the Study}

The demands of parents, policy makers, government leaders, and even students themselves for better results of student persistence is a call to action to higher education institutions. The quality and impact of instructional activities and interactions between faculty and students is significant for students' integration into an institution (Pascarella \& Terenzini, 1980). However, more research into students' expectations of faculty and how faculty actually perform needed to be done. The purpose of this study was to compare student expectations of instructional activities inside and outside the classroom to faculty approaches to instructional activities inside and outside the classroom to identify areas of congruence and incongruence between students and faculty to be able to reinforce successful persistence practices and highlight target areas for faculty and staff development. A quantitative study was conducted to examine the differences between students' expectations and faculty approaches. 


\section{Participants}

The participants for this study were traditional-age undergraduate students born between 1992 and 1998 who were enrolled at a 4-year comprehensive Midwestern public university in the fall of 2016, and undergraduate faculty who taught at a 4-year comprehensive

Midwestern public university. All respondents were invited to participate in the study via email and were sent two reminder emails. Usable data were collected from 1,261 students, for a response rate of $11.4 \%$, and 131 faculty, for a response rate of $12.5 \%$. The majority of students were female (73.3\%), White/Caucasian (79.1\%), freshmen (41.2\%), and non-first-generation $(68.3 \%)$. The majority of faculty were female (57.3\%), White/Caucasian $(90.1 \%), 35$ to 55 years old, or Generation X (56.5\%), full professors $(31.3 \%)$, and tenured $(57.3 \%)$.

\section{Research Design and Methodology}

A cross-sectional online survey design was administered to students and faculty. The survey instruments used in this study were constructed by the researcher and adapted from Pascarella and Terenzini's 1980 Institutional Integration Scale (see Appendix A) and Russo’s 2013 survey for examining Millennial characteristics for classroom strategy changes (see Appendix B). The student instrument for the present study was divided into five sections (see Appendix C). The first section consisted of questions to determine specific characteristics about the respondents. The next three sections were constructed of Likert-type items for instructional activities inside the classroom, instructional activities outside the classroom, and institutional and goal commitment. The fifth section was a qualitative section with three open-ended questions. Likert-type items were developed drawing on the research of Millennial characteristics, retention and persistence, and pedagogy. The faculty instrument for the present study was divided into four sections (see Appendix D). The first section consisted of questions 
to determine specific characteristics about the respondents. The next two sections were constructed of Likert-type items for instructional activities inside the classroom and instructional activities outside the classroom. The fourth section was a qualitative section with three open-ended questions. For comparison, items under the instructional activities' sections were the same as the students' items but worded differently for faculty.

Since the two instruments were untested, a pilot study was conducted to assess reliability of the instruments and feasibility of the study process. Tests of reliability from the pilot study showed that all scales of the Likert-type items on the instruments surpassed the minimum threshold of . 70 for Cronbach's alpha. Tests of reliability from the present study showed that all the scales for the student instrument surpassed the minimum threshold of .70 for Cronbach's alpha, but the scales for the faculty instrument had slightly lower levels of reliability. The present study surveys were administered through SelectSurvey, and data were analyzed using SPSS version 24 and the TagCrowd word cloud generator. Statistical significance for all t-tests was set at $p \leq .05$. The following is a discussion of the findings relative to each of the six research questions.

\section{Research Question One}

Research question one was: What are students' expectations of instructional activities inside the classroom? This question was designed to determine the expectations that students have of the instructional activities faculty conduct inside the classroom. These instructional activities are teaching and teaching-related activities and interactions such as answering students' questions in class, taking attendance, giving lectures, using technology for classroom materials, providing instructions on assignments, and communicating classroom rules. Figure 7 provides a visual representation in a column chart of the percentages of notable student 
responses for instructional activities inside the classroom.

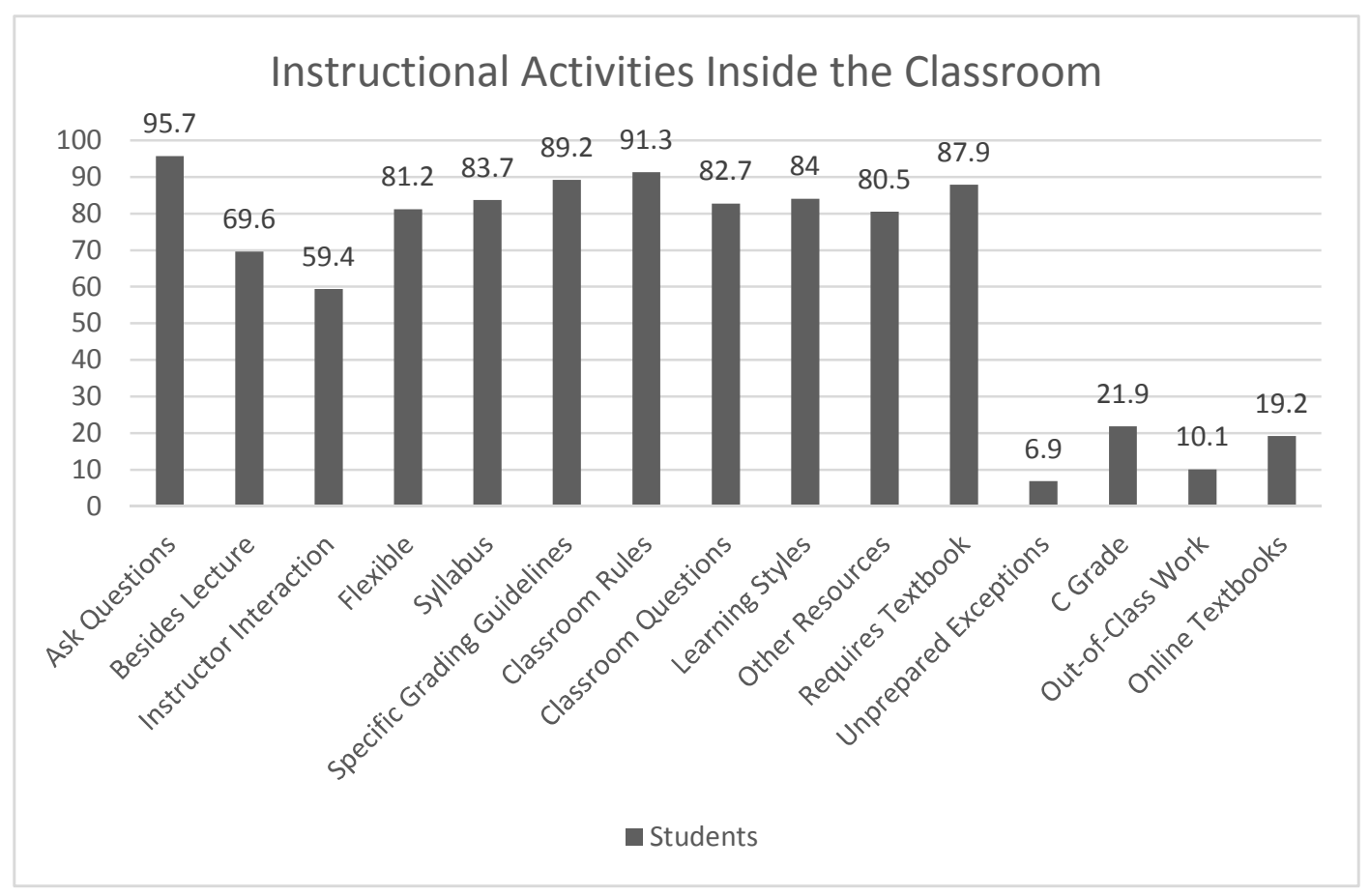

Figure 7. Percentages of Combined Agree and Strongly Agree Student Responses for Instructional Activities Inside the Classroom

Results from this study, when combining agree and strongly agree responses, indicated that $95.7 \%$ of students expected to be able to ask questions during class and get answers from their instructors. According to Bean and Eaton (2000), asking questions in class is an academic approach behavior, which has a positive relationship with academic integration. When asked if instructors should do different things in class rather than stand at the front of the classroom and only explain class content, $69.6 \%$ agreed and $23.3 \%$ were neutral. These responses support the research that Millennials want a more interactive experience in the classroom (Moore, 2007).

When students were asked if they wanted more interaction with instructors in class, 59.4\% agreed and 33.8\% were neutral. Through their formal teaching and informal nonteaching roles, faculty have the potential to influence students' persistence and increase their motivation 
and commitment (Monaco \& Martin, 2007; Pascarella \& Terenzini, 1980). In one of the openended questions, students were asked if there was anything else they wanted to share about what they expected of their instructors. Comments from this question may provide some insight into their satisfaction with that instructor interaction and be of interest when examining the student-faculty relationship:

- I feel that today's standards in the classroom inhibit many student's questions. I think instructors should have more office hours. Instructor's office hours are on average between 3.5 to 4 hours per week. I feel for these large classes, usually 300 classes and below, there is rarely much classroom discussion. Instead of having a prolonged class period to account for discussion, cut it shorter, use it wiser, and have more office time for one on one help/appointments as well as more time to grade and prepare material.

- Class sizes are very big for me right now. I wish they were smaller so there was more interaction between the class and professor.

- Large lectures hall don't let you get a chance to bond with your professor. You may have a good professor but because they don't know as well as small classes you may not want to ask that professor for a letter of recommendation, etc. Especially if they are a good professor.

- College is a very important phase for anyone, I feel professors and/or TA's should connect with students, so the students will have an opportunity to find a mentor.

Results of the present study also showed that over $80 \%$ of students expected instructors to be flexible for their classroom success $(81.2 \%)$, provide a syllabus that listed the due dates for every assignment $(83.7 \%)$, provide specific grading guidelines for each assignment 
(89.2\%), and clearly communicate classroom rules (91.3\%). These results are aligned with research on Millennials that indicates they expect rules to be communicated and enforced, trust and count on authority (DeBard, 2004; Russo, 2013), and expect faculty to stick to a syllabus, be prepared, and follow through (Nilson, 2010). According to Howe and Strauss (2007), these students want their faculty to outline "a clear goal, define an objective measure of success, [and] explain possible strategies" (p. 158).

Over $80 \%$ of students also agreed that instructors should leave enough time in class to go over the material and answer their questions $(82.7 \%)$, and use more than one way to teach the material (84\%). Instructors using more than one way to teach material could indicate instructors are utilizing more active learning techniques to create significant learning experiences (Fink, 2013). Students expected their instructors to tell them about tutoring and other resources on campus to help them be successful (80.5\%). Similar to asking questions, a student who seeks out academic help such as tutoring is also exhibiting academic approach behavior (Bean \& Eaton, 2000).

Students expected to use the textbook for assignments and tests if the textbook was required for the class $(87.9 \%)$. The response to textbook use could be attributed to concerns about the high costs of textbooks. Approximately " $90 \%$ of college courses rely on one or more textbooks as a complementary form of instruction" (Landrum, Gurung, \& Spann, 2012, p. 17), and textbooks and materials cost an average of $\$ 1,200$ per year (Senack, 2014). A 2013 study from the U.S. PIRG Education Fund and The Student Public Interest Research Groups (Senack, 2014) of 2,039 students from more than 150 different institutions reported that the high cost of textbooks was a deterrent for students; in their study, $65 \%$ had decided against purchasing an assigned textbook because of its cost. Those results don't agree with the present study where 
$80.9 \%$ indicated they had purchased all of the required materials, such as textbooks, online codes, and workbooks for their classes.

Over $70 \%$ of students did not expect their instructors to make exceptions if they were unprepared for class $(71.2 \%)$. This seems to contradict some of the stereotypes that faculty and other university staff may have about this generation. Hall, Swart, and Duncan (2012) report that Millennial students often have certain expectations about their performance in coursework. When they are not doing well in a class, they may expect professors to modify academic standards to help them maintain high grades. This expectation is a negotiation of academic standards and may involve grade inflation, tolerance of low-quality work and late work, academic integrity issues, and tolerance of tardiness (Hall et al., 2012). Other themes from research on Millennial students indicate they see themselves as the exception to the rule and expect rules to be changed for them (Much et al., 2014); however, results from the present study imply that students do not necessarily expect instructors to make those exceptions.

Other results from the present study show that $53.2 \%$ of students did not expect to get at least a $\mathrm{C}$ grade just for attending class, and $65.9 \%$ did not expect that they would do very little out-of-class work. This also seems to contradict some of the negative stereotypes reported by Hall et al. (2012) and Much et al. (2014). Students did not prefer online textbooks to traditional textbooks at $57.6 \% ; 23.2 \%$ were neutral for that item and only $19.2 \%$ agreed or strongly agreed. The results for online textbooks don't necessarily align with Millennial characteristics as Millennials want technology, are fluent in the use of technological tools, have been immersed in the internet and the digital world, and have been exposed to the tools of technology since a very young age (Black, 2010; Moore, 2007; Roehl et al., 2013). These results also don't align with the U.S. PIRG study (Senack, 2014), which reported that students 
had significant interest in digital alternatives to traditional hard copy textbooks, and were especially open to free textbooks online.

\section{Research Question Two}

Research question two was: What are students' expectations of instructional activities outside the classroom? This question was designed to determine the expectations that students have of the instructional activities faculty conduct outside the classroom. These instructional activities are teaching and teaching-related activities and interactions such as answering students' emails, offering individualized attention, grading assignments, giving feedback on assignments, and using an online course management system. Figure 8 provides a visual representation in a column chart of the percentages of notable student responses for instructional activities outside the classroom.

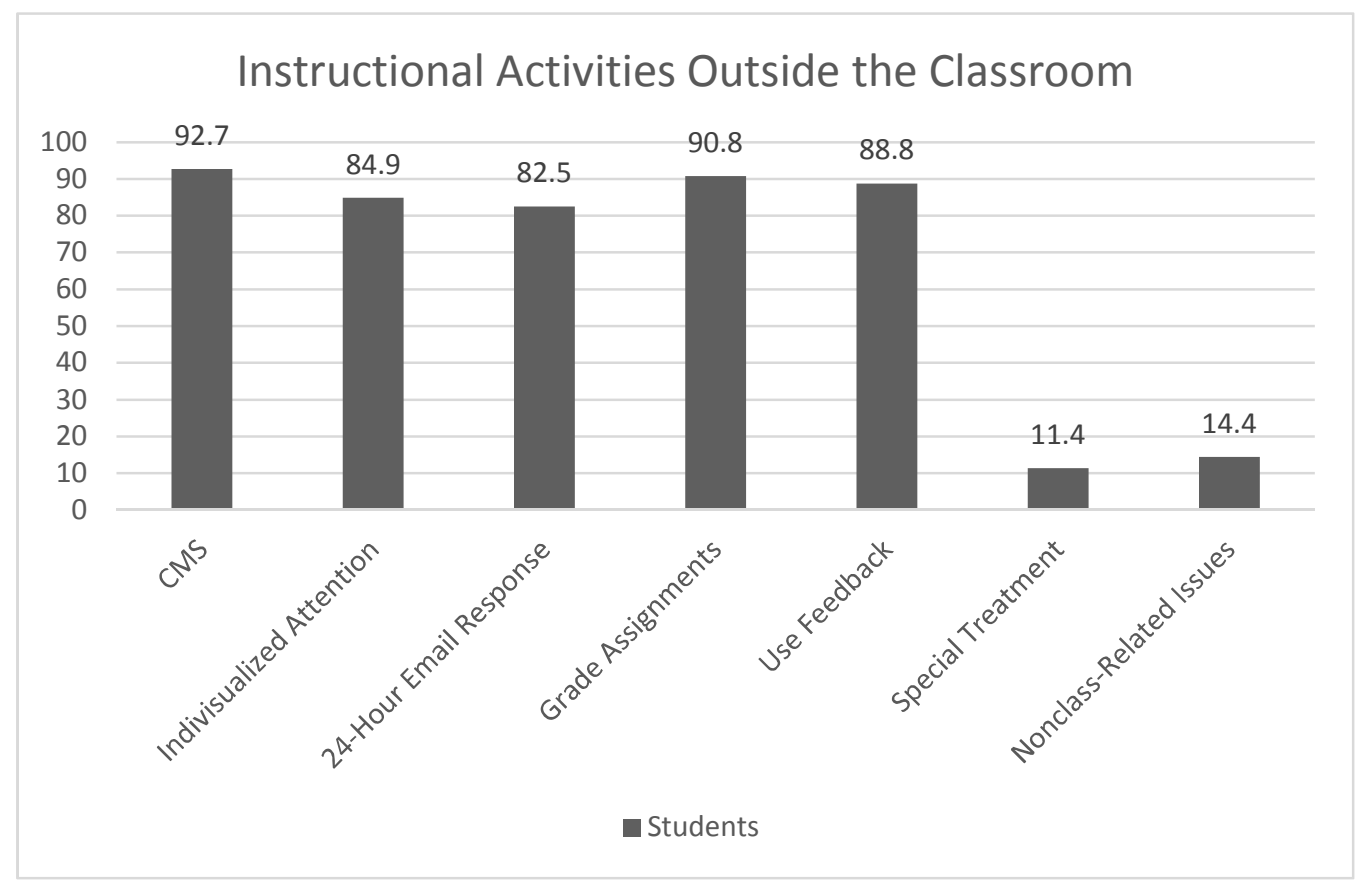

Figure 8. Percentages of Combined Agree and Strongly Agree Student Responses for Instructional Activities Outside the Classroom 
Results from this study, when combining agree and strongly agree responses, indicated that $92.7 \%$ of students expected instructors to use the online course management system to post grades, assignments, and classroom study materials. These results are in agreement with what Carter (2008) notes as Millennials expectations of "streamlined communication environments, networking opportunities with other novices and experts, immediate evaluative feedback, and continually-improving use of multiple tools and resources” (p. 25).

From the results, over $80 \%$ of students expected instructors to be available to provide individualized attention (84.9\%), answer emails within 24 hours or sooner $(82.5 \%)$, and have assignments graded and returned within 2 weeks of the due date or sooner $(90.8 \%)$. This also aligns with research that indicates Millennials need frequent feedback (Howe \& Strauss, 2007; Moore, 2007). According to Monaco and Martin (2007), "they thrive on constant feedback and become paralyzed, often unable to proceed forward, without feedback and direction" (p. 43). Millennials are drawn to the individualized attention they receive from faculty and staff (Montag et al., 2012). Students also agreed that they used their instructor feedback from assignments to prepare future assignments $(88.8 \%)$.

Study results showed that $62.3 \%$ of students did not think it was fine to ask instructors for special treatment; $26.3 \%$ were neutral, and only $11.4 \%$ agreed or strongly agreed. This seems to contradict some of the negative stereotypes reported by Hall et al. (2012) and Much et al. (2014) for students expecting exceptions to classroom rules. Also, $69.3 \%$ of students disagreed that they contacted instructors outside of class about nonclass-related issues. This may offer support for Bean's (1985) findings that informal faculty contacts are not as important for a student's retention as contacts with peers. It is also possible that students who regularly contacted their instructors outside of class about these issues did not participate in the study. 


\section{Research Question Three}

Research question three was: What are faculty approaches to instructional activities inside the classroom? This question was designed to determine the approaches of faculty to instructional activities inside the classroom. In addition to the activities mentioned in research question one, these are teaching and teaching-related activities and interactions such as going over the syllabus, giving specific grading guidelines, using textbooks and other resources, providing study guides, telling students about resources, and awarding points for participation. Figure 9 provides a visual representation in a column chart of the percentages of notable faculty responses for instructional activities inside the classroom.

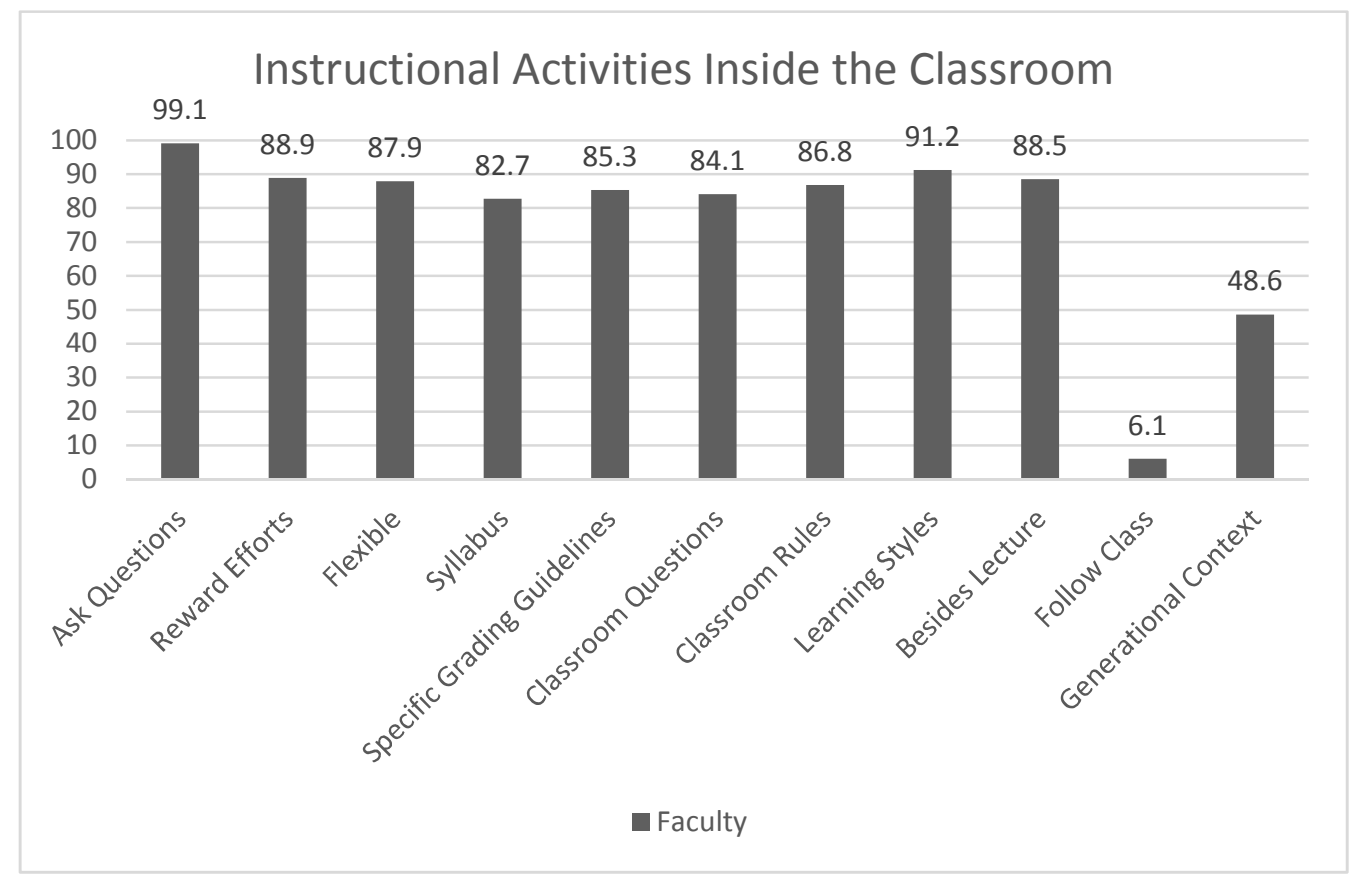

Figure 9. Percentages of Combined Agree and Strongly Agree Faculty Responses for Instructional Activities Inside the Classroom

Results from this study, combining agree and strongly agree responses, indicated that $99.1 \%$ of faculty encouraged students to ask questions during class so they could clarify the 
material. A majority of faculty rewarded students for efforts in class (88.9\%), were flexible for students' classroom success $(87.9 \%)$, provided a syllabus listing due dates for every assignment (82.7\%), provided specific grading guidelines for each assignment $(85.3 \%)$, left enough time in class to go over the material and answer students' questions (84.1\%), clearly communicated classroom rules $(86.8 \%)$, and used more than one way to teach the material $(91.2 \%)$.

These are actions desired by the Millennial generation and follow the basic principles of a learning-centered classroom rather than a teacher-centered classroom (Monaco \& Martin, 2007). High agreement to these items also translates to faculty possessing characteristics that Bain $(2004,2012)$ attributes to the best college teachers. For example, the most effective instructors use the lecture as "a way to clarify and simplify complex material while engaging important and challenging questions" (Bain, 2004, p. 107). Effective teachers also give students the opportunity to learn by doing rather than just memorizing facts (Bain, 2012).

When asked if they did different things in class rather than stand at the front of the classroom and only explain content, $88.5 \%$ of faculty reported that they practiced other teaching methods. Faculty standing alone in front of the classroom while students take notes is the general definition of a lecture (Davis \& Arends, 2013). These responses indicated that a majority of faculty are recognizing the importance of incorporating other teaching methods besides just lecturing into their pedagogical skillset.

According to Fink (2013), faculty are concerned about the attention given to mobile devices. This coincides with faculty responses when asked if students could follow the class while they texted or surfed the internet; $76.5 \%$ did not think students could stay caught up; however, $17.6 \%$ of faculty allowed students to surf the internet or text others while in class. 
When faculty were asked if they were meeting this generation of students where it was at academically and socially, $48.6 \%$ agreed or strongly agreed and $41.4 \%$ were neutral. The large number of neutral responses could be a result of a number of factors. For example, faculty may not care about generational characteristics or subscribe to the research about generational theory in education. A few comments from the open-ended question when faculty were asked if there was anything else they wanted to share about teaching this generation of students might provide some insight:

- Generation related variables probably play the smallest role in determining positive versus negative teaching outcomes. But generation issues make a great excuse for teachers to do a very poor job teaching and for students doing a poor job learning.

- To be honest, I don't really buy most of the generational research (i.e., generation X, millennials, etc.) While there are useful tips generated by the research, I find that being open, consistent, and supportive with students.

- I think that we need to get away from this notion that this generation of students is different from others. At the core, people are no different than they've been in the past; they simply have more sophisticated toys to obsess with. As a faculty, we have an obligation to teach students to be responsible towards themselves and others without having to make excuses for themselves.

- Really not that different than other generations. Too much is made of the small differences.

In the section of the faculty survey related to specific characteristics about respondents, $67.2 \%$ of faculty indicated they would be willing to participate in professional development opportunities about the characteristics of the students in their classes. Although some faculty 
may not subscribe to the idea of generational differences, quite a few were willing to take advantage of opportunities that helped them learn more about populations they were serving.

\section{Research Question Four}

Research question four was: What are faculty approaches to instructional activities outside the classroom? This question was designed to determine the approaches of faculty to instructional activities outside the classroom. In addition to the activities mentioned in research question two, these are teaching and teaching-related activities and interactions such as contacting students outside of class, mentoring students, interacting informally with students outside of class, communicating through social media, and talking to students outside of class about other topics besides class-related material. Figure 10 provides a visual representation in a column chart of the percentages of notable faculty responses for instructional activities outside the classroom.

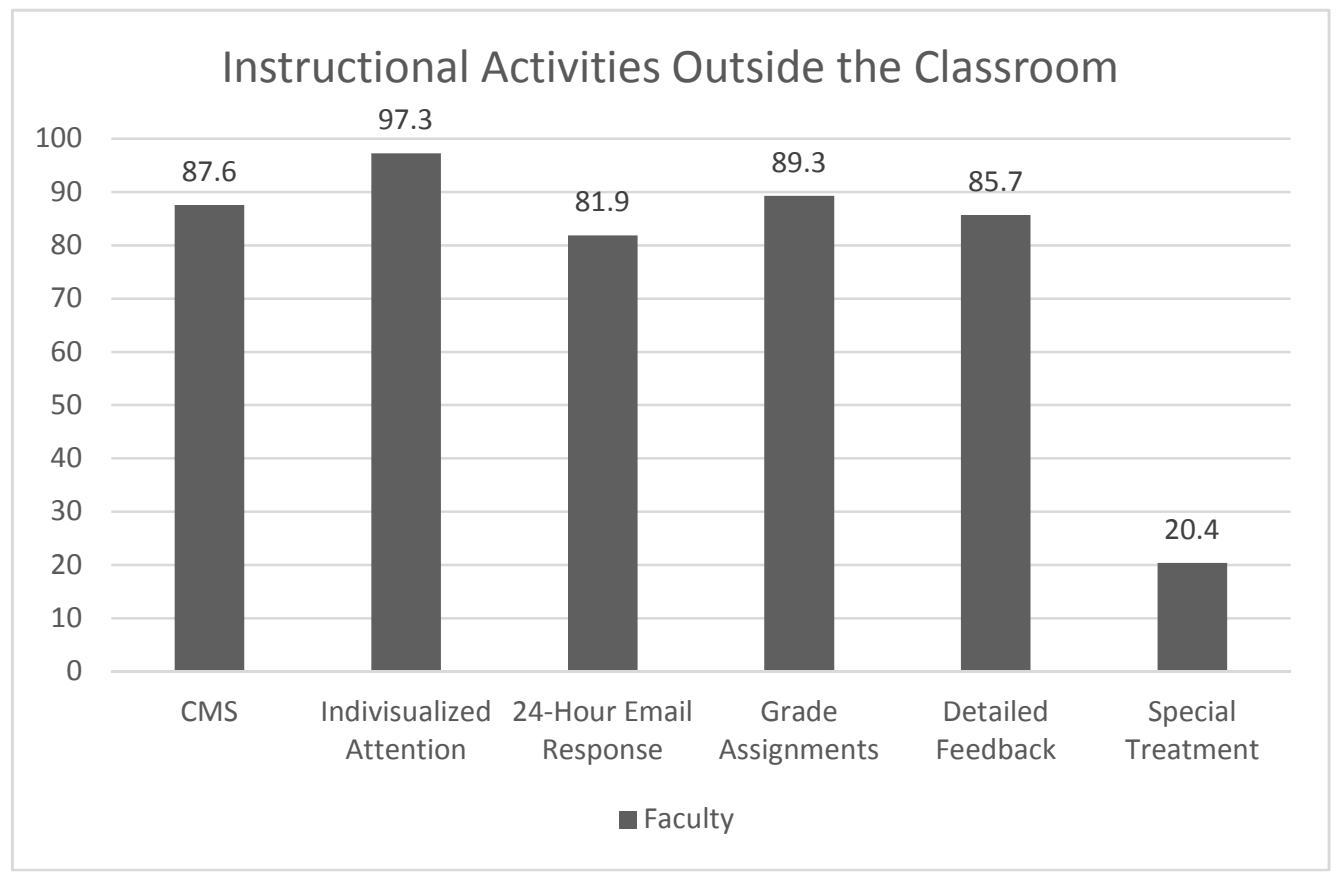

Figure 10. Percentages of Combined Agree and Strongly Agree Faculty Responses for Instructional Activities Outside the Classroom 
Results from this study, when combining agree and strongly agree responses, indicated that $97.3 \%$ of faculty agreed they were available to provide individualized attention if students needed it. A majority of faculty had assignments graded and returned within 2 weeks of the due date or sooner $(89.3 \%)$, answered emails within 24 hours or sooner $(81.9 \%)$, gave detailed feedback on students' coursework (85.7\%), and used the online course management system to post grades, assignments, and classroom study materials (87.6\%). These faculty behaviors are preferred by Millennial students (Montag et al., 2012), and reflect the characteristics of the highly effective teachers who provide intellectual and emotional support for students (Bain, 2012). Giving prompt feedback is also one of the seven principles for good practice in undergraduate education cited by Chickering and Gamson (1987).

When asked if it was fine for students to ask them for special treatment, $20.4 \%$ of faculty agreed or strongly agreed, while $38.9 \%$ were neutral and $40.7 \%$ disagreed or strongly disagreed. There has been much debate on the student-as-a-customer focus, with researchers such as Davis (2011) adamant that treating college students as customers rather than learners is detrimental to the fundamental purpose of higher education. Mark (2013) notes that "many educators are reluctant to embrace the student-customer model and are often suspicious of any attempt to apply business concepts to an educational setting” (p. 3). It is possible that special treatment may be perceived as a customer-focused approach, and faculty may not want to appear they are pandering to their students.

\section{Research Question Five}

Research question five was: To what extent do faculty approaches to instructional activities inside the classroom differ from students' expectations of those instructional activities? This question was designed to compare the responses of students and faculty for 
instructional activities inside the classroom. It was intended to identify areas of congruence and incongruence between students and faculty in attitudes toward variables such as class structure, technology use, class planning, and use of resources. Figure 11 provides a visual representation in a column chart of the percentages of notable faculty and student responses for instructional activities inside the classroom.

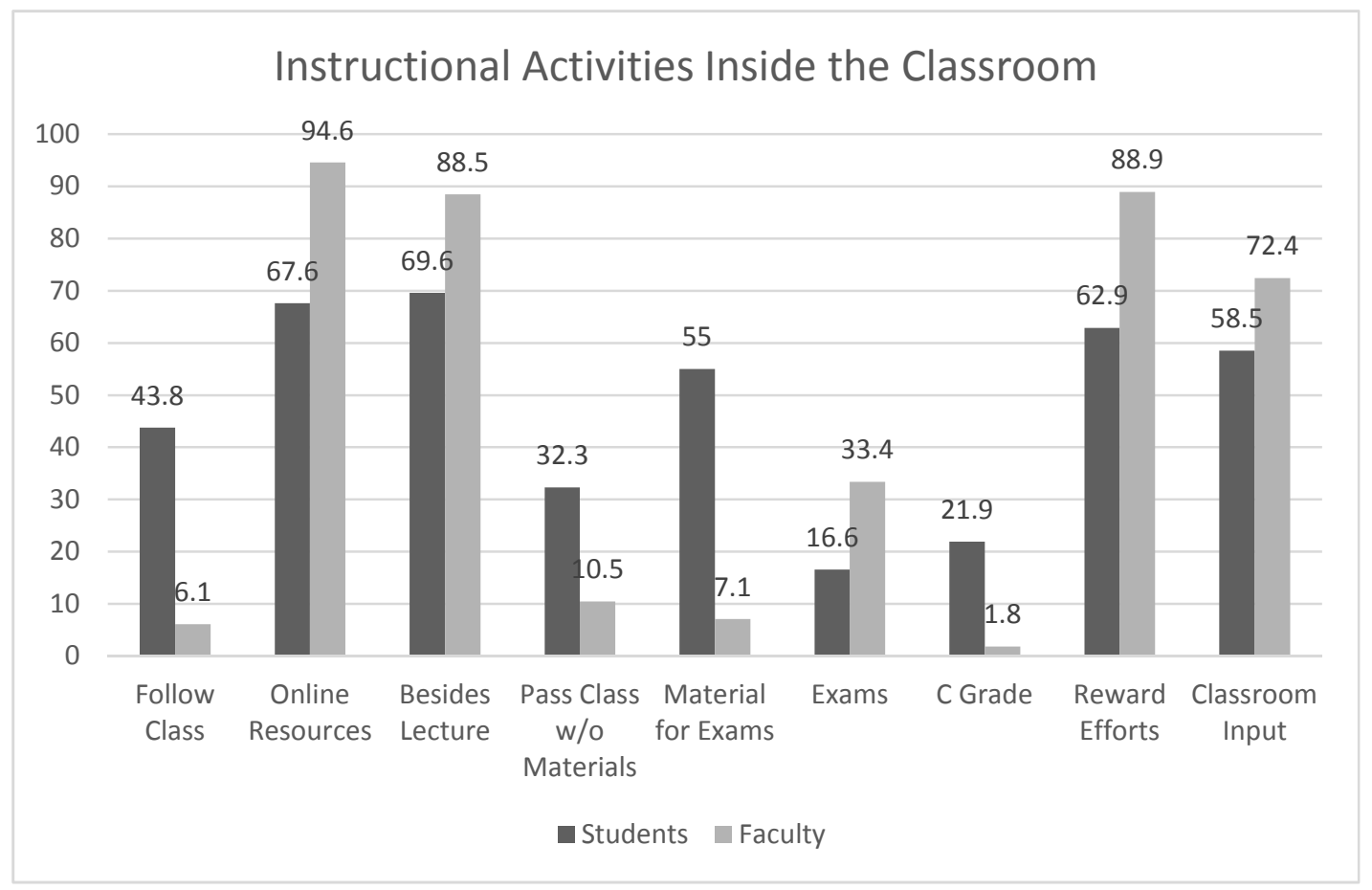

Figure 11. Percentages of Combined Agree and Strongly Agree Faculty and Student Responses for Instructional Activities Inside the Classroom

Findings from this study indicated that there was a statistically significant difference between faculty and students when comparing responses of faculty and students for instructional activities inside the classroom when $p \leq .05$. Faculty and students differed in their responses to whether students could still follow along in class while texting or surfing the internet. When combining agree and strongly agree responses, only $6.1 \%$ of faculty thought this was possible compared to $43.8 \%$ of students. These results were not surprising as students 
"have been technologically stimulated throughout their childhood and demand this connectivity as they matriculate through college" (Monaco \& Martin, 2007, p. 43). They are used to having information at their disposal and access to everyone they know; they depend on their technology (Monaco \& Martin, 2007). The student results are also in agreement with the ECAR Study of Undergraduate Students and Information Technology, 2016 (Brooks, 2016). The ECAR study found that $40-50 \%$ of students said they were not distracted in class by digital activities such as texting, surfing the web, or using social media.

However, when asked if instructors should use online resources in class such as websites and articles, $67.6 \%$ agreed or strongly agreed compared to the $94.6 \%$ of faculty who reported they did utilize online resources. Instructors also reported that they did different things in class rather than stand at the front of the classroom and only explain content at $88.5 \%$ compared to $69.6 \%$ of students who thought their instructor should do these things. Faculty have been given recommendations to add a variety of technology mediums to their teaching style and change the way they traditionally deliver content (Monaco \& Martin, 2007; Worley, 2011). These results indicate that almost one-third of Millennials don't seem interested in these techniques or care one way or the other about them.

For students being able to pass a class without the required textbooks or course materials, $10.5 \%$ of faculty thought this was possible compared to $32.3 \%$ of students. Research from Landrum et al. (2012) found that "if students do not read the textbook, then it is difficult for students to obtain the benefits that instructors aim to provide with textbook selection" ( $\mathrm{p}$. 22). Most instructors have a specific purpose for assigning a textbook. This may indicate why $82.3 \%$ of faculty used a textbook for assignments and tests if they required the textbook for the class. 
The largest difference in responses between the two groups came from the item about covering just the material for exams; $55 \%$ of students preferred to cover just the material for exams compared to $7.1 \%$ of faculty who said they only covered that material. Before coming to college, students were taught to be passive learners and to follow a prescribed curriculum. This curriculum prepared them to pass their tests (Cook-Sather et al., 2014); essentially they were taught to the test, and this is what they know. But even though students are familiar with exams and a high percentage preferred to cover only that material, only $16.6 \%$ preferred to have exams count for the majority of their class grade compared to $33.4 \%$ of faculty who stated that exams counted for the majority of the class grade.

On whether students should get a $\mathrm{C}$ just for attending class, $1.8 \%$ of faculty agreed compared to $21.9 \%$ of students. Although the majority of student respondents did not agree with this statement, the one-fifth who did fall into the group of Millennial students that Hall et al. (2012) refer to as expecting modification or negotiation of academic standards. Another difference was seen in students being rewarded for their efforts in class; $62.9 \%$ of students thought their instructors should reward their efforts, while $88.9 \%$ of instructors said they did reward students for their efforts. Although approximately $60 \%$ of students thought they should be rewarded, which coincides with the special characteristic of the Millennial typology (Howe \& Strauss, 2004; Monaco \& Martin, 2007), the agree and strongly agree responses of the faculty were unexpected, especially since rewarding students could be perceived as a customerfocused approach.

For classroom input, $72.4 \%$ of faculty said they let students have input into classroom decisions compared to $58.5 \%$ of students who thought their instructors should let them have input. Students helping to design and teach courses is one of the active learning techniques 
cited by Chickering and Gamson (1987) as a principle for good practice in undergraduate education. Student input is also recommended for creating significant learning experiences and for engaging students as partners in learning and teaching (Fink, 2013; Cook-Sather et al., 2014). If faculty are aware that including students in classroom decisions provides studentlearning benefits and makes faculty more effective teachers, this may be why faculty had a higher percentage of agreed and strongly agreed responses to this item. But because students are coming to the institution from an educational system that promotes passive learning and a prescribed curriculum, they may be confused or frustrated when presented with a different approach to teaching, and not realize this opportunity is possible or beneficial (Cook-Sather, et al., 2014), thus having a lower level of agreement.

\section{Research Question Six}

Research question six was: To what extent do faculty approaches to instructional activities outside the classroom differ from students' expectations of those instructional activities? This question was designed to compare the responses of students and faculty for instructional activities outside the classroom. It was intended to identify areas of congruence and incongruence between students and faculty in attitudes toward variables such as feedback and assessment, faculty/student interaction outside the classroom, and personal regard. Figure 12 provides a visual representation in a column chart of the percentages of notable faculty and student responses for instructional activities outside the classroom. 


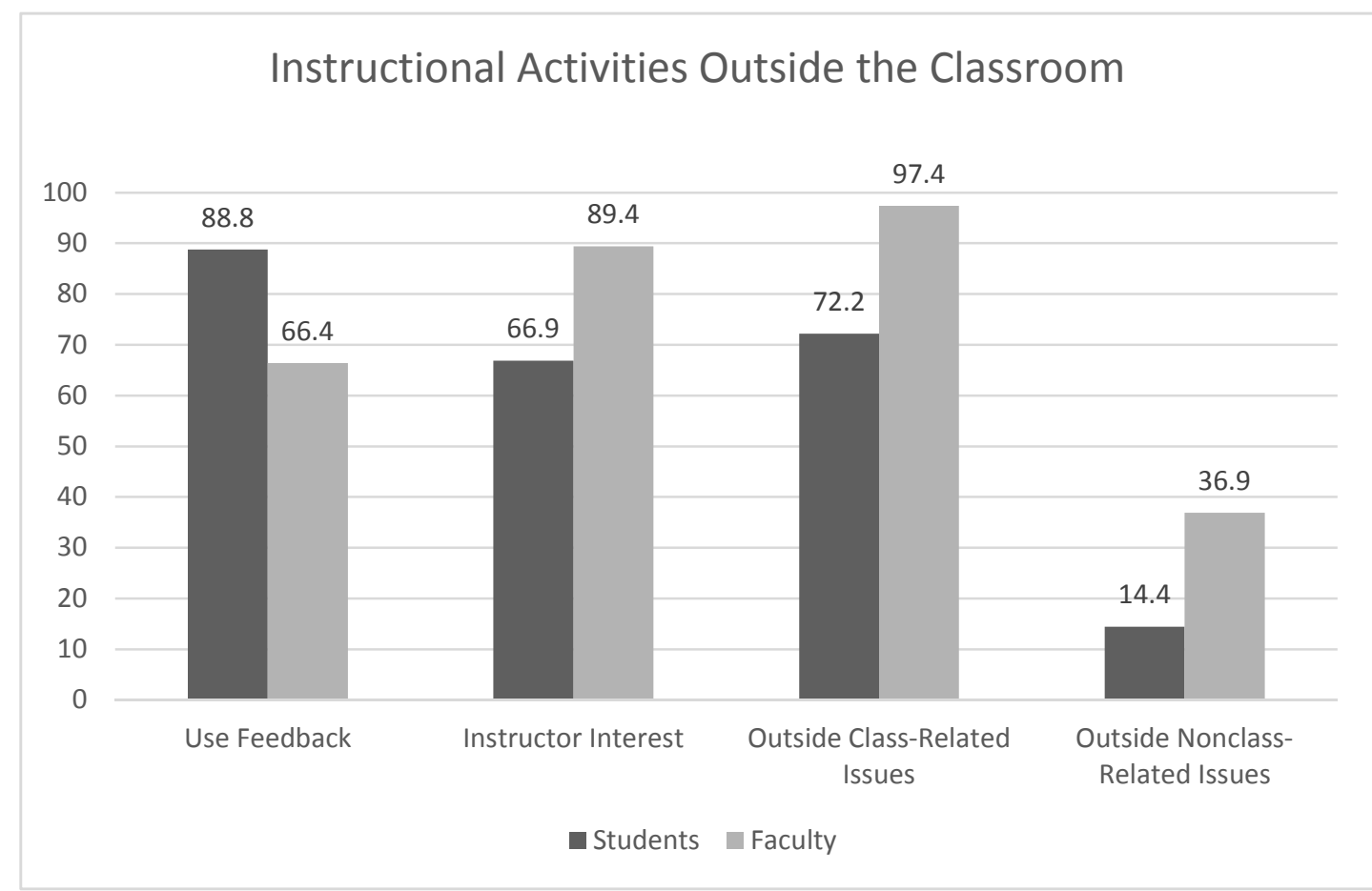

Figure 12. Percentages of Combined Agree and Strongly Agree Faculty and Student Responses for Instructional Activities Outside the Classroom

Findings from this study indicated that there was a statistically significant difference between faculty and students when comparing responses of faculty and students for instructional activities outside the classroom when $p \leq .05$. Faculty and students differed in their responses to whether students used instructor feedback from assignments to prepare future assignments. When combining agree and strongly agree responses, only $66.4 \%$ of faculty thought students were using faculty feedback from assignments to prepare future assignments compared to $88.8 \%$ of students who said they used instructor feedback.

This difference could be attributed to the way faculty and students view feedback and their use of it. Ambrose, Bridges, DiPietro, Lovett, and Normal (2010) point out that faculty, as experts, see things differently than their students and may not recognize when stated goals are unclear or criteria is misinterpreted. Faculty may perceive it as a student not listening or not 
paying attention when it is actually a student not understanding what the faculty is asking. If assignments are completely different, students also don't get the chance to practice using the feedback they were given (Ambrose et al., 2010).

For instructor interest, $89.4 \%$ of faculty thought it was important that they got to know their students and show an interest in them compared to $66.9 \%$ of students who thought it was important for their instructors to do so. Faculty responses indicated congruence with the principles for good practice in undergraduate education from Chickering and Gamson (1987). "Faculty concern helps students get through rough times and keep on working" and "frequent student-faculty contact in and out of classes is the most important factor in student motivation and involvement" (Chickering \& Gamson, 1987, p. 3).

On whether students contacted instructors outside of class about class-related issues, $72.2 \%$ of students agreed compared to $97.4 \%$ of faculty who thought students contacted them outside of class. The highest difference in responses between the two groups came from the item about outside nonclass-related issues; $14.4 \%$ of students said they contacted their instructors outside of class about nonclass-related issues, while $36.9 \%$ of faculty said students contacted them outside of class about these issues. Bean (1985) found that informal faculty contacts are not as important for a student's retention as contacts with peers. This may be indicative of why only $14.4 \%$ of students reported they contacted instructors outside of class about nonclass-related issues. However, research on Millennials suggests they are "social creatures in and out of the classroom" (Monaco \& Martin, 2007, p. 45) and want that interaction with faculty outside of the classroom. 


\section{Contextual Considerations}

The location of the study was chosen for several reasons: an undergraduate enrollment between 15,000 and 20,000, a high graduation rate, and a diverse campus with almost $25 \%$ of undergraduate students from underrepresented groups. The target institution was also intentionally chosen because of its high persistence rate. If a high-performing institution, such as the target institution, is experiencing statistically significant differences between students and faculty, what might that indicate for institutions with lower persistence rates? It is possible there is even more of a mismatch between student expectations of instructional activities and faculty approaches to instructional activities at institutions where students persist at lower rates.

According to data from the College Scorecard (U.S. Department of Education, 2017), the persistence of first-time, full-time undergraduates who returned after their freshmen year from $2015-2016$ was $81 \%$ at the target institution, while the national average was $68 \%$. This figure of $81 \%$ is the second highest persistence rate of the 12 public universities in the state. The highest was $93 \%$ and the lowest was $60 \%$. Since results from the study rejected the null hypotheses and suggest students' expectations of instructional activities inside and outside the classroom are significantly different than faculty approaches to instructional activities inside and outside the classroom, and the target institution had such a high persistence rate, the findings could mean that institutions with lower persistence rates might have an even greater level of incongruity between faculty and student responses. However, the present study was attached to this particular institution, and more analysis would be needed to determine how the research design could be applied at other institutions and what those findings might indicate. 


\section{Limitations and Delimitations}

While the overall persistence rate at the institution was $81.1 \%$, this rate varied for different groups. Underrepresented groups such as Black or African American students and Hispanics had persistence rates of $72.3 \%$ and $73.1 \%$, respectively. These students also had lower participation in the present study. The majority of participants were White/Caucasian (79.1\%), while only 5.2\% of African American/Black and 6.9\% of Hispanic/Latino participated. Not enough students from underrepresented groups participated in the study to provide adequate data for analysis of these different groups.

The total response rate itself was also low. Although a high number of responses were received, they only represented $12.5 \%$ of faculty and $11.4 \%$ of students. Responses from faculty also indicated a high level of agreement with positive instructional activities. It is possible that faculty who model effective teaching and are examples of the best college teachers referred to by Bain $(2004,2012)$ are the ones who participated in the survey, and those who are not as effective or care as much about their instructional strategies did not take the survey. This could be a reason for such high levels of agreement for these desired behaviors.

Although results of the present study point to statistically significant findings, the study has a narrow scope since it was only conducted at one institution. This affects the generalizability of the results. When completing the survey, students were asked to think of their overall experience with college courses and instruction, while faculty were asked to focus on one face-to-face class they taught. This difference in lenses could have affected their responses, as well as how they defined concepts such as class-related issues, nonclass-related issues, and classroom input. For the Likert-type items that were used to compare student and faculty responses, students were asked to report on what they could do or expected their faculty 
to do, while faculty were asked to report on what they did or thought their students were doing. The purpose of the study was to compare expectations versus approaches, but the differences between preferences and actual behaviors should be acknowledged.

\section{Implications}

Exploring the differences in expectations of students versus the approaches of faculty toward instructional activities inside and outside the classroom has implications for the Scholarship of Teaching and Learning, as it can help build the body of knowledge to improve teaching practices and enhance learning (Bishop-Clark \& Dietz-Uhler, 2012). Research shows that when faculty improve their teaching methods, there is evidence of an improvement in student learning (Condon, Iverson, Manduca, Rutz, \& Willett, 2016). Results from the present study may help inform the strategy for changing faculty teaching methods and interactions with students to influence the student-faculty relationship and student success and persistence. The implications of this study will be discussed first, including how interactions between students and faculty may affect student persistence, and then the next section will detail possible strategies for improved teaching practices and student engagement.

The quality and impact of instructional activities and interactions between faculty and students is significant for students' integration into an institution (Pascarella \& Terenzini, 1980), as the more students engage with their campus community, the more likely they are to stay at the institution and graduate (Tinto, 2012). The results of this study indicated there was a statistically significant difference between faculty and students when comparing their responses for instructional activities inside and outside the classroom. The student responses for institutional and goal commitment indicated that $91.2 \%$ of students agreed or strongly agree that it was important to them to graduate from that university, but only $40.7 \%$ felt connected to 
their instructors. The neutral response for that item was almost the same as agree or strongly agree at $38.1 \%$. For relationships with instructors being an important part of their college experience, $70 \%$ agreed or strongly agreed and $23.4 \%$ were neutral. When asked about instructor interest, $72 \%$ agreed or strongly agreed and $19.7 \%$ were neutral on whether most instructors they'd had contact with were genuinely interested in students.

These results showed that a majority of students planned to graduate from the institution, but not as many felt connected to instructors, or they were instead neutral about that connection. According to the research, a student's integration into the social and academic systems of an institution most directly relates to his continued enrollment at that institution (Tinto, 1975). Part of that integration is how he connects with faculty since faculty interest in students and good teaching methods are positive influences in how students perceive the commitment of their institution to their well-being (Braxton et al., 2014). Academic and social integration are also not mutually exclusive and may coexist at different levels, and student interactions with faculty can enhance both types of integration (French \& Oakes, 2004).

Expectations are predictors of behavior (Tinto, 1975). Students have certain expectations of their faculty, and faculty have certain expectations of their students. Because of their expectations, faculty have certain approaches that they use inside and outside of the classroom. As this study showed there is a significant difference between students and faculty in terms of those expectations and approaches, and because of the importance of the studentfaculty relationship for persistence, faculty and other institutional staff need to consider strategies that might improve those relationships and strengthen students' connections to their institution. According to Skipper (2005), "isolated efforts to increase retention are unlikely to produce large-scale improvements in student persistence rates. Rather, efforts must be 
institution-wide and tailored to address the unique needs of the students a campus serves" ( $p$. 73).

\section{Recommendations for Practice}

As noted in the first chapter, the increasing diversity of college students calls for more faculty development, and practices recommended and previous outcomes achieved 10 years ago are probably not relevant for the present day (Beach, 2016). This study showed there were significant differences in how students and faculty perceived instructional activities inside and outside the classroom, which may have an effect on student persistence. While a single study cannot provide a sound basis for the practice of good teaching methods, this study and other studies with similar findings about Millennials would suggest that there are strategies that faculty can use to improve their teaching methods and strategies that administrators can use to encourage collaboration and an institutional culture that advances student success. Knowing these results is therefore important for faculty and administrators, especially since retaining students is a primary goal of higher education institutions (Renn \& Reason, 2013).

\section{What Faculty Can Do}

There are several strategies that faculty can consider to improve their teaching methods, and research shows that even if only a few faculty start to make changes, this can have a spread effect across campus (Condon et al., 2016). Condon et al. (2016) point out that when faculty are able to successfully apply strategies they've learned to a particular course or assignment, they often apply those strategies to all their courses and assignments. This learning can then spread to colleagues and other departments or programs. "Faculty development impacts everyone within a faculty community" (Condon et al., 2016, p. 72). 
Feedback. Students and faculty differed in their responses to whether students used instructor feedback from assignments to prepare their future assignments. Faculty did not see this happening as often as students reported it happening. The way feedback is interpreted and used could be a contributing factor to the incongruence in responses (Ambrose et al., 2010). A majority of faculty reported giving detailed feedback on students' coursework, but the definition of detailed was left to interpretation.

Fink (2013) recommends providing "FIDeLity" feedback. This evaluation of a student's performance is frequent, immediate, discriminating, and performed lovingly. Frequent doesn't mean two midterms and a final; it means at least every week. Immediate means close to when the learning activity actually occurred. Discriminating feedback is based on clear criteria and standards such as in a rubric. It's not an "OK" or "Nice job." Faculty who give feedback lovingly or supportively do so with empathy and personal understanding, and students are more open to the feedback (Fink, 2013).

Lecturing and active learning. A majority of faculty reported that they were doing different things in class other than only lecturing while not as many students seemed to think this was important. This difference in opinion could be attributed to students' past educational context. They were taught to be passive learners and to learn material for tests, and traditional lecturing is what they know (Cook-Sather et al., 2014). They don't necessarily have the expectation that instructors should do more, and that active learning has the potential to make them more engaged and learn more (Fry et al., 2003). This could also be a contributing factor to why students had a lower percentage of agreement than faculty for being able to have input into classroom decisions, and why more preferred to cover just the material for exams. Over 50\% of participants were also freshmen (41.2\%) and sophomores (13.5\%), indicating they may still 
have the same classroom expectations from when they were in high school.

Lecture is the predominant teaching method and will most likely remain so for a while to come (Davis \& Arend, 2013; Fry et al., 2003; Roehl et al., 2013). Although its efficacy has been called into question (Fink, 2013), there are ways to make it more effective even when dealing with large numbers of students. This involves a structured approach because "students will learn and remember much more if their learning is organized" (Fry et al., 2003, p. 79). Fry et al. (2003) suggest not overloading lectures with content, organizing lectures so demands on students are changed every 10 to 15 minutes, making lectures more participatory right from the start, and teaching students new ways to take notes such as concept maps or mind maps.

Other suggestions for making lectures more effective include limiting them to short sessions with discussion breaks, bringing in guest speakers, talking less and doing more, visually stimulating students with graphics, videos, and PowerPoints (Worley, 2011), and developing elements that include pop culture (Wilson \& Gerber, 2008). Faculty can utilize teaching strategies designed around Millennials’ learning characteristics by offering modularized formats where courses are broken down into manageable units, helping students to become less distracted (Wilson \& Gerber, 2008). Wilson and Gerber (2008) found that introducing small packages of material in breakout sessions resulted in more engagement and discussion. They suggest teaching less; abbreviate the content, but not to the detriment of colleagues since ensuring students still have mastery of basic knowledge is essential.

When designing their courses, faculty can let students have input. The faculty member is still the expert in the discipline, but the student can bring her perspective from attending many different classes and doing many different assignments (Cook-Sather et al., 2014). Suggestions include letting students write their own essay questions, asking them to identify 
course objectives, having them redesign virtual learning environments, asking them to determine the weight of assignments, and allowing them to write multiple-choice questions for tests (Cook Sather et al., 2014).

Instructor interest and contact. Monaco and Martin (2007) point out how "frequent and quality contact between students and faculty can increase the motivation and commitment of the Millennial student" (p. 45). A majority of faculty indicated they thought it was important to get to know their students and show interest in them, but responses from students reflected almost a $25 \%$ difference in that opinion. It appears that faculty recognize the importance of their interactions with students on student success and persistence, but some students may not see that connection or know how important it is for their success. This was also evident in the responses to students contacting instructors outside of class about class-related issues and nonclass-related issues. Not as many students were contacting instructors outside of class about either issues compared to the number of faculty who thought students were contacting them. Past research shows Millennials want that interaction with faculty outside the classroom (Monaco \& Martin, 2007), so strategies may be needed to encourage students to initiate that contact. A student has to invest in the activities that lead to his success (Tinto, 2012), but it might take some prodding on the part of the faculty.

Faculty can show their interest in students by calling them by name, asking about their weekend, promising to help them learn, expressing high expectations, and encouraging their success (Nilson, 2010). Faculty need to make sure to schedule time for frequent and quality interactions. They can do this by sending emails, encouraging students to use their office hours, participating in extracurricular activities where students are present, and leaving time for interaction in class (Monaco \& Martin, 2007). Bain (2012) notes that the best college teachers 
genuinely care about their students, and Millennials want to know their faculty cares about them (Nilson, 2010). A critical element of a student-ready college is a caring educator, whose daily actions demonstrate passion and empathy for the students in his classroom and those he encounters in his personal sphere of influence on campus (McNair, Albertine, Cooper, McDonald, \& Major, Jr., 2016).

Technology use. Faculty are concerned with the time students give to mobile devices in their classrooms (Fink, 2013). In the present study, almost $50 \%$ of students thought they could still follow the class while they texted or surfed the internet compared to $6.1 \%$ of faculty who thought students could still pay attention. However, it does not appear that mobile devices are going anywhere. According to the Pew Research Center (2017), 95\% of Americans own some type of cellphone. Of that $95 \%, 92 \%$ between the ages of $18-29$ own a smartphone. Approximately 50\% of American adults own a tablet. The ECAR 2016 undergraduate technology study (Brooks, 2016) found that "students use their devices extensively and view them as important to their academic success" (p. 5) and their learning experiences.

With the ubiquitous nature of mobile devices, faculty may want to incorporate use of them into their classroom in a way that stops students from using them to text or surf the internet. Research shows there is some interest from faculty in using mobile devices to advance learning. Results from the ECAR Study of Faculty and Information Technology, 2015 (Brooks, 2015 ) found that $34 \%$ to $45 \%$ of faculty were interested in using student-owned technologies such as laptops, tablets, social media, and smartphones to improve classroom instruction. Faculty can limit the impact of digital distractions by outlining technology etiquette (Brooks, 2016), and offer relevant and engaging experiences using smartphones as a mobile learning tool. Mobile learning is described as "experience and opportunity afforded by the evolution of 
educational technologies” (McQuiggan, Kosturko, McQuiggan, \& Sabourin, 2015).

Faculty can boost engagement through the use of social media like Twitter; use websites such as Poll Everywhere or Kahoot! for polls or games; and promote the use of productivity apps such as Any.do for reminders or One Note for notetaking, as well as lecture recording apps so students can go back and listen to lectures for information they missed (Cortez, 2016). Brooks $(2015,2016)$ recommends getting assistance from instructional designers to redesign or design courses in a way that takes advantage of using mobile devices to deepen learning and limits the opportunities for extracurricular use.

No textbook/no problem. From the present study, results indicated that approximately $30 \%$ of students thought they could pass their classes without the required textbooks or course materials compared to approximately $10 \%$ of faculty who thought they could pass. According to Fink (2013), students do not buy textbooks for several reasons, one of which is that faculty cover the same material in class so students don't feel they need the book. Another reason students may not buy textbooks is because of the high cost of books (Senack, 2014). To tackle the issue with covering the same material in class, Fink (2013) recommends not lecturing on the same material as a reading assignment but instead doing something else that holds students accountable, such as a quiz or in-class activity. If books are too expensive, faculty can consider adopting open textbooks in the classroom. These textbooks are open source, meaning they are free online (Senack, 2014). If the books are free, students might prefer online textbooks more than traditional textbooks. Faculty can also use websites to give students better visual information (Fink, 2013). 


\section{What Faculty Developers Can Do}

All members of an institution are stakeholders in developing persistence strategies.

Centers for teaching and learning and faculty developers have the chance to significantly help educators develop their teaching skills (Leafstedt \& Pacansky-Brock, 2016). "Faculty development has measurable impacts on teaching (Condon et al., 2016, p. 114); those who participate in a greater and more diverse amount of faculty development make larger changes in their teaching than faculty who might only participate in one workshop (Condon et al., 2016). Leafstedt and Pacansky-Brock (2016) explain that "the goal of faculty development is to provide learning opportunities for faculty that result in the continued growth and development of one's teaching" (para. 6).

Faculty developers can utilize the conceptual framework of this study, persistence, generational theory, and pedagogy, and the results of the study, students' expectations of instructional activities inside and outside the classroom and faculty approaches to instructional activities inside and outside the classroom, to augment the material they cover in their professional development activities. Programming could include topics such as designing classes for active learning, strategies for working with shifting generations such as Millennial to Generation Z, how to use social media and mobile technologies to deepen classroom learning, where to find open source textbooks, and how to promote positive student-faculty relationships (Cortez, 2016; Fink, 2013; Moore, Moore, \& Fowler, 2005; Senack, 2014).

Faculty may have difficulty finding the time to learn about new methods of teaching, and then make those changes. If they do get motivated to find the time, they may become overwhelmed by the sheer amount of information about college teaching (Fink, 2013). Faculty developers can design learning experiences that reach faculty members wherever they may be 
at the time. There isn't a required specific place or time to learn. Leafstedt and Pacansky-Brock (2016) refer to this as untethering, where faculty developers provide "faculty development opportunities that include multiple points of access and multiple modes of interaction" (para. 6). Faculty developers could use untethered faculty development to provide an online resource site, online asynchronous courses or online toolkits; encourage faculty to blog about their teaching practices and reflections; and share links, videos, photos, tips, and ideas on social media (Leafstedt \& Pacansky-Brock, 2016). The digital learning gained from these strategies can better equip faculty to integrate technology into their classrooms, and these strategies are also in line with the habits of Millennial students who blog, instant message, download music and videos, and communicate with a large network of individuals online (Moore et al., 2005).

Diaz et al. (2009) recommend that faculty developers offer development opportunities focused on persistence; provide flexible scheduling and multiple delivery options; institute a multiple-year support and development plan that focuses on faculty in different phases of their teaching experience, such as new faculty and those with five or more years of experience; and blend technology with teaching and learning methodologies and pedagogies. As more faculty begin to retire, their ranks may be filled by those who share the same characteristics as their students (Diaz et al., 2009). Research, such as the findings from the present study, can help faculty developers meet the needs of these new faculty and identify topics that will enhance instructional experience.

\section{Recommendations for Future Research}

The findings from this study suggest there is a significant difference between students' expectations and faculty approaches to instructional activities inside and outside the classroom. This study was conducted at a 4-year comprehensive Midwestern public university, and the 
number of responses for faculty was low. The director of the university technology office estimated this would be the case, because faculty at the institution tended to avoid participating in research studies. One faculty member also refused to participate because of concerns with offering a gift card as an incentive. According to Bryant (2004), many doctoral dissertations are conducted with small numbers, and larger studies may result in more robust findings. Future research could include surveying students and faculty at other public institutions to see if the results are consistent across multiple universities and to ideally get more faculty participation. This might also result in a higher level of consistency for the faculty Likert scales, since the Cronbach alpha coefficients for the faculty instrument were lower for the present study than for the pilot study.

Additional research also seems needed on digital distractions and how students can follow along in classes when using their mobile technology. Recommendations for practice include using mobile technology in the classroom, but faculty may need to see more evidence of the impact of mobile technology on student learning before they decide these devices are worth using (Brooks, 2015). More research also seems needed on the expectations of Millennial first-generation students, who may have lower levels of academic engagement than non-first-generation students (Soria \& Stebelton, 2012). In the present study, $31.7 \%$ of the student participants were first-generation students. Soria and Stebelton (2012) note that firstgeneration students are less likely to interact with faculty during lectures or ask insightful questions in class. Separating responses of first-generation students from non-first-generation students might provide insight into expectations of that population and how those expectations compare to teaching methods faculty are using inside and outside the classroom. Other possible groups to survey include traditional-age graduate students and traditional-age students from 
underrepresented groups such as Black or African American and Hispanic, since the percentage of students from underrepresented groups in higher education is expected to increase.

It is possible that the incongruences between students and faculty on a number of items, such as classroom input, and covering just the material for exams were a result of passive learning experienced in high school or even college classes where faculty did not utilize active learning. Future research could include more exploration of both student and faculty interpretations of classroom input and active learning. Many of the Likert-type items were extremely general, and future study could include more context to gather richer data. The research could also include other lenses, such as what students perceive faculty actually do versus what students expect, and what faculty expect of their students. Similar to how findings from this study provided a basis for designing and implementing strategies for faculty and faculty developers, findings from a study on faculty expectations and student actions might provide a basis for recommendations to help students implement their own strategies for classroom success.

This study collected data on all class years, freshmen through senior. Breaking down the results into class year, and then comparing those responses to faculty responses, might yield insight into how students interpret faculty interactions at different times in their university experience. The study also collected between 548 and 854 student responses to the open-ended questions, and 67 and 85 faculty responses to the open-ended questions. Only a basic analysis of frequently used words was conducted for the present study. A future study could examine the patterns identified in the responses to the open-ended questions and promulgate another study that delves more deeply into those patterns. Ideally future research will strengthen the existing knowledge base for student persistence and faculty teaching methods. 


\section{Summary}

Students who engage academically and socially with others on campus are more likely to stay at the institution and graduate (Tinto, 2012). Their desire to stay is an educational goal and a reflection of their persistence (Bean, 1990). The continued success of higher education institutions depends on student persistence (Baum et al., 2013), and although there is an extensive body of literature for student retention and faculty teaching practices, more research was needed on how student persistence may be affected by the interactions between students and faculty, especially when students and faculty are members of different generational cohorts. The present study aimed to help bridge that gap of knowledge by investigating the differences between students' expectations and faculty approaches to instructional activities inside and outside the classroom, and using a research design that focused on Millennial characteristics, pedagogical characteristics, and faculty/student interaction.

The results of this study provide insight into the opinions of students and what they expect of their faculty inside the classroom and outside the classroom, as well as faculty approaches to teaching inside and outside the classroom. Tinto (2007) notes that the role of faculty has largely been absent from retention efforts even though their actions in the classroom have been established as a vital component of enhancing student retention. Faculty need to be more involved in the efforts to improve student persistence. With faculty buy-in and the support of senior institutional leadership, strategies to enhance the student-faculty relationship and improve faculty teaching methods can be implemented and hopefully begin to form the basis of a framework that guides higher education institutions on how to successfully improve retention, a framework that Tinto (2012) says is still missing despite years of effort. 


\section{REFERENCES}

AASCU. (2015, January). Top 10 higher education state policy issues for 2015. Retrieved from http://www.aascu.org/policy/publications/policymatters/Top10StatePolicyIssues2015.p df

ACT. (2016). 2016 retention/completion summary tables. Retrieved from http://www.act.org/content/dam/act/unsecured/documents/Retention-Summary-Tables2016.pdf

Allen, I. E., Seaman, J., Lederman, D., \& Jaschik, S. (2012, August). Digital faculty: Professors, teaching and technology, 2012. Inside Higher Ed and Babson Survey Research Group. Retrieved from http://files.eric.ed.gov/fulltext/ED535215.pdf

Alreck, P. L., \& Settle, R. B. (1995). The survey research handbook. Boston, MA: Irwin/ McGraw Hill.

Ambrose, S. A., Bridges, M. W., DiPietro, M., Lovett, M. C., \& Norman, M. K. (2010). How learning works: Seven research-based principles for smart teaching. San Francisco, CA: Jossey-Bass.

Arnold, A. (1999, March). Retention and persistence in postsecondary education: A summation of research studies. Texas Guaranteed Loan Corporation. Retrieved from https://www.tgslc.org/pdf/persistence.pdf

Astin, A. W. (1984). Student involvement: A developmental theory for higher education. Journal of College Student Personnel, 25(4), 297-308.

Bain, K. (2004). What the best college teachers do. Cambridge, MA: Harvard University Press.

Bain, K. (2012). What the best college students do. Cambridge, MA: Harvard University Press.

Bandura, A. (1977). Self-efficacy: Toward a unifying theory of behavioral change. Psychological Review, 84(2), 191-215. doi: 10.1037/0033-295x.84.2.191

Baum, S., Kurose, C., \& McPherson, M. (2013, Spring). An overview of American higher education. The Future of Children, 23(1), 17-39. Princeton University. Retrieved from Project MUSE database.

Beach, A. L. (2016). Boyer's impact on faculty development. In E. L. Boyer, D. Moser, T. C. Ream, J. M. Braxton, \& Associates (Eds.), Scholarship reconsidered: Priorities of the professoriate (pp. 13-18). San Francisco, CA: Jossey-Bass.

Bean, J. P. (1985). Interaction effects based on class level in an explanatory model of college student dropout syndrome. American Educational Research Journal, 22(1), 35 64. doi: 10.3102/00028312022001035 
Bean, J. P. (1990). Using retention research in enrollment management. In D. Hossler, J., P. Bean, \& Associates (Eds.), The strategic management of college enrollments (pp. 170-185). San Francisco, CA: Jossey-Bass.

Bean, J. \& Eaton, S. B. (2000). A psychological model of college student retention. In J.M. Braxton (Ed.), Reworking the departure puzzle: New theory and research on college student retention (pp. 48-61). Nashville, TN: Vanderbilt University Press.

Benhamou, L. (2015, February 12). Everything you need to know about Generation Z. Business Insider. Retrieved from http://www.businessinsider.com/afp-generation-zborn-in-the-digital-age-2015-2

Berger, J. B., Ramirez, G. B., \& Lyons, S. (2012). Past to present: A historical look at retention. In A. Seidman (Ed.), College student retention: Formula for student success (2nd ed; pp. 7-34). New York: Rowman \& Littlefield Publishers.

Bishop-Clark, C., \& Dietz-Uhler. B. (2012). Engaging in the scholarship of teaching and learning: A Guide to the process, and how to develop a project from start to finish. Sterling, VA: Stylus Publishing.

Bishop, P. A., \& Herron, R. L. (2015). Use and misuse of Likert items responses and other ordinal measures. International Journal of Exercise Science, 8(3), 297-302. Retrieved from http://digitalcommons.wku.edu/cgi/viewcontent.cgi?article=1675\&context=ijes

Black, A. (2010, Winter). Gen Y: Who they are and how they learn. Educational Horizons, 88(2), 92-101. Retrieved from http://files.eric.ed.gov/fulltext/EJ872487.pdf

Boone Jr., H. N., \& Boone, D. A. (2012, April). Analyzing Likert data. Journal of Extension, 50(2). Retrieved from https://www.joe.org/joe/2012april/pdf/JOE_v50_2tt2.pdf

Braxton, J. M. (2006, June). Faculty professional choices in teaching that foster student success. National Postsecondary Education Cooperative. Retrieved from http://web.ewu.edu/groups/academicaffairs/IR/NPEC_1_Braxton_Report.pdf

Braxton, J. M., \& Bayer, A. E. (1999). Faculty misconduct in collegiate teaching. Baltimore, MD: The Johns Hopkins University Press.

Braxton, J. M., Bray, N. J., \& Berger, J. B. (2000). Faculty teaching skills and their influence on the college student departure process. Journal of College Student Development, 41 (2), 215-226. Retrieved from http://scholarworks.umass.edu/cgi/viewcontent.cgi?article=1000\&context=cie_faculty_ pubs

Braxton, J. M., Doyle, W. R., Hartley III, H. V., Hirschy, A. S., Jones, W. A., \& McLendon, M. K. (2014). Rethinking college student retention. San Francisco, CA: Jossey-Bass. 
Braxton, J. M., \& Lien, L. A. (2000). The viability of academic integration as a central construct in Tinto's interactionalist theory of college student departure. In J. M. Braxton (Ed.), Reworking the student departure puzzle (pp. 22-28). Nashville, TN: Vanderbilt University.

Braxton, J. M., Sullivan, A. S., \& Johnson, R. M. (1997). Appraising Tinto's theory of college student departure. In J. C. Smart (Ed.), Higher education: A handbook of theory and research (Vol. 12, pp. 107-164). New York, NY: Agathon Press.

Brooks, C. (2015). ECAR study of faculty and information technology, 2015. EDUCAUSE Center for Analysis and Research. Retrieved from https://library.educause.edu/ /media/files/library/2015/8/ers1510r.pdf

Brooks, C. (2016). ECAR study of undergraduate students and information technology, 2016. EDUCAUSE Center for Analysis and Research. Retrieved from https://ibrary.educause.edu/resources/2016/6/ /media/files/library/2016/10/ers1605.pdf

Brown, J. D. (2011, March). Likert items and scales of measurement? SHIKEN: JALT Testing \& Evaluation SIG Newsletter, 15(1), 10-14. Retrieved from http://jalt.org/test/PDF/Brown34.pdf

Bryant, M. T. (2004). The portable dissertation advisor. Thousand Oaks, CA: Corwin Press.

Burdick, D., Doherty, T., \& Schoenfeld, N. (2015, June). Encouraging faculty attendance at professional development events. To Improve the Academy, 34(1-2), 367-405. doi: 10.1002/tia2.20019

Cabrera, A. F., Nora, A., \& Castaneda, A. (1993). College persistence: Structural equations modeling test of an integrated model of student retention. Journal of Higher Education, 64(2), 123-139. doi: 10.2307/2960026

Carter, T. L. (2008-2009, Winter). Millennial expectations, constructivist theory, and changes in a teacher preparation course. SRATE Journal, 18(1), 25-31. Retrieved from http://files.eric.ed.gov/fulltext/EJ948666.pdf

Chickering, A. W., \& Gamson, Z. F. (1987). Seven principles for good practice in undergraduate education. AAHE Bulletin, 39(7), 3-7. Retrieved from http://files.eric.ed.gov/fulltext/ED282491.pdf

Cidell, J. (2010). Content clouds as exploratory qualitative data analysis. Area, 42(4), 514-523. doi: 10.1111/j.1475-4762.2010.00952.x

Collier, P. J., \& Morgan, D. L. (2007). "Is that paper really due today?”: Differences in first-generation and traditional college students' understanding of faculty expectations. Higher Education, 55(4), 425-446. doi: 10.1007/s10734-007-9065-5 
Condon, W., E., R., Iverson, Maduca, C. A., Rutz, C., \& Willett, G. (2016) Faculty development and student learning: Assessing the connections. Bloomington, IN: Indiana University Press.

Cook-Sather, A., Bovill, C., \& Felten, P. (2014). Engaging students as partners in learning and teaching: A guide for faculty. San Francisco, CA: Jossey-Bass.

Coomes, M. D., \& DeBard, R. (2004). A generational approach to understanding students. New Directions for Student Services, 106, 5-16. doi: 10.1002/ss.121

Cortez, M. B. (2016, September 29). Why faculty shouldn't ban smartphones in classrooms. EdTech. Retrieved from http://www.edtechmagazine.com/higher/article/2016/09/whyfaculty-shouldn-t-ban-smartphones-classrooms

Creswell, J. H. (2009). Research design: Qualitative, quantitative, and mixed method approaches (3rd ed.). Los Angeles, CA: Sage Publications.

Davis, J. R., \& Arend, B. D. (2013). Facilitating seven ways of learning: A resources for more purposeful, effective, and enjoyable college teaching. Sterling, VA: Stylus Publishing.

Davis, T. (2011). In this age of consumerism, what are the implications of giving students what they want? In P. M. Magolda, \& M. B. Baxter Magolda (Eds.), Contested issues in student affairs: Diverse perspectives and respectful dialogue (pp. 85-96). Sterling, VA: Stylus.

DeBard, R. (2004). Millennials coming to college. New Directions for Student Services, 106, 33-45. doi: 10.1002/ss.123

Demetriou, C., \& Schmitz-Sciborski, A. (2011). Integration, motivation, strengths and optimism: Retention theories past, present and future. In R. Hayes (Ed.), Proceedings of the 7th national symposium on student retention, 2011, Charleston (pp. 300-312).

Diaz, V., Garrett, P. B., Kinley, E. R., Moore, J. F., Schwartz, C. M., \& Kohrman, P. (2009). Faculty development for the 21st century. EDUCAUSE Review, 44(3), 46-55. Retrieved from http://er.educause.edu/ /media/files/article-downloads/erm0933.pdf

Durkheim, E. (1951). Suicide: A study in sociology. Toronto, Canada: The Free Press.

Fink, L. D. (2013). Creating significant learning experiences: An integrated approach to designing college courses. San Francisco, CA: Jossey-Bass.

Freire, P. (2004). Pedagogy of the oppressed. In E. J. Whitt (Ed.), Ashe Reader on College Student Affairs Administration (pp. 319-326). Boston, MA: Pearson. 
French, B. F., \& Oakes, W. (2004, February). Reliability and validity evidence for the institutional integration scale. Educational and Psychological Measurement, 64(1), 8898. doi: $10.1177 / 0013164403258458$

Fry, H., Ketteridge, S., \& Marshall, S. (2003). A handbook for teaching \& learning in higher education ( $2^{\text {nd }}$ ed.). New York, NY: Routledge.

Fry, R. (2016, April 25). Millennials overtake Baby Boomers as America's largest generation. Pew Research Center. Retrieved from http://www.pewresearch.org/facttank/2016/04/25/millennials-overtake-baby-boomers/

Gingery, T. (2009, December 22). Survey research definitions: Central tendency bias. Inquisium Blog. Retrieved from http://survey.cvent.com/blog/market-research-designtips-2/survey-research-definitions-central-tendency-bias

Government Accountability Office. (2014, December). Higher education: State funding trends and policies on affordability. Retrieved from http://www.gao.gov/assets/670/667557.pdf

Habley, W. R., Bloom, J. L., \& Robbins. S. (2012). Increasing persistence: Researchbased strategies for college student success. San Francisco, CA: Jossey-Bass.

Hall, C., Swart, W., \& Duncan. S. (2012). Balancing customer needs and standards in higher education. Quality Approaches in Higher Education, 3(1), 2-7. Retrieved from http://asq.org/edu/2012/02/best-practices/quality-approaches-in-higher-education-vol-3no-1.pdf

Hagedorn, L. S. (2012). How to define retention: A new look at an old problem. In A. Seidman (Ed.), College student retention: Formula for student success $\left(2^{\text {nd }}\right.$ ed.; pp. 8199). New York, NY: Rowman \& Littlefield Publishers.

Hesel, R. A., \& May, S. B. (2007, February). Dispelling the Millennial myth. Council for Advancement and Support of Education. Retrieved from https://www.case.org/Publications_and_Products/2007/February_2007/Dispelling_the_ Millennial_Myth.html

Howe, N. (2014, October 27). Introducing the homeland generation (part 1 of 2). Forbes. Retrieved from http://www.forbes.com/sites/neilhowe/2014/10/27/introducing-thehomeland-generation-part-1-of-2/\#5aaf4f7b4fdc

Howe, N., \& Strauss, W. (2000). Millennials rising: The next great generation. New York, NY: Vintage.

Howe, N., \& Strauss, W. (2007). Millennials go to college (2 $2^{\text {nd }}$ ed.). Great Falls, VA: LifeCourse Associates. 
IPEDS. (2016, August 24). 2015-16 survey materials: Glossary. Retrieved from https://surveys.nces.ed.gov/ipeds/Downloads/Forms/IPEDSGlossary.pdf

Jamieson, S. (2004, December). Likert scales: How to ab(use) them. Medical Education, 38(12), 1217-1218. doi: 10.1111/j.1365-2929.2004.02012.x

Kuh, G. D., Kinzie, J., Buckley, J. A., Bridges, B. K., \& Hayek, J. C. (2006, July). What matters to student success: A review of the literature. Retrieved from http://nces.ed.gov/npec/pdf/kuh_team_report.pdf

Kuh, G. D., Kinzie, J., Schuh, J. H., Whitt, E. J., \& Associates (2005). Student success in college: Creating conditions that matter. San Francisco, CA: Jossey-Bass

Landrum, R. E., Gurung, R. A. R., Spann, N. (2012). Assessments of textbook usage and the relationship to student course performance. College Teaching, 60, 17-24. doi: $10.1080 / 87567555.2011 .609573$

The Lawlor Group. (2014). Trends for 2014: Five factors facing private higher education. Retrieved from http://clients.thelawlorgroup.com/Lawlor_Trends_2014.pdf

Leafstedt, \& Pacansky-Brock (2016, October 6). A step-by-step guide to 'untethered' faculty development. EdSurge News. Retrieved from https://www.edsurge.com/news/2016-10-06-a-step-by-step-guide-to-untethered-facultydevelopment

Levine, A., \& Dean, D. R. (2012). Generation on a tightrope: A portrait of today's college student. San Francisco, CA: Jossey-Bass.

Library of Congress (1990). S. 580 - Student right-to-know and campus security act. Retrieved from https://www.congress.gov/bill/101st-congress/senate-bill/580

Mangold, K. (2007). Educating a new generation: Teaching baby boomer faculty about Millennial students. Nurse Educator, 32(1), 21-23. doi: 10.1097/00006223-20070100000007

Mark, E. (2013). Student satisfaction and the customer focus in higher education. Journal of Higher Education Policy and Management, 35(1), 2-10. doi: 10.1080/1360080X.2012.727703

Mason, M. (2010, September). Sample size and saturation in $\mathrm{PhD}$ studies using qualitative interviews. Forum: Qualitative Social Research, 11(3). Retrieved from http://www.qualitative-research.net/index.php/fqs/article/viewArticle/1428/3027

McNair, T. B., Albertine, S., Cooper, M. A., McDonald, N., \& Major, Jr. T. (2016). Becoming a student-ready college: A new culture of leadership for student success. San Francisco, CA: Jossey-Bass. 
McNaught, C., \& Lam, P. (2010). Using Wordle as a supplementary research tool. The Qualitative Report, 15(3), 630-643. Retrieved from http://nsuworks.nova.edu/tqr/vol15/iss3/8/

McQuiggan, S., L. Kosturko, J. McQuiggan, \& J. Sabourin (2015). Mobile learning: A handbook for developers, educators, and learners. Hoboken, NJ: Wiley \& Sons.

Monaco, M., \& Martin, M. (2007). The Millennial student: A new generation of learners. Athletic Training Journal, 2, 42-46. Retrieved from

http://natajournals.org/doi/pdf/10.4085/1947-380X-2.2.42

Monk, P. E., Irons, E. J., Carlson, N. L., Kirk, E., Stephens, L. M., \& Abernathy, K. (2010). Higher education: Generational perceptions of faculty/student classroom behaviors, attitudes, and technology integration. National Social Science Association Proceedings Journal, 44(2), 174-180.

Montag, T., Campo, J, Weissman, J., Walmsley, A., \& Snell, A. (2012). In their own words: Best practices for advising Millennial students about majors. NACADA Journal, 32(2), 26-35. doi: 10.12930/0271-9517-32.2.26

Moore, A. (2007, January 1). They've never taken a swim and thought about Jaws: Understanding the Millennial generation. College and University, 82(4), 41-48.

Moore, A., Moore, J., \& Fowler, S. (2005). Faculty development for the net generation. In. D. G. Oblinger \& J. L. Oblinger (Ed.), Educating the net generation (pp. 11.111.16). EDUCAUSE.

Morrison, L., \& Silverman, L. (2012). Retention theories, models, and concepts. In A. Seidman (Ed.), College student retention: Formula for student success $\left(2^{\text {nd }}\right.$ ed.; pp. 6180). New York, NY: Rowman \& Littlefield Publishers.

Much, K., Wagener, A. M., Breitkreutz, H. L., \& Hellenbrand, M. (2014). Working with the Millennial generation: Challenges facing 21 st-century students from the perspective of university staff. Journal of College Counseling, 17, 37-47. doi: 10.1002/j.21611882.2014.00046.x

NACADA. (2006). The history of NACADA. Retrieved from https://www.nacada.ksu.edu/About-Us/History.aspx

National Center for Education Statistics. (2015, May). The condition of education: Characteristics of postsecondary students. Retrieved from http://nces.ed.gov/programs/coe/indicator_csb.asp

Nilson, L. B. (2010). Teaching at its best: A research-based resource for college Instructors ( $3^{\text {rd }}$ ed.). San Francisco, CA: Jossey-Bass. 
Noel-Levitz. (2008, November). Student success, retention, and graduation: Definitions, theories, practices, patterns, and trends. Retrieved from

http://www.stetson.edu/law/conferences/highered/archive/media/Student $\% 20$ Success, $\%$ 20Retention, \%20and\%20Graduation-

\%20Definitions, \%20Theories,\%20Practices,\%20Patterns,\%20and\%20Trends.pdf

Nulty, D. D. (2008, June). The adequacy of response rates to online and paper surveys:

What can be done? Assessment \& Evaluation in Higher Education, 33(2), 301-314. doi: $10.1080 / 02602930701293231$

Pascarella, E. T., \& Terenzini, P. (1980). Predicting freshman persistence and voluntary dropout decisions from a theoretical model. The Journal of Higher Education, 51(1), 60-75. doi: $10.2307 / 1981125$

Petty, T. (2014, March). Motivating first-generation students to academic success and college completion. College Student Journal, 48(1), 257-264.

Pew Research Center. (2017, January 12). Mobile fact sheet. Retrieved from http://www.pewinternet.org/fact-sheet/mobile/

Qualtrics. (2007, October 22). How to increase online survey response rates. Retrieved from http://www.qualtrics.com/blog/how-to-increase-online-survey-response-rates/

Randall, L. E. (2008, Fall). Rethinking faculty development: Toward sustaining a community of learners. Senate Forum, 24(1), 18-22. Retrieved from http://www.fullerton.edu/senate/documents/forum/Fall_08/6_Rethinking_Faculty_Deve lopment_Randall.pdf

Reason, R. D. (2009, November/December). An examination of persistence research through the lens of a comprehensive conceptual framework. Journal of College Student Development, 50(6), 659-682. doi: 10.1353/csd.0.0098

Renn, K. A., \& Reason, R. D. (2013). College students in the United States: Characteristics, experiences, and outcomes. San Francisco, CA: Jossey-Bass.

Ribera, T., Fernandez, S., \& Gray, M. (2012, January-February). Considering the scholarship of teaching and learning in student affairs. About Campus, 16(6), 25-28. doi: 10.1002/abc. 20084

Roberts, C. M. (2004). The dissertation journey: A practical and comprehensive guide to planning, writing, and defending your dissertation. Thousand Oaks, CA: Corwin Press.

Roberts, J., \& McNeese, M. N. (2010). Student involvement/engagement in higher education based on student origin. Research in Higher Education Journal, 7. Retrieved from http://www.aabri.com/manuscripts/09346.pdf 
Roehl, A., Reddy, S. L., \& Shannon, G. J. (2013). The flipped classroom: An opportunity to engage Millennial students through active learning strategies. Journal of Family and Consumer Sciences, 105(2), 44-49. doi: 10.14307/jfcs105.2.12

Rotter, J. (1966). Generalized expectancies for internal versus external control of reinforcement. Psychological Monographs: General and Applied, 80(1), 1-28. doi: $10.1037 / \mathrm{h} 0092976$

Russo, T. (2013). Examining Millennial characterizations as guidance for choosing classroom strategy changes. International Journal for the Scholarship of Teaching and Learning, 7(2), 1-18. doi: 10.20429/ijsotl.2013.070212

Sandeen, C. (2008). Boomers, Xers, and Millennials: Who are they and what do they really want from continuing higher education? Continuing Higher Education Review, 72, 11 31. Retrieved from http://files.eric.ed.gov/fulltext/EJ903434.pdf

Schuh, J. H., \& Gansemer-Topf, A. M. (2010, December). The role of student affairs in student learning assessment. National Institute for Learning Outcomes Assessment. Retrieved from http://www.learningoutcomeassessment.org/documents/studentAffairsrole.pdf

Seemiller, C., \& Grace, M. (2016). Generation Z goes to college. San Francisco, CA: Jossey-Bass.

Senack, E. (2014). Fixing the broken textbook market: How students respond to high textbook costs and demand alternatives. U.S. PIRG Education Fund \& The Student PIRGs. Retrieved from http://www.uspirg.org/reports/usp/fixing-broken-textbook-market

Skipper, T. L. (2005). Student development in the first college year: A primer for college educators. Columbia, SC: University of South Carolina, National Resource Center for The First-Year Experience and Students in Transition.

Soria, K. M.; Stebleton, M. J.; \& Huesman, Jr. R. L. (2011). Mapping the academic and social engagement of first-year students@UMNTC. Retrieved from http://purl.umn.edu/159737.

Soria, K. M., \& Stebleton, M. J. (2012). First-generation students' academic engagement and retention. Teaching in higher education, 17(6), 673-685. doi: 10.1080/13562517.2012.666735

Spady, W. G. (1970). Dropouts from higher education: An interdisciplinary review and synthesis. Interchange, 1(1), 64-85. doi: 10.1007/bf02214313

Spady, W. G. (1971). Dropouts from higher education: Toward an empirical model. Interchange, 2(3), 38-62. doi: 10.1007/bf02282469

Strauss, W., \& Howe, N. (1991). Generations: The history of America's future, 15842069. New York, NY: Quill. 
Swail, W. S. (2004, June 21). The art of student retention: A handbook for practitioners and administrators. Educational Policy Institute. Retrieved from http://files.eric.ed.gov/fulltext/ED485498.pdf

TagCrowd. (n.d.) Frequently asked questions. Retrieved from http://tagcrowd.com/faq.html

Taylor, P. (2014). The next America: Boomers, Millennials, and the looming generational showdown. New York, NY: Public Affairs.

Thabane, L., Ma, J., Chu, R., Cheng, J., Ismaila, A., Rios, L., Robson, R., Thabane, M., Giangregorio, L., \& Goldsmith C. (2010). A tutorial on pilot studies: The what, why and how. BMC Medical Research Methodology, 10(11), 1-10. doi: 10.1186/1471-2288$10-1$

Tierney, W. G. (1992). An anthropological analysis of student participation in college. Journal of Higher Education, 63(6), 603-618. doi: 10.2307/1982046

Tinto, V. (1975). Dropout from higher education: A theoretical synthesis of recent research. Review of Educational Research, 45(1), 89-125. doi: 10.3102/00346543045001089

Tinto, V. (1987). Leaving college: Rethinking the causes and cures of student attrition. Chicago, IL: University of Chicago Press.

Tinto, V. (2004, July). Student retention and graduation: Facing the truth, living with the consequences. The Pell Institute. Retrieved from http://files.eric.ed.gov/fulltext/ED519709.pdf

Tinto, V. (2007). Research and practice of student retention: What next? Journal of College Student Development, 8(1), 1-19. doi: 10.2190/c0c4-eft9-eg7w-pw

Tinto, V. (2012). Completing college: Rethinking Institutional action. Chicago, IL: The University of Chicago Press.

U.S. Department of Education. (2011). Meeting the nation's 2020 goal: State targets for increasing the number and percentage of college graduates with higher education. Retrieved from https://www.whitehouse.gov/sites/default/files/completion_state_by_state.pdf

U.S. Department of Education. (2015, September). Better information for better college choice and institutional performance. Retrieved from https://collegescorecard.ed.gov/assets/BetterInformationForBetterCollegeChoiceAndIns titutionalPerformance.pdf

U.S. Department of Education. (2017, January 13). College Scorecard. Retrieved from https://collegescorecard.ed.gov/ 
Vogt. W. P. (2007). Quantitative research methods for professionals. Boston, MA: Pearson Education.

Vogt, W. P., \& Johnson, R. B. (2011). Dictionary of statistics \& methodology (4 ${ }^{\text {th }}$ ed.). Los Angeles, CA: Sage Publications.

The White House, Office of the Press Secretary. (2012). FACT SHEET: President Obama's blueprint for keeping college affordable and within reach for all Americans [Press release]. Retrieved from http://www.whitehouse.gov/the-press-office/2012/01/27/factsheet-president-obama-s-blueprint-keeping-college-affordable-and-wi

Williams, D. J. (2004, August). Student development theory: Missing ingredient in informed teaching. E-Source for College Transitions. Retrieved from http://tech.sa.sc.edu/fye/esource/files/ES_2-1_Aug04.pdf

Wilson, M., \& Gerber, L. E. (2008, Fall). How generational theory can improve teaching strategies for working with the "Millennials." Currents in Teaching and Learning, 1(1). $29-44$.

Worley, K. (2011). Educating college students of the net generation. Adult Learning, 22(3), 31-39. doi: 10.1177/10451595110220030

Wyrick, J. (2014, April 15). Persistence vs. retention. Retrieved from http://www.pearsoned.com/education-blog/persistence-vs-retention/ 


\section{APPENDIX A}

PASCARELLA AND TERENZINI'S 1980 INSTITUTIONAL INTEGRATION SCALE (IIS)

(FIVE-POINT LIKERT-TYPE ITEMS)

\section{Scale I: Peer-Group Interactions}

1. Since coming to this university, I have developed close personal relationships with other students.

2. The student friendships I have developed at this university have been personally satisfying.

3. My interpersonal relationships with other students have had a positive influence on my personal growth, attitudes, and values.

4. My interpersonal relationships with other students have had a positive influence on my intellectual growth and interest in ideas.

5. It has been difficult for me to meet and make friends with other students.

6. Few of the students I know would be willing to listen to me and help me if I had a personal problem.

7. Most students at this university have values and attitudes different from my own.

Scale II: Interactions with Faculty

8. My nonclassroom interactions with faculty have had a positive influence on my personal growth, values, and attitudes.

9. My nonclassroom interactions with faculty have had a positive influence on my intellectual growth and interest in ideas.

10. My nonclassroom interactions with faculty have had a positive influence on my career goals and aspirations.

11. Since coming to this university I have developed a close, personal relationship with at least one faculty member.

12. I am satisfied with the opportunities to meet and interact informally with faculty members.

Scale III: Faculty Concerns for Student Development and Teaching

13. Few of the faculty members I have had contact with are generally interested in students.

14. Few of the faculty members I have had contact with are generally outstanding or superior teachers.

15. Few of the faculty members I have had contact with are willing to spend time outside of class to discuss issues of interest and importance to students.

16. Most of the faculty I have had contact with are interested in helping students grow in more than just academic areas.

17. Most faculty members I have had contact with are genuinely interested in teaching. 
Scale IV: Academic and Intellectual Development

18. I am satisfied with the extent of my intellectual development since enrolling in this university.

19. My academic experience has had a positive influence on my intellectual growth and interest in ideas.

20. I am satisfied with my academic experience at this university.

21. Few of my courses this year have been intellectually stimulating.

22. My interest in ideas and intellectual matters has increased since coming to this university.

23. I am more likely to attend a cultural event (for example, a concert, lecture, or art show) now than I was before coming to this university.

24. I have performed academically as well as I anticipated I would.

Scale V: Institutional and Goal Commitment

25. It is important for me to graduate from college.

26. I am confident that I made the right decision in choosing this university.

27. It is likely that I will register at this university next fall.

28. It is not important to me to graduate from this university.

29. I have no idea at all what I want to major in.

30. Getting good grades is not important to me.

Pascarella, E. T., \& Terenzini, P. (1980). Predicting freshman persistence and voluntary dropout decisions from a theoretical model. The Journal of Higher Education, 51(1), 60-75. doi: $10.2307 / 1981125$ 


\section{APPENDIX B}

\section{RUSSO’S 2013 SURVEY}

\section{(FIVE-POINT LIKERT-TYPE ITEMS)}

\section{$\underline{\text { Special }}$}

1. My teacher should be available to provide individual attention should I need it.

2. I will be rewarded for my learning efforts.

3. My instructors should reward me for my efforts in class.

4. My teacher should be flexible to allow for my classroom success.

5. It is ok to ask instructors for special treatment.

6. I expect my instructors to give me credit for trying, regardless of how well I perform.

\section{Conventional}

7. My teacher should provide specific grading guidelines for each assignment.

8. I am frustrated when my instructor doesn't tell me specifically what he or she wants in an assignment.

9. My instructor should clearly communicate all classroom rules.

10. I'd rather have step-by-step instructions for a project than be told to decide on my own how to accomplish it.

11. I prefer classes that are very structured.

12. I expect my instructors to provide study guides.

13. I expect the rules for proper classroom conduct to be relatively consistent from instructor to instructor.

14. My instructors provide clear criteria for good performance.

\section{Confident}

15. I expect that, when I graduate from college, I will have the knowledge and skills I need to get a good job.

16. I am confident that my studies will prepare me well for a professional job.

17. I am confident my studies have prepared me to be a well-informed citizen.

18. I am confident that my studies have prepared me for a long-term career.

19. I think my degree will be worth the money it cost.

\section{Team-Oriented}

20. I prefer group work over all other teaching method.

21. I look forward to opportunities to work on class projects with my peers.

22. I like to hear what other students have to say about ideas in class.

23. I am comfortable calling on other students in my class for help.

24. I am comfortable with evaluation of my performance by my peers. 
Sheltered

25. I am in college because my parents expect it.

26. My parents expect me to earn at least a B in each class I take.

27. I talk with my mom or dad every day.

28. I am at college to please my parents.

29. I can call on my family for help with my class work.

30. I am in college because I don't want to let my family down.

31. My parents expect me to excel in my classes because they have paved the way for my college successes.

32. My parents expect me to get a good job directly out of college.

Technology

33. I prefer online discussions over classroom discussions.

34. I text message during class.

35. I learn more from videos or other media than from lectures.

36. Students should be allowed to surf the web or message others while in class.

37. I have no problems doing several things at once, like studying, listening to music, and messaging with my friends.

38. My instructors should use technology in the classroom.

39. I prefer lecture over any other teaching method.

40. I learn more from the Internet than from classroom discussion.

41. I can still follow the class while I text or surf the web.

$\underline{\text { Instructors }}$

42. When my papers or exams are returned, all I'm interested in is the grade.

43. The grade I get in class is all that matters.

44. I prefer to cover just the material that is required for exams.

45. I do not get enough detail in feedback from my instructors.

46. I expect to get a B in a class just for attending the lectures.

47. I expect to get a $B$ in a class just for completing the required reading.

48. I find it hard to stay awake during class.

49. I find it hard to pay attention in class.

50. I am not comfortable writing; I'd rather just have exams.

51. I expect all the information I need to know for my coursework (assignments, papers, exams) to be covered in class and not require out-of-class work.

52. In each class, I want to know specifically why I should learn.

53. I am generally reluctant to speak up when we have class activities.

54. I am comfortable talking with instructors about topics other than class.

55. I would like to be able to talk with my instructors about topics other than class.

\section{Consumers}

56. most important objective at college is getting a degree so I can find a job.

57. My most important objective at college is getting good grades.

58. My most important objective at college is having a good time.

Russo, T. (2013). Examining Millennial characterizations as guidance for choosing classroom strategy changes. International Journal for the Scholarship of Teaching and Learning, 7(2), 1-18. doi: 10.20429/ijsot1.2013.070212 


\section{APPENDIX C}

\section{PRESENT STUDY STUDENT INSTRUMENT}

1. What is your gender?
a. Male
b. Female
c. Transgender
d. Another gender
e. Prefer not to respond

2. What year where you born? (Open-ended number)

3. Which of the following best describes your race or ethnicity?
a. African American/Black
b. Asian/Pacific Islander
c. White/Caucasian
d. Hispanic/Latino
e. Multiracial
f. Native American/American Indian
g. Another racial identity
h. Prefer not to respond

4. What is your best estimate of your family's total income last year?
a. Less than $\$ 20,000$
b. $\$ 20,000-\$ 39,999$
c. $\$ 40,000-\$ 74,999$
d. $\$ 75,000$ - $\$ 99,999$
e. $\$ 100,000$ - $\$ 149,999$
f. $\$ 150,000$ - or more
g. Do not know

5. How many people, including yourself, live in your household?
a. 1
b. 2
c. 3
d. 4
e. 5
f. $6+$

6. What is your major? (Open-ended question)

7. What is your class year?
a. Freshman
b. Sophomore
c. Junior
d. Senior 
8. Did you purchase all of the required materials (textbooks, online codes, workbooks, etc.) for your classes?
a. Yes
b. No

9. Do you receive classroom accommodations for having a disability?
a. Yes
b. No

10. Did either of your parents attend college?
a. Yes
b. No

11. Did either of your parents graduate from college?
a. Yes
b. No

12. Was this institution your first choice?
a. Yes
b. No

\section{Likert Scale Survey}

1 - Strongly Disagree

2 - Disagree

3 - Neutral

4 - Agree

5 - Strongly Agree

Please indicate the extent to which you agree with the following. As you answer questions, please think of your overall experience with college courses and instruction.

\section{Instructional Activities Inside the Classroom}

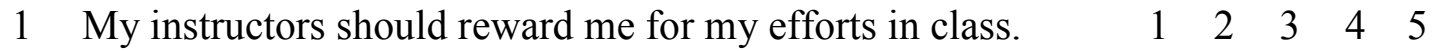

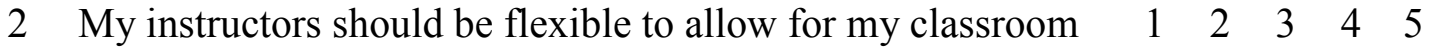
success.

$\begin{array}{lllllll}3 & \text { My instructors should give me credit for trying, regardless of } & 1 & 2 & 3 & 4 & 5\end{array}$ how well I perform on my coursework.

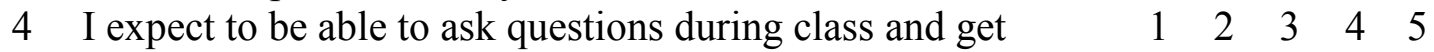
answers from my instructors.

5
If I am unprepared for class, I expect my instructors to make $\quad \begin{array}{lllll}1 & 2 & 3 & 4 & 5\end{array}$ exceptions.

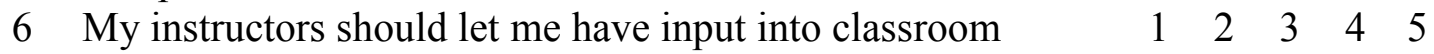
decisions.

$\begin{array}{lllllll}7 & \text { Class attendance should not count toward classroom grades. } & 1 & 2 & 3 & 4 & 5\end{array}$

$\begin{array}{llllllll}8 & \text { The syllabus for a class should detail when every assignment } & 1 & 2 & 3 & 4 & 5\end{array}$ is due for the semester. 
$\begin{array}{lllllll}9 & \text { My instructors should provide specific grading guidelines for } & 1 & 2 & 3 & 4 & 5\end{array}$ each assignment.

10 My instructors should clearly communicate all classroom $\quad \begin{array}{lllll}1 & 2 & 3 & 4 & 5\end{array}$ rules.

11 I would rather have step-by-step instructions for a project $\quad \begin{array}{lllll}1 & 2 & 3 & 4 & 5\end{array}$ than decide on my own how to accomplish it.

12 I prefer classes that are very structured.

13 I expect my instructors to provide study guides.

14 My instructors should tell me about tutoring and other resources I can use on campus to help me be successful.

15 I should be allowed to surf the internet or text others while in $\begin{array}{lllll}1 & 2 & 3 & 4 & 5\end{array}$ class.

16 I can still follow the class while I text or surf the internet. $\begin{array}{llllll}1 & 2 & 3 & 4 & 5\end{array}$

17 My instructors should use technology besides PowerPoint $\quad \begin{array}{lllll}1 & 2 & 3 & 4 & 5\end{array}$ presentations in the classroom, such as interactive whiteboards, music, clickers, and videos.

18 My instructor should use online resources in class, such as $\begin{array}{lllll}1 & 2 & 3 & 4 & 5\end{array}$ websites and articles.

19 I prefer online textbooks to traditional textbooks.

20 I expect to get at least a $\mathrm{C}$ in a class just for attending.

21 I prefer to have exams count for the majority of my class grade.

22 I can pass my classes without the required textbooks or course materials.

23 My instructors should link course assignments with stated $\begin{array}{lllll}1 & 2 & 3 & 4 & 5\end{array}$ course goals or learning objectives.

24 I would like more interaction with my instructors in class. $\begin{array}{llllll}1 & 2 & 3 & 4 & 5\end{array}$

25 My instructor should do different things in class rather than $\begin{array}{lllll}1 & 2 & 3 & 4 & 5\end{array}$ stand at the front of the classroom and only explain class content.

$\begin{array}{lllllll}26 & \text { If my instructor requires a textbook for the class, I expect to } & 1 & 2 & 3 & 4 & 5\end{array}$ use it for my assignments and tests.

27 I prefer to cover just the material required for exams. $\quad \begin{array}{llllll}1 & 2 & 3 & 4 & 5\end{array}$

28 I expect to do very little out-of-class work. $\quad 1 \quad \begin{array}{lllll} & 2 & 3 & 4 & 5\end{array}$

29 My instructors use more than one way to teach the material. $\begin{array}{llllll}1 & 2 & 3 & 4 & 5\end{array}$

30 Instructors should meet my generation where it is at $\quad \begin{array}{lllll}1 & 2 & 3 & 4 & 5\end{array}$ academically and socially.

$\begin{array}{lllllll}31 & \text { Instructors should leave enough time in class to go over the } & 1 & 2 & 3 & 4 & 5\end{array}$ material and have time for my questions.

\section{Instructional Activities Outside the Classroom}

$\begin{array}{lllllll}32 & \text { My instructors should be available to provide individualized } & 1 & 2 & 3 & 4 & 5\end{array}$ attention if I need it.

$\begin{array}{lllllll}33 & \text { I expect my instructors to answer my emails within } 24 \text { hours } & 1 & 2 & 3 & 4 & 5\end{array}$ or sooner. 
34 It is fine to ask instructors for special treatment.

35 My instructors should use the online course management

$\begin{array}{lllll}1 & 2 & 3 & 4 & 5\end{array}$

system to post grades, assignments, and classroom study materials.

$\begin{array}{lllllll}36 & \text { My instructors should have assignments graded and returned } & 1 & 2 & 3 & 4 & 5\end{array}$ within two weeks of the due date or sooner.

37 I expect detailed feedback from my instructors on my coursework.

$\begin{array}{lllllll}38 & \text { I use instructor feedback from assignments to prepare future } & 1 & 2 & 3 & 4 & 5\end{array}$ assignments.

$\begin{array}{lllllll}39 & \text { My interactions with instructors outside the classroom have } & 1 & 2 & 3 & 4 & 5\end{array}$ had a positive influence on my personal growth at this institution.

$\begin{array}{lllllll}40 & \text { I contact my instructors outside of class about class-related } & 1 & 2 & 3 & 4 & 5\end{array}$ issues.

41 I am satisfied with the opportunities to meet and interact informally with instructors.

$\begin{array}{lllllll}42 & \text { It is important that my instructors get to know me and show } & 1 & 2 & 3 & 4 & 5\end{array}$ an interest in me.

43 I would like more interaction with my instructors outside of $\begin{array}{lllll}1 & 2 & 3 & 4 & 5\end{array}$ class.

44 I contact my instructors outside of class about non-classrelated issues.

\section{Institutional and Goal Commitment}

45 It is important for me to graduate from college.

46 I plan to graduate within the time allotted for my degree program.

47 I am confident I made the right decision in choosing this university.

48 It is likely I will register for classes next semester.

49 It is important to me to graduate from this university.

50 I am performing academically as well as I anticipated I would.

51 I am satisfied with my academic experience at this university.

52 I feel connected to my instructors.

53 Most instructors I have had contact with are genuinely interested in students.

$\begin{array}{lllllll}54 & \text { My relationships with instructors are an important part of my } & 1 & 2 & 3 & 4 & 5\end{array}$ college experience.

$\begin{array}{lllllll}55 & \text { Since coming to this university, I have started to develop a } & 1 & 2 & 3 & 4 & 5\end{array}$ close relationship with at least one instructor who I can see as a possible mentor. 
Please comment on the following:

1. How are your instructors meeting your needs inside and outside the classroom?

2. How are your instructors not meeting your needs inside and outside the classroom?

3. Is there anything else you want to share about what you expect of your instructors?

This instrument was constructed by the researcher and adapted from existing research materials with permission granted from Dr. Pascarella and The Ohio State University Press, and Dr. Russo.

Pascarella, E. T., \& Terenzini, P. (1980). Predicting freshman persistence and voluntary dropout decisions from a theoretical model. The Journal of Higher Education, 51(1), 60-75. doi: 10.2307/1981125

Russo, T. (2013). Examining Millennial characterizations as guidance for choosing classroom strategy changes. International Journal for the Scholarship of Teaching and Learning, 7(2), 1-18. doi: 10.20429/ijsotl.2013.070212

\section{Survey Closing Page for Present Study}

Thank you for participating in this research study. The purpose of the study is to compare students' expectations of instructional activities inside and outside the classroom with faculty approaches to instructional activities inside and outside the classroom. Your responses are very valuable and will add insight into this important topic aimed at improving student success.

If you want to be entered into the raffle to win one of two \$100 online Amazon gift cards, please click on the following link to provide your email address. Your email address will not be connected to your previous responses in any way as the link is for a different survey that only collects one piece of data, your email address for the raffle.

https://survey.illinoisstate.edu/coe/teachered/TakeSurvey.aspx?SurveyID=n4L14m44

\section{Student Raffle Survey Instructions}

To be entered into the raffle to win one of two $\$ 100$ online Amazon gift cards, please enter your ISU email address. Your email address will not be connected to your previous responses in any way. Thank you.

\section{Survey Closing Page for Student Raffle}

Thank you for participating. Two random winners for the $\$ 100$ online Amazon gift card will be chosen within two weeks of the survey closing. The code for the gift card will be sent to the email address provided by the winning participants. 


\section{APPENDIX D}

\section{PRESENT STUDY FACULTY INSTRUMENT}

1. What is your gender?
a. Male
b. Female
c. Transgender
d. Another gender
e. Prefer not to respond

2. What year where you born? (Open-ended number)

3. Which of the following best describes your race or ethnicity?
a. African American/Black
b. Asian/Pacific Islander
c. White/Caucasian
d. Hispanic/Latino
e. Multiracial
f. Native American/American Indian
g. Another racial identity
h. Prefer not to respond

4. What year did you first begin teaching? (Open-ended number)

5. What year did you first begin teaching at this institution? (Open-ended number)

6. Do you have at least 10 years of teaching experience at a 4-year public institution?
a. Yes
b. No

7. What is your academic rank?
a. Full Professor
b. Associate Professor
c. Assistant Professor
d. Instructor
e. Other, Please Specify

8. What is your tenure status at this institution?
a. Tenured
b. On tenure track
c. Not on tenure track 
9. What is your academic college?
a. College of Applied Science and Technology
b. College of Arts and Sciences
c. College of Business
d. College of Education
e. College of Fine Arts
f. Other, Please Specify

10. Out of $100 \%$, what percentage of time do you prefer to spend on teaching? (Open-ended one line)

11. Out of $100 \%$, besides the percentage of time for teaching, what percentage of time do you prefer to spend on research? (Open-ended one line)

12. Out of $100 \%$, besides the percentage of time for teaching and research, what percentage of time do you prefer to spend on service? (Open-ended one line)

13. How many courses are you teaching at this institution this semester?
a. 0
b. 1
c. 2
d. 3
e. 4
f. $5+$

14. Are you also teaching at another institution this semester?
a. Yes
b. No

15. If so, how many classes?
a. 1
b. 2
c. 3
d. 4
e. $5+$

16. How many of the courses you are teaching this semester at this institution are general education courses?
a. 0
b. 1
c. 2
d. 3
e. 4
f. $5+$ 
17. How many of the courses you are teaching this semester at this institution are courses required for an undergraduate major (not general education)?
a. 0
b. 1
c. 2
d. 3
e. 4
f. $5+$

18. How many of the courses you are teaching this semester at this institution are noncredit developmental/remedial courses?
a. 0
b. 1
c. 2
d. 3
e. 4
f. $5+$

19. During the past 2 years, have you taken advantage of any professional development opportunities to improve your teaching at this institution?
a. Yes
b. No

20. If so, what types? (Open-ended question)

21. Would you participate if there were professional development opportunities available about the characteristics of the students in your classes?
a. Yes
b. No

22. I update my course material at least once every years.
a. 1
b. 2
c. 3
d. 4
e. 5
f. 6
g. $7+$

23. In a typical week, how many hours do you spend grading/providing feedback on student work?
a. 1-2
b. 3-4
c. 5-6
d. $7-8$
e. 9-10
f. $11+$ 
24. In a typical week, how many hours do you spend teaching?
a. 1-2
b. 3-4
c. 5-6
d. 7-8
e. $9-10$
f. $11+$

25. In a typical week, how many hours do you spend preparing for teaching?
a. 1-2
b. 3-4
c. 5-6
d. 7-8
e. $9-10$
f. $11+$

26. In a typical week, how many hours do you spend doing research?
a. 0
b. 1-2
c. 3-4
d. 5-6
e. 7-8
f. $9-10$
g. $11+$

27. In a typical week, how many hours do you spend participating in service responsibilities?
a. 0
b. 1-2
c. 3-4
d. 5-6
e. 7-8
f. $9-10$
g. $11+$

28. In a typical week, how many hours do you spend interacting with students outside of class?
a. 0
b. $1-2$
c. $3-4$
d. $5-6$
e. $7-8$
f. $9-10$
g. $11+$ 


\section{Likert Scale Survey}

1 - Strongly Disagree

2 - Disagree

3 - Neutral

$4-$ Agree

5 - Strongly Agree

Please indicate the extent to which you agree with the following. As you answer questions, please focus on one face-to-face class you teach. It is also important to answer the survey questions based on how you actually teach rather than how you would prefer to teach.

\section{Instructional Activities Inside the Classroom}

1 I reward students for their efforts in class.

2 I am flexible to allow for students' classroom success.

3 I give students credit for trying, regardless of how well they

$\begin{array}{lllll}1 & 2 & 3 & 4 & 5\end{array}$ perform on their coursework.

$\begin{array}{lllllll}4 & \text { Students are encouraged to ask questions during class so I } & 1 & 2 & 3 & 4 & 5\end{array}$ can clarify the material.

5 If students are unprepared for class, I make exceptions.

$6 \quad$ I let students have input into classroom decisions.

7 I do not count class attendance toward classroom grades.

8 The syllabi for my classes detail when every assignment is due for the semester.

9 I provide specific grading guidelines for each assignment. $\begin{array}{llllll}1 & 2 & 3 & 4 & 5\end{array}$

10 I clearly communicate all classroom rules.

11 I provide step-by-step instructions for a project rather than let students decide on their own how to accomplish it.

12 My classes are very structured.

13 I provide study guides.

14 I tell students about tutoring and other resources they can use $\begin{array}{llllll}1 & 2 & 3 & 4 & 5\end{array}$ on campus to help them be successful. class.

16 Students can still follow the class while they text or surf the $\begin{array}{llllll}1 & 2 & 3 & 4 & 5\end{array}$ internet.

17 I use technology besides PowerPoint presentations in the classroom, such as interactive whiteboards, music, clickers, and videos.

18 I use online resources in my classes, such as websites and articles.

19 I prefer using online textbooks to traditional textbooks.

20 I give students at least a $\mathrm{C}$ in a class just for attending.

21 Exams count for the majority of the class grade.

$\begin{array}{lllll}1 & 2 & 3 & 4 & 5\end{array}$

$\begin{array}{lllll}1 & 2 & 3 & 4 & 5\end{array}$

$\begin{array}{lllll}1 & 2 & 3 & 4 & 5\end{array}$

$\begin{array}{lllll}1 & 2 & 3 & 4 & 5\end{array}$
N/A 
22 Students can pass my classes without the required textbooks $\quad 1 \quad \begin{array}{lllll}1 & 2 & 3 & 4 & 5\end{array}$ or course materials.

$\begin{array}{lllllll}23 & \text { I link course assignments with stated course goals or learning } & 1 & 2 & 3 & 4 & 5\end{array}$ objectives.

24 I would like more interaction with my students in class. $\quad \begin{array}{llllll}1 & 2 & 3 & 4 & 5\end{array}$

25 I do different things in class rather than stand at the front of $\begin{array}{llllll}1 & 2 & 3 & 4 & 5\end{array}$ the classroom and only explain class content.

26 If I require a textbook for the class, I use it for assignments $\begin{array}{llllll}1 & 2 & 3 & 4 & 5\end{array}$ and tests.

27 I cover just the material required for exams.

28 Students are expected to do very little out-of-class work.

$\begin{array}{lllll}1 & 2 & 3 & 4 & 5 \text { or }\end{array}$

$\begin{array}{ccccc}1 & 2 & 3 & 4 & 5\end{array}$

29 I use more than one way to teach the material.

30 I am meeting this generation of students where it is at academically and socially.

$\begin{array}{lllllll}31 & \text { I leave enough time in my class to go over the material and } & 1 & 2 & 3 & 4 & 5\end{array}$ have time for students' questions.

\section{Instructional Activities Outside the Classroom}

$\begin{array}{lllllll}32 & \text { I am available to provide individualized attention if students } & 1 & 2 & 3 & 4 & 5\end{array}$ need it.

33 I answer students' emails within 24 hours or sooner.

34 It is fine for students to ask me for special treatment.

$\begin{array}{lllll}1 & 2 & 3 & 4 & 5\end{array}$

$\begin{array}{lllll}1 & 2 & 3 & 4 & 5\end{array}$

$\begin{array}{lllllll}35 & \text { I use the online course management system to post grades, }\end{array} \begin{array}{llllll}1 & 2 & 3 & 4 & 5\end{array}$ assignments, and classroom study materials.

$\begin{array}{lllllll}36 & \text { I have assignments graded and returned within two weeks of } & 1 & 2 & 3 & 4 & 5\end{array}$ the due date or sooner.

37 I give detailed feedback on students' coursework.

38 Students use my feedback from assignments to prepare future assignments.

39 My interactions with students outside the classroom have had a positive influence on their personal growth at this institution.

40 Students contact me outside of class about class-related issues.

41 I am satisfied with the opportunities to meet and interact informally with students.

42 It is important I get to know my students and show an $\quad \begin{array}{lllll}1 & 2 & 3 & 4 & 5\end{array}$ interest in them.

43 I would like more interaction with my students outside of $\begin{array}{llllll}1 & 2 & 3 & 4 & 5\end{array}$ class.

44 Students contact me outside of class about non-class-related $\begin{array}{llllll}1 & 2 & 3 & 4 & 5\end{array}$ issues. 
Please comment on the following:

1. How could faculty better meet the needs of this generation of students?

2. How do you develop relationships with students?

3. Is there anything else you want to share about teaching this generation of students?

This instrument was constructed by the researcher and adapted from existing research materials with permission granted from Dr. Pascarella and The Ohio State University Press, and Dr. Russo

Pascarella, E. T., \& Terenzini, P. (1980). Predicting freshman persistence and voluntary dropout decisions from a theoretical model. The Journal of Higher Education, 51(1), 60-75. doi: 10.2307/1981125

Russo, T. (2013). Examining Millennial characterizations as guidance for choosing classroom strategy changes. International Journal for the Scholarship of Teaching and Learning, 7(2), 1-18. doi: 10.20429/ijsotl.2013.070212

\section{Survey Closing Page for Present Study}

Thank you for participating in this research study. The purpose of the study is to compare students' expectations of instructional activities inside and outside the classroom with faculty approaches to instructional activities inside and outside the classroom. Your responses are very valuable and will add insight into this important topic aimed at improving student success.

If you want to be entered into the raffle to win one of two \$100 online Amazon gift cards, please click on the following link to provide your email address. Your email address will not be connected to your previous responses in any way as the link is for a different survey that only collects one piece of data, your email address for the raffle.

https://survey.illinoisstate.edu/coe/teachered/TakeSurvey.aspx?SurveyID=n4L14n44

\section{Faculty Raffle Survey Instructions}

To be entered into the raffle to win one of two $\$ 100$ online Amazon gift cards, please enter your ISU email address. Your email address will not be connected to your previous responses in any way. Thank you.

\section{Survey Closing Page for Faculty Raffle}

Thank you for participating. Two random winners for the $\$ 100$ online Amazon gift card will be chosen within two weeks of the survey closing. The code for the gift card will be sent to the email address provided by the winning participants. 


\section{APPENDIX E}

\section{PASCARELLA PERMISSION TO USE INSTITUTIONAL INTEGRATION SCALE}

From: O'Brien, Julie

Sent: Tuesday, March 1, 2016 4:53 PM

To: Pascarella, Emest T

Subject: Re: Permission to Use Institutional Integration Scale

Thanks so much for the super fast response. I will definitely make sure to cite the article. Have a great day!

From: Pascarella, Ernest T <ernest-pascarella@uiowa.edus Sent: Tuesday, March 1, 2016 4:51 PM

To: O'Brien, Julie

Subject: RE: Permission to Use Institutional Integration Scale

Julie: Certainly - feel free to use the scales. Simply cite the 1980 article. Best of luck with your research. Ernie

From: O'Brien, Julie [mailto:jaobrie@ilstu.edu]

Sent: Tuesday, March 01, 2016 4:19 PM

To: Pascarella, Ernest T

Subject: Permission to Use Institutional Integration Scale

Dear Dr. Pascarella,

My name is Julie Brines, and I am a doctoral student at Illinois State University. I am working on the literature review and methods chapters of my dissertation proposal and am focusing on retention theory, generational theory and faculty teaching methods. The purpose of my study is to compare the expectations of faculty versus the expectations of students with regard to the issue of faculty teaching methods and interactions inside and outside the classroom. My proposed research questions are:

1) What is the relationship between generational cohort and the expectations of faculty teaching methods and faculty interaction in the classroom?

2) What is the relationship between generational cohort and the expectations of faculty teaching methods and faculty interaction outside the classroom?

3) Does a difference in generational cohort between faculty and students in the classroom decrease students' academic engagement and social engagement?

I am requesting your permission to utilize and modify parts of the Institutional Integration Scale you created with Dr. Terenzini in 1980 . Thank you so much for your consideration. I look forward to hearing back from you.

Sincerely,

Julie 


\section{APPENDIX F}

\section{RUSSO PERMISSION TO USE 2013 SURVEY}

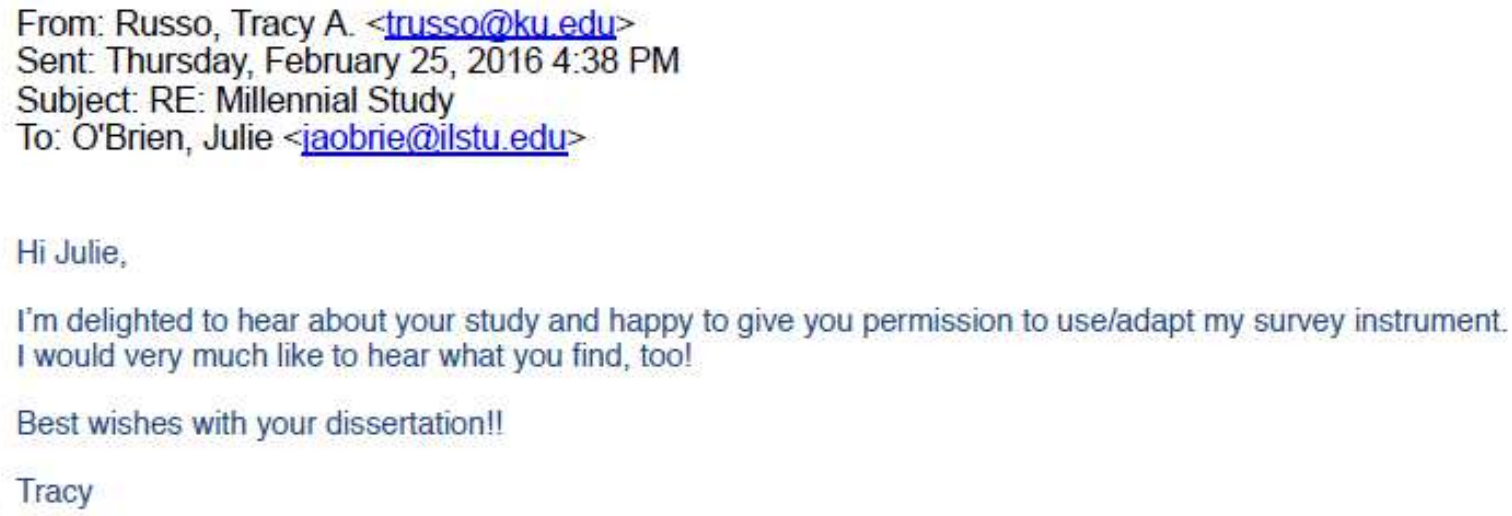

From: O'Brien, Julie [mailtojaobrie@ilstuedu]

Sent: Monday, February 22, 2016 12:31 AM

To: Russo, Tracy A. <trusso@kuedu>

Subject: Millennial Study

Hello Dr. Russo,

My name is Julie Brines, and I am a doctoral student at Illinois State University. I am working on the literature review of my dissertation proposal and am focusing on retention theory, generational theory and faculty teaching methods. In my research, I found your study "Examining Millennial Characterizations as Guidance for Choosing Classroom Strategy Changes." Your survey items are very reflective of the type of questions I want to ask in my questionnaire to students and faculty. The purpose of my study is to compare the expectations of faculty versus the expectations of students with regard to the issue of faculty teaching methods and interactions inside and outside the classroom. My research questions are:

1) What is the relationship between generational cohort and the expectations of faculty teaching methods and faculty interaction in the classroom?

2) What is the relationship between generational cohort and the expectations of faculty teaching methods and faculty interaction outside the classroom?

3) Does a difference in generational cohort between faculty and students in the classroom decrease students' academic integration and social integration?

I am requesting your permission to utilize and modify parts of your survey instrument into my own instrument. I was very excited to see that many of your items represented the variables I have been researching and plan to include in my instrument. Thank you so much for your consideration. I look forward to hearing back from you.

Sincerely,

Julie 


\section{APPENDIX G}

\section{PILOT STUDY STUDENT RECRUITMENT EMAIL}

Subject: [Research] Students' Expectations of Instructional Activities

Dear Student,

You are being asked to participate in a pilot research study. The purpose of the main study is to compare students' expectations of instructional activities inside and outside the classroom with faculty approaches to instructional activities inside and outside the classroom. With this pilot, we hope to gather psychometric data to test the feasibility of the main study. This study is being conducted by Julie O'Brien, MS, who is a Ph.D candidate in the Higher Education Administration program in the Department of Educational Administration and Foundations at Illinois State University, under the supervision of Dr. Wendy Troxel, Associate Professor.

You must be at least 18 years old to participate in this research and no older than 24 . The survey is anonymous and should take no longer than 15 minutes to complete. It will be available until October 24, 2016.

By clicking on the link below, you will be redirected to a website for the survey. There, you will be presented with a consent form and the survey.

To participate in this survey, click on the link below or copy and paste it into a new browser window:

https://survey.illinoisstate.edu/coe/teachered/TakeSurvey.aspx?SurveyID=n2L1483K

Please feel free to contact the researchers with any questions you may have about the study.

- Julie O'Brien, MS, at XXXXXXX@ilstu.edu or XXX-XXX-XXXX

- Dr. Wendy Troxel at XXXXXXXX@ilstu.edu or XXX-XXX-XXXX

Thank you so much for taking the time to consider participating in the study.

Sincerely,

Julie O’Brien, MS 


\title{
APPENDIX H
}

\section{PILOT STUDY FACULTY RECRUITMENT EMAIL}

\author{
Subject: [Research] Faculty Approaches to Instructional Activities
}

(Please note that I am performing the recruitment for my survey as an ISU doctoral student and not an employee of Western. I was asked to reiterate this by the WIU Institutional Review Board.)

Dear Faculty Member,

You are being asked to participate in a pilot research study. The purpose of the main study is to compare students' expectations of instructional activities inside and outside the classroom with faculty approaches to instructional activities inside and outside the classroom. With this pilot, we hope to gather psychometric data to test the feasibility of the main study. The study is being conducted by Julie O'Brien, MS, who is a $\mathrm{PhD}$ candidate in the Higher Education Administration program in the Department of Educational Administration and Foundations at Illinois State University, under the supervision of Dr. Wendy Troxel, Associate Professor.

You must be primarily an undergraduate faculty member with approximately 10 or more years of teaching experience at four-year public institutions to participate in this research. The survey is anonymous and should take no longer than 15 minutes to complete. It will be available until October 24, 2016.

By clicking on the link below, you will be redirected to a website for the survey. There you will be presented with a consent form and the survey.

To participate in this survey, click on:

https://survey.illinoisstate.edu/coe/teachered/TakeSurvey.aspx?SurveyID=n2L1493K

Please feel free to contact the researchers with any questions you may have about the study.

- Julie O'Brien, MS, at XXXXXXX@ilstu.edu or XXX-XXX-XXXX

- Dr. Wendy Troxel at XXXXXXXX@ilstu.edu or XXX-XXX-XXXX

Thank you so much for taking the time to consider participating in the study.

Sincerely,

Julie O’Brien, MS 


\section{APPENDIX I}

\section{PILOT STUDY STUDENT REMINDER EMAIL}

Subject: [Research] Reminder - Students' Expectations of Instructional Activities

Dear Student,

Just a short time ago you were invited to participate in a pilot research study. The purpose of the main study is to compare students' expectations of instructional activities inside and outside the classroom with faculty approaches to instructional activities inside and outside the classroom. With this pilot, we hope to gather psychometric data to test the feasibility of the main study.

If you already completed the survey, thank you for taking the time to help us out!

If you have not had a chance to take the survey, please consider participating. As a reminder, you must be at least 18 years old to participate in this research and no older than 24 . The survey is anonymous and should take no longer than 15 minutes to complete. It will be available until October 24, 2016.

From the link below, you will be redirected to a website for the survey. There you will be presented with a consent form and the survey.

To participate, click on the link or copy and paste it into a new browser window:

https://survey.illinoisstate.edu/coe/teachered/TakeSurvey.aspx?SurveyID=n2L1483K

Please feel free to contact the researchers with any questions you may have about the study.

- Julie O’Brien, MS, at XXXXXXX@ilstu.edu or XXX-XXX-XXXX

- Dr. Wendy Troxel at XXXXXXXX@ilstu.edu or XXX-XXX-XXXX

Thank you so much for taking the time to consider participating in the study.

Sincerely,

Julie O’Brien, MS 


\section{APPENDIX J}

\section{PILOT STUDY FACULTY REMINDER EMAIL}

Subject: [Research] Faculty Approaches to Instructional Activities

(Please note that I am performing the recruitment for my survey as an ISU doctoral student and not an employee of Western. I was asked to reiterate this by the WIU Institutional Review Board.)

Dear Faculty Member,

Just a short time ago you were invited to participate in a pilot research study. The purpose of the main study is to compare students' expectations of instructional activities inside and outside the classroom with faculty approaches to instructional activities inside and outside the classroom. With this pilot, we hope to gather psychometric data to test the feasibility of the main study.

If you already completed the survey, thank you for taking the time to help us out!

If you have not had a chance to take the survey, please consider participating. As a reminder, you must be primarily an undergraduate faculty member with approximately 10 or more years of teaching experience at four-year public institutions to participate in this research. The survey is anonymous and should take no longer than 15 minutes to complete. It will be available until October 24, 2016.

From the link below, you will be redirected to a website for the survey. There you will be presented with a consent form and the survey.

To participate in this survey, click on:

https://survey.illinoisstate.edu/coe/teachered/TakeSurvey.aspx?SurveyID=n2L1493K

Please feel free to contact the researchers with any questions you may have about the study.

- Julie O'Brien, MS, at XXXXXXX@ilstu.edu or XXX-XXX-XXXX

- Dr. Wendy Troxel at XXXXXXXX@ilstu.edu or XXX-XXX-XXXX Thank you so much for taking the time to consider participating in the study.

Sincerely,

Julie O’Brien, MS 


\section{APPENDIX K}

\section{PRESENT STUDY STUDENT RECRUITMENT EMAIL}

Subject: [Research] 10-Minute Survey to Enter \$100 Amazon Gift Card Raffle

Dear ISU Student,

You are being invited to participate in a research study comparing students' expectations of instructional activities inside and outside the classroom with faculty approaches to instructional activities inside and outside the classroom. This study is being conducted by Julie O'Brien, MS, who is a Ph.D candidate in the Higher Education Administration program in the Department of Educational Administration and Foundations at Illinois State University, under the supervision of Dr. Wendy Troxel, Associate Professor.

You must be at least 18 years old to participate in this research and no older than 24 . The survey is anonymous and should take no longer than 15 minutes to complete. It will be available until November 23, 2016.

At the end of the survey, you will be given the opportunity to enter a raffle to win one of two online Amazon gift cards worth $\mathbf{\$ 1 0 0 . 0 0}$.

By clicking on the link below, you will be redirected to a website for the survey. There you will be presented with a consent form and the survey.

To participate, click on the link or copy and paste it into a new browser window:

https://survey.IllinoisState.edu/coe/teachered/TakeSurvey.aspx?SurveyID=84L15814

Please feel free to contact the researchers with any questions you may have about the study.

- Julie O'Brien, MS, at XXXXXXX@IllinoisState.edu or XXX-XXX-XXXX

- Dr. Wendy Troxel at XXXXXXXX@IllinoisState.edu or XXX-XXX-XXXX

Thank you so much for taking the time to consider participating in the study. We hope to gather information to help in curricular decisions that lead to more meaningful interactions between faculty and students, which are so vital for student success.

Sincerely,

Julie O'Brien, MS 


\section{APPENDIX L}

\section{PRESENT STUDY FACULTY RECRUITMENT EMAIL}

Subject: [Research] 10-Minute Survey to Enter \$100 Amazon Gift Card Raffle

Dear ISU Faculty Member,

You are being invited to participate in a research study comparing faculty approaches to instructional activities inside and outside the classroom with students' expectations of instructional activities inside and outside the classroom. This study is being conducted by Julie O'Brien, MS, who is a PhD candidate in the Higher Education Administration program in the Department of Educational Administration and Foundations at Illinois State University, under the supervision of Dr. Wendy Troxel, Associate Professor.

You must be primarily an undergraduate faculty member with approximately 10 or more years of teaching experience at four-year public institutions to participate in this research. The survey is anonymous and should take no longer than 15 minutes to complete. It will be available until November $23,2016$.

At the end of the survey, you will be given the opportunity to enter a raffle to win one of two online Amazon gift cards worth $\mathbf{\$ 1 0 0 . 0 0}$.

By clicking on the link below, you will be redirected to a website for the survey. There you will be presented with a consent form and the survey.

To participate, click on the link or copy and paste it into a new browser window:

https://survey.IllinoisState.edu/coe/teachered/TakeSurvey.aspx?SurveyID=84L15914

Please feel free to contact the researchers with any questions you may have about the study.

- Julie O'Brien, MS, at XXXXXXX@IllinoisState.edu or XXX-XXX-XXXX

- Dr. Wendy Troxel at XXXXXXXX@IllinoisState.edu or XXX-XXX-XXXX

Thank you so much for taking the time to consider participating in the study. We hope to gather information to help in curricular decisions that lead to more meaningful interactions between faculty and students, which are so vital for student success.

Sincerely,

Julie O'Brien, MS 


\section{APPENDIX M}

\section{PRESENT STUDY STUDENT REMINDER EMAIL}

Subject: [Research] 10-Minute Survey to Enter \$100 Amazon Gift Card Raffle

Dear ISU Student,

Just a short time ago you were invited to participate in a research study comparing students' expectations of instructional activities inside and outside the classroom with faculty approaches to instructional activities inside and outside the classroom.

If you already completed the survey, thank you for taking the time to help us out!

If you have not had a chance to take the survey, please consider participating. As a reminder, you must be at least 18 years old to participate in this research and no older than 24 . The survey is anonymous and should take no longer than 15 minutes to complete. It will be available until November 23, 2016.

At the end of the survey, you will be given the opportunity to enter a raffle to win one of two online Amazon gift cards worth $\$ \mathbf{1 0 0 . 0 0}$.

By clicking on the link below, you will be redirected to a website for the survey. There you will be presented with a consent form and the survey.

To participate, click on the link or copy and paste it into a new browser window:

https://survey.IllinoisState.edu/coe/teachered/TakeSurvey.aspx?SurveyID=84L15814

Please feel free to contact the researchers with any questions you may have about the study.

- Julie O'Brien, MS, at XXXXXXX@IllinoisState.edu or XXX-XXX-XXXX

- Dr. Wendy Troxel at XXXXXXXX@IllinoisState.edu or XXX-XXX-XXXX

Thank you so much for taking the time to consider participating in the study. We hope to gather information to help in curricular decisions that lead to more meaningful interactions between faculty and students, which are so vital for student success.

Sincerely,

Julie O'Brien, MS 


\section{APPENDIX N}

\section{PRESENT STUDY FACULTY REMINDER EMAIL}

Subject: [Research] 10-Minute Survey to Enter \$100 Amazon Gift Card Raffle

Dear ISU Faculty Member,

Just a short time ago you were invited to participate in a research study comparing faculty approaches to instructional activities inside and outside the classroom with students' expectations of instructional activities inside and outside the classroom.

If you already completed the survey, thank you for taking the time to help us out!

If you have not had a chance to take the survey, please consider participating. As a reminder, you must be primarily an undergraduate faculty member with approximately 10 or more years of teaching experience at four-year public institutions to participate in this research. The survey is anonymous and should take no longer than 15 minutes to complete. It will be available until November 23, 2016.

At the end of the survey, you will be given the opportunity to enter a raffle to win one of two online Amazon gift cards worth $\$ 100.00$.

By clicking on the link below, you will be redirected to a website for the survey. There you will be presented with a consent form and the survey.

To participate, click on the link or copy and paste it into a new browser window:

https://survey.IllinoisState.edu/coe/teachered/TakeSurvey.aspx?SurveyID=84L15914

Please feel free to contact the researchers with any questions you may have about the study.

- Julie O'Brien, MS, at XXXXXXX@IllinoisState.edu or XXX-XXX-XXXX

- Dr. Wendy Troxel at XXXXXXXX@IllinoisState.edu or XXX-XXX-XXXX

Thank you so much for taking the time to consider participating in the study. We hope to gather information to help in curricular decisions that lead to more meaningful interactions between faculty and students, which are so vital for student success.

Sincerely,

Julie O'Brien, MS 


\section{APPENDIX O}

\section{PILOT STUDY CONSENT FORM}

\section{Information and Consent}

\section{Introduction}

You are being asked to participate in a pilot research study. The purpose of the main study is to compare students' expectations of instructional activities inside and outside the classroom with faculty approaches to instructional activities inside and outside the classroom. With this pilot, the researchers hope to gather psychometric data to test the feasibility of the main study. Your participation is greatly appreciated!

\section{What Are the Procedures?}

- If you choose to take part in this research study, you will be asked to complete a survey that should take approximately 10 to 15 minutes.

\section{Risks/Discomforts}

- The risks associated with this research are no greater than those encountered in everyday life.

- You may feel uncomfortable answering some questions, but you have the option to skip questions or withdraw from the study at any time.

- Participating in this study will not affect your standing with any university organization or your university employment as the researcher has no influence on these matters.

\section{Benefits}

- There are no direct benefits to participants. However, your participation will help the researchers assess the reliability and validity of the instruments for the main study. The main study is intended to help educators identify areas of congruence and incongruence between student expectations of instructional activities inside and outside the classroom and faculty approaches to instructional activities inside and outside the classroom to be able to reinforce successful persistence practices and highlight target areas for faculty and staff development.

\section{Anonymity}

- All information provided will remain anonymous and only be reported as group data with no identifying information.

- No identifying information will be collected that connects participants to their survey responses, and all data will be reported as aggregate.

- All raw data will be saved on a password-protected computer; confidential printed materials will be kept locked in a filing cabinet in a personal office and destroyed upon completion of the study. 


\section{Participation}

- Participating in this study is voluntary.

- The researchers will not know if you participate.

- Not participating will not affect your current standing with Western Illinois University.

- Refusal to participate involves no penalty or loss of benefits. You may discontinue participation at any time. You can also skip questions you do not feel like answering.

\section{Questions About the Research}

- Please direct questions about this study to the researcher, Julie O'Brien, MS (XXXXXXX@ilstu.edu or XXX-XXX-XXXX) or the research advisor in charge of this study, Dr. Wendy Troxel (XXXXXXXX@ilstu.edu or XXX-XXX-XXXX).

- This study has been approved by the IRB at Illinois State University. If you have general questions about being a research participant, please contact:

○ Illinois State University's Research Ethics \& Compliance Office at 309-4382529 or via email at rec@ilstu.edu.

○ Western Illinois University's Compliance Specialist, Office of Sponsored Projects at 309-298-1191 or via IRB@wiu.edu..

\section{Documentation of Informed Consent}

You are voluntarily making a decision to participate in this study. Participants must be at least 18 years old. Choosing "yes" below means you have read the information presented above and decided to participate. Thank you for taking time out of your busy day to help us with our research!

Please print a copy of this consent form for your records.

_ Yes, I have read the consent information and agree to participate in this study.

_ No, I do not agree to participate in this study. 
APPENDIX P

PRESENT STUDY CONSENT FORM

\section{Information and Consent}

\section{Introduction}

You are being asked to participate in a research study. The purpose of this study is to compare students' expectations of instructional activities inside and outside the classroom with faculty approaches to instructional activities inside and outside the classroom. Your participation is greatly appreciated!

\section{What Are the Procedures?}

- If you choose to take part in this research study, you will be asked to complete a survey that should take approximately 10 to 15 minutes.

\section{Risks/Discomforts}

- The risks associated with this research are no greater than those encountered in everyday life.

- You may feel uncomfortable answering some questions, but you have the option to skip questions or withdraw from the study at any time.

\section{Benefits}

- There are no direct benefits to participants. However, your participation will help educators identify areas of congruence and incongruence between student expectations of instructional activities inside and outside the classroom and faculty approaches to instructional activities inside and outside the classroom to be able to reinforce successful persistence practices and highlight target areas for faculty and staff development.

\section{Anonymity}

- All information provided will remain anonymous and only be reported as group data with no identifying information.

- No identifying information will be collected that connects participants to their survey responses, and all data will be reported as aggregate.

- All raw data will be saved on a password-protected computer; confidential printed materials will be kept locked in a filing cabinet in a personal office and destroyed upon completion of the study.

\section{Compensation}

- At the end of the survey, you will be given the opportunity to go to a separate link where you can enter your email address in a raffle to win one of two online Amazon gift cards worth $\$ 100$. 


\section{Participation}

- Participating in this study is voluntary.

- The researchers will not know if you participate.

- Not participating will not affect your current standing with Illinois State University.

- Refusal to participate involves no penalty or loss of benefits. You may discontinue participation at any time. You can also skip questions you do not feel like answering.

\section{Questions About the Research}

- Please direct questions about this study to the researcher, Julie O'Brien, MS (XXXXXXX@ilstu.edu or XXX-XXX-XXXX) or the research advisor in charge of this study, Dr. Wendy Troxel (XXXXXXXX@ilstu.edu or XXX-XXX-XXXX).

- This study has been approved by the IRB at Illinois State University. If you have general questions about being a research participant, please contact:

○ Illinois State University's Research Ethics \& Compliance Office at 309-4382529 or via email at rec@ilstu.edu.

\section{Documentation of Informed Consent}

You are voluntarily making a decision to participate in this study. Participants must be at least 18 years old. Choosing "yes" below means you have read the information presented above and decided to participate. Thank you for taking time out of your busy day to help us with our research!

Please print this consent form for your records if you would like a copy.

_ Yes, I have read the consent information and agree to participate in this study.

No, I do not agree to participate in this study. 


\section{APPENDIX Q}

STATISTICAL ANALYSIS OF ONLY FACULTY WITH 10 YEARS OF EXPERIENCE

Table Q-1

Cronbach's Alpha Coefficients for 10-Year Only Faculty

\begin{tabular}{lcc}
\hline Instrument & Items & Coefficient \\
\hline $\begin{array}{l}\text { Faculty } \\
\quad \text { Instructional Activities Inside }\end{array}$ & 31 & .65 \\
$\quad \begin{array}{l}\text { Classroom } \\
\text { Instructional Activities Outside }\end{array}$ & 13 & .60 \\
$\quad$ Classroom & 44 & .74 \\
$\quad$ All Items & & \\
$\begin{array}{l}\text { Faculty } \\
\quad \text { Millennial Characteristics Subscale }\end{array}$ & 16 & .58 \\
$\quad$ Pedagogical Characteristics Subscale & 15 & .55 \\
\hline
\end{tabular}

Table Q-2

Results from t-test Comparing Responses of Faculty and Students for Instructional Activities Inside the Classroom

\begin{tabular}{lrrrcccr}
\hline Group & $\mathrm{n}$ & Mean & $\mathrm{SD}$ & $\mathrm{t}$ & $\mathrm{df}$ & $\mathrm{p}$ & Decision \\
\hline Students & 1205 & 3.5495 & .37047 & -3.507 & 1294 & .000 & Reject \\
Faculty & 91 & 3.4094 & .32359 & & & & \\
\hline
\end{tabular}

Table Q-3

Results from t-test Comparing Responses of Faculty and Students for Instructional Activities Outside the Classroom

\begin{tabular}{lrcccccc}
\hline Group & $\mathrm{n}$ & Mean & $\mathrm{SD}$ & $\mathrm{t}$ & $\mathrm{df}$ & $\mathrm{p}$ & Decision \\
\hline Students & 1163 & 3.7400 & .40336 & 4.120 & 1250 & .000 & Reject \\
Faculty & 89 & 3.9210 & .34085 & & & & \\
\hline
\end{tabular}


Table Q-4

Results from t-test Comparing Responses of Faculty and Students for Millennial Characteristics Subscale

\begin{tabular}{lrcccccc}
\hline Group & $\mathrm{n}$ & Mean & $\mathrm{SD}$ & $\mathrm{t}$ & $\mathrm{df}$ & $\mathrm{p}$ & Decision \\
\hline Students & 1205 & 3.3111 & .43201 & -4.030 & 1294 & .000 & Reject \\
Faculty & 91 & 3.1227 & .40500 & & & & \\
\hline
\end{tabular}

Table Q-5

Results from t-test Comparing Responses of Faculty and Students for Pedagogical Characteristics Subscale

\begin{tabular}{lrcccccc}
\hline Group & $\mathrm{n}$ & Mean & $\mathrm{SD}$ & $\mathrm{t}$ & $\mathrm{df}$ & $\mathrm{p}$ & Decision \\
\hline Students & 1205 & 3.8034 & .40955 & -2.214 & 1294 & .027 & Reject \\
Faculty & 91 & 3.7050 & .40175 & & & & \\
\hline
\end{tabular}


APPENDIX R

EXCLUDED TAGCROWD WORDS

$\begin{array}{lllll}\text { Anyone } & \text { End } & \text { Lot } & \text { Room } & \text { Teachers } \\ \text { Anything } & \text { Etc } & \text { Making } & \text { School } & \text { Things } \\ \text { Based } & \text { Everything } & \text { Minute } & \text { Seems } & \text { Throughout } \\ \text { Bases } & \text { Faculty } & \text { Multiple } & \text { Semester } & \text { Told } \\ \text { Best } & \text { Far } & \text { Net } & \text { Sessions } & \text { Towards } \\ \text { Better } & \text { Fine } & \text { Ones } & \text { Shows } & \text { Truly } \\ \text { Class } & \text { Gen } & \text { Overall } & \text { Simply } & \text { University } \\ \text { College } & \text { General } & \text { Period } & \text { Someone } & \text { Upcoming } \\ \text { Comes } & \text { Given } & \text { Pretty } & \text { Something } & \text { Usually } \\ \text { Current } & \text { Going } & \text { Professors } & \text { Sometimes } & \text { Via } \\ \text { Done } & \text { Hall } & \text { Really } & \text { Soon } & \text { World } \\ \text { Dont } & \text { Instructors } & \text { Regarding } & \text { Students } & \text { Year } \\ \text { Ed } & \text { ISU } & \text { Reggie } & \text { Sure } & \\ \text { End } & \text { Keep } & \text { Reggienet } & \text { Ta } & \end{array}$




\section{APPENDIX S}

\section{LARGE FIGURE 1}

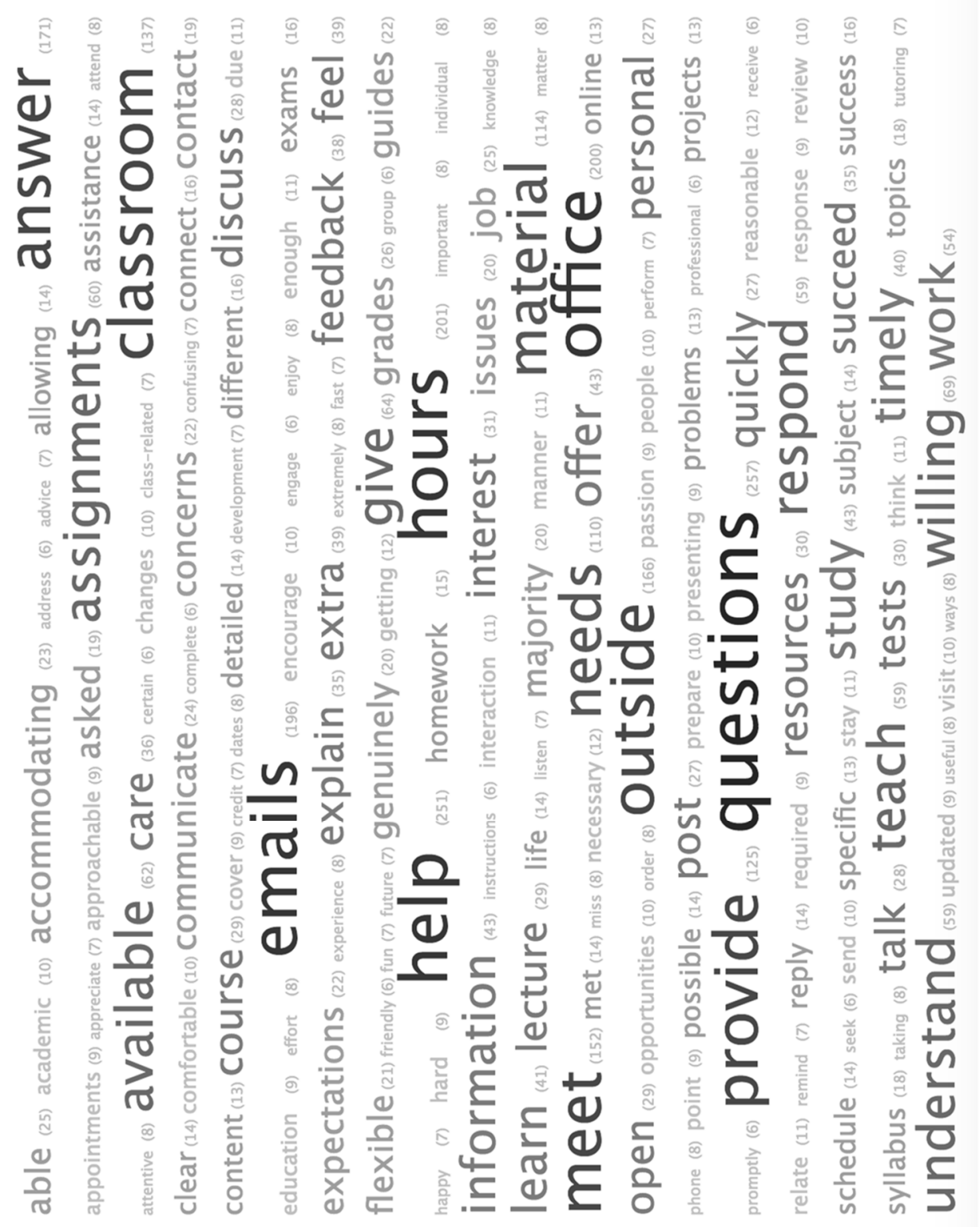




\section{APPENDIX T}

\section{LARGE FIGURE 2}

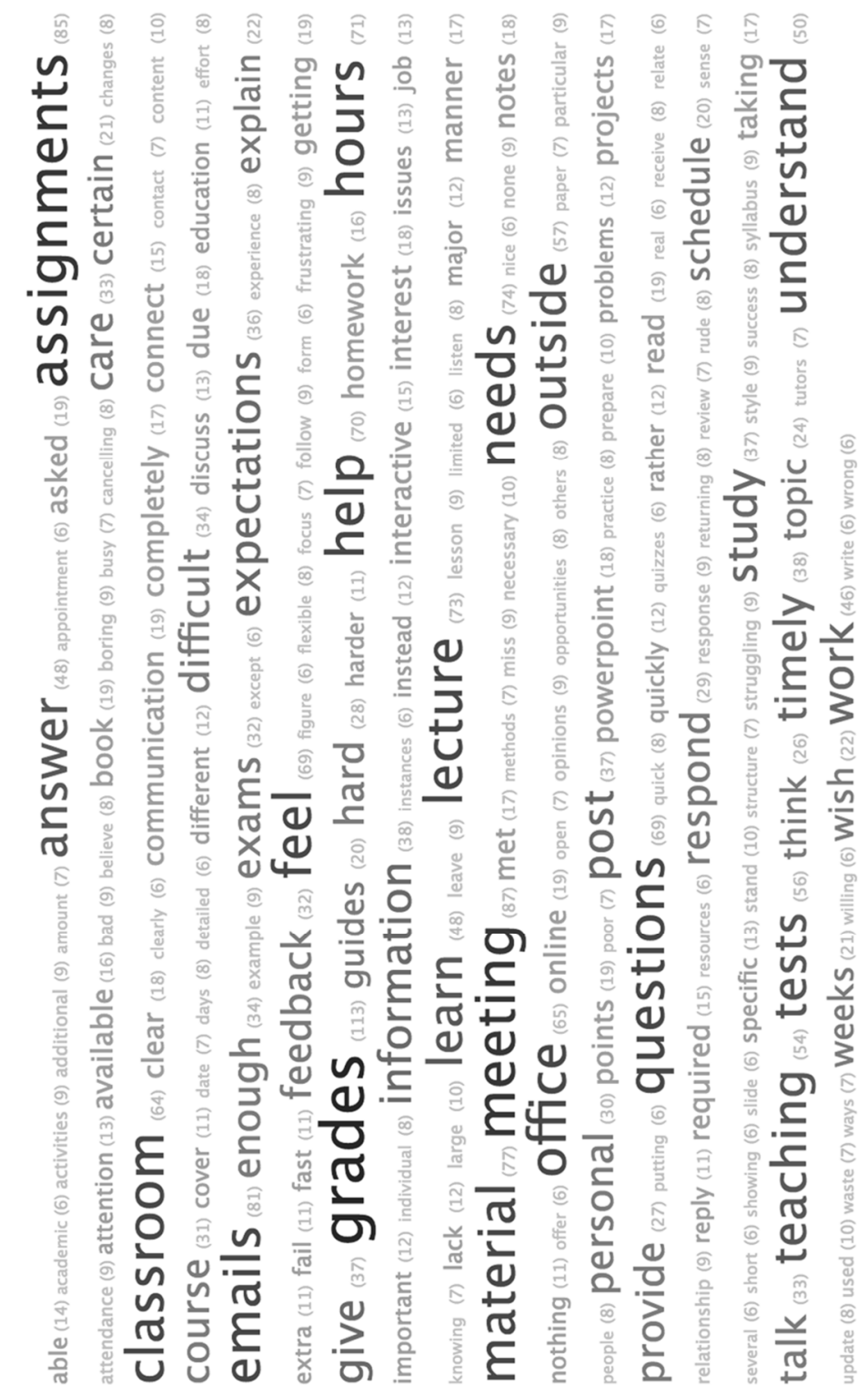


APPENDIX U

LARGE FIGURE 3

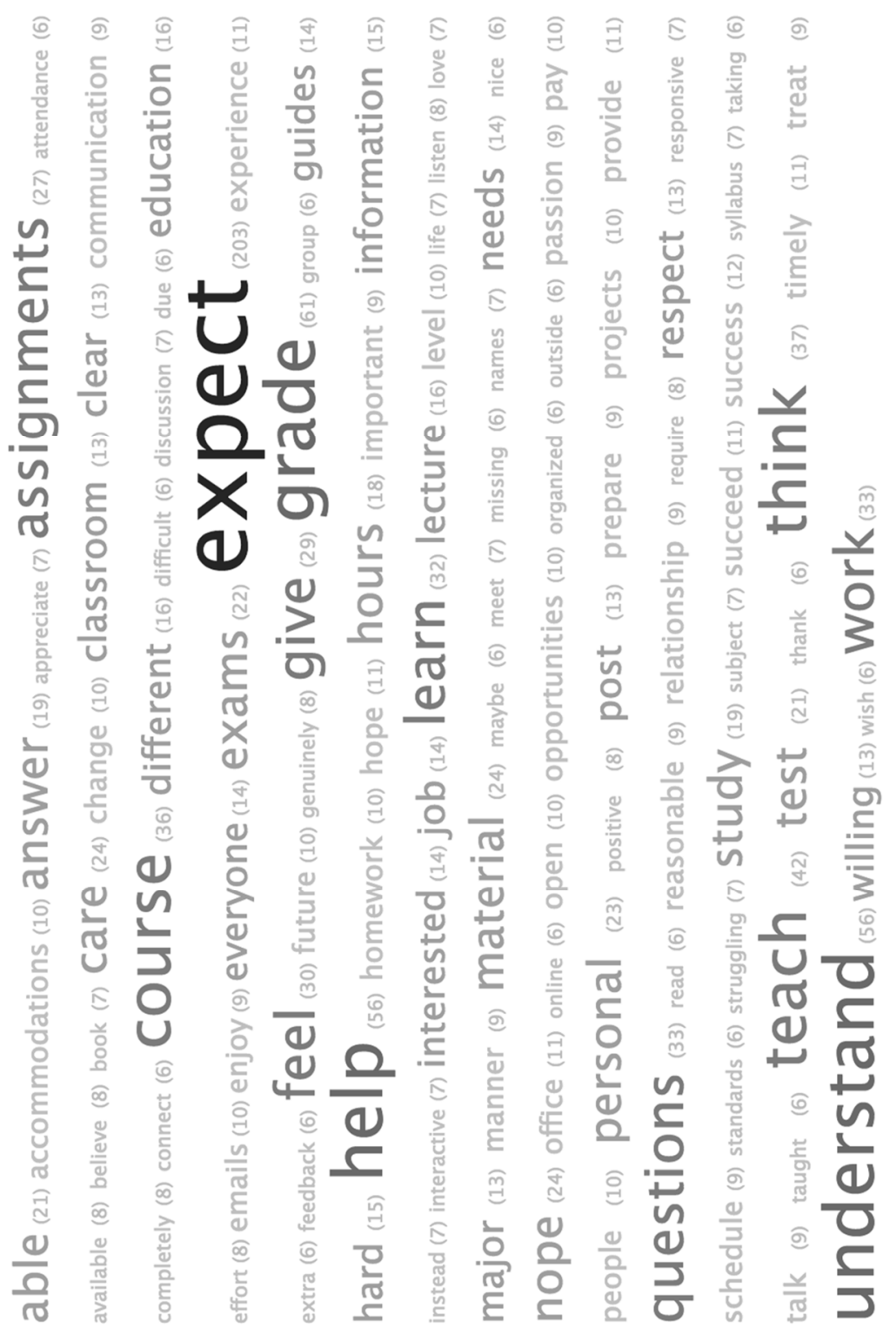


APPENDIX V

LARGE FIGURE 4

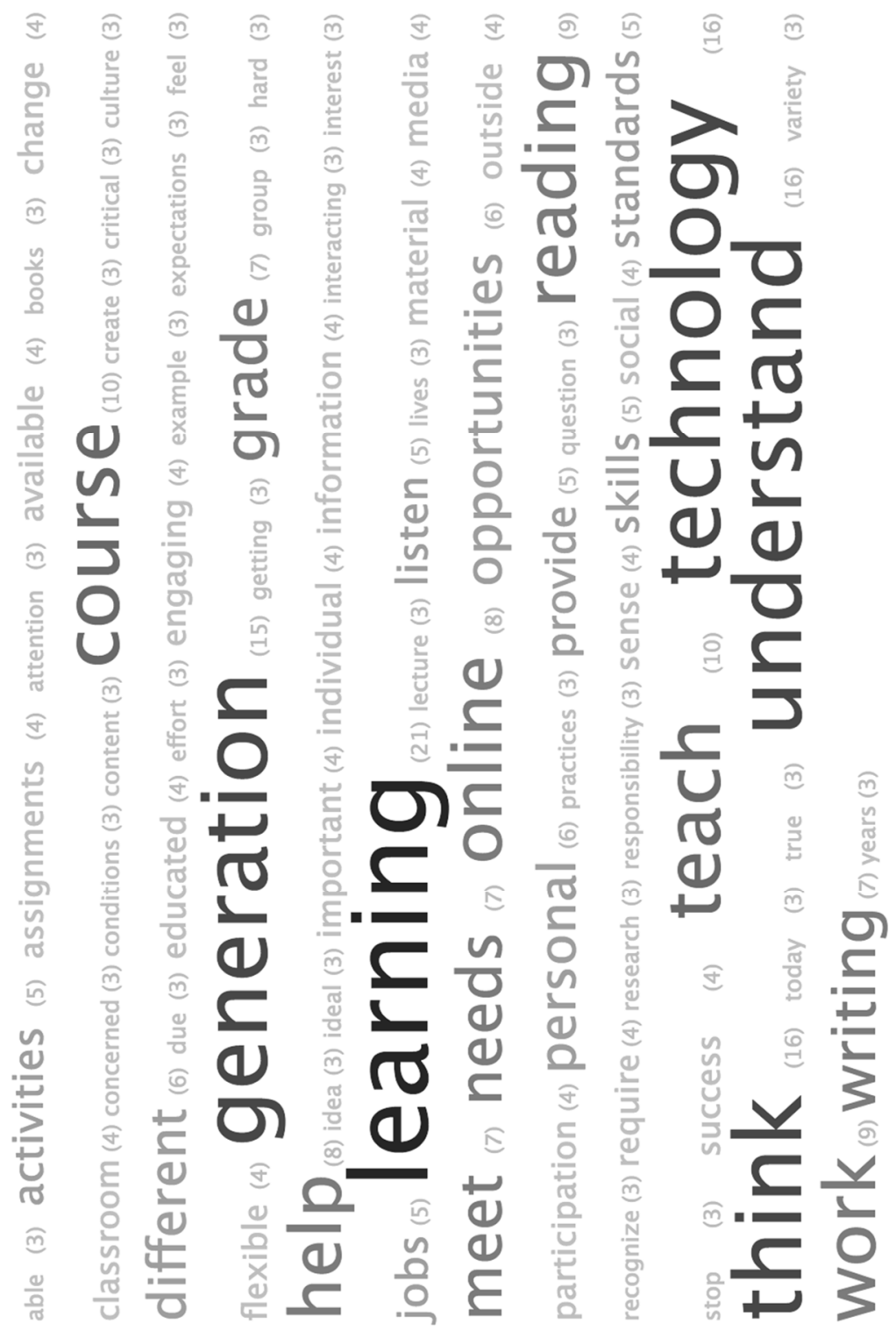


APPENDIX W

LARGE FIGURE 5

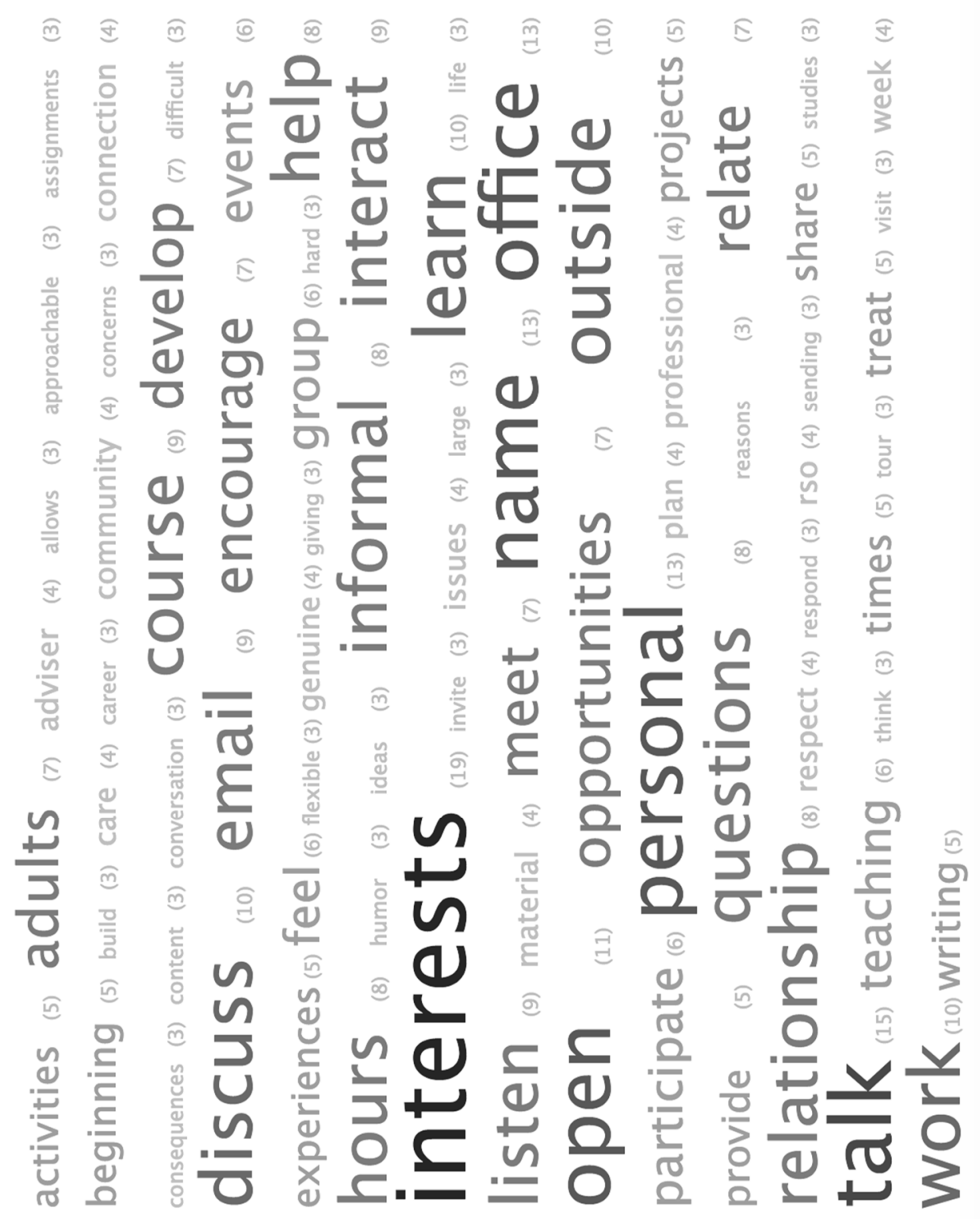


APPENDIX X

LARGE FIGURE 6

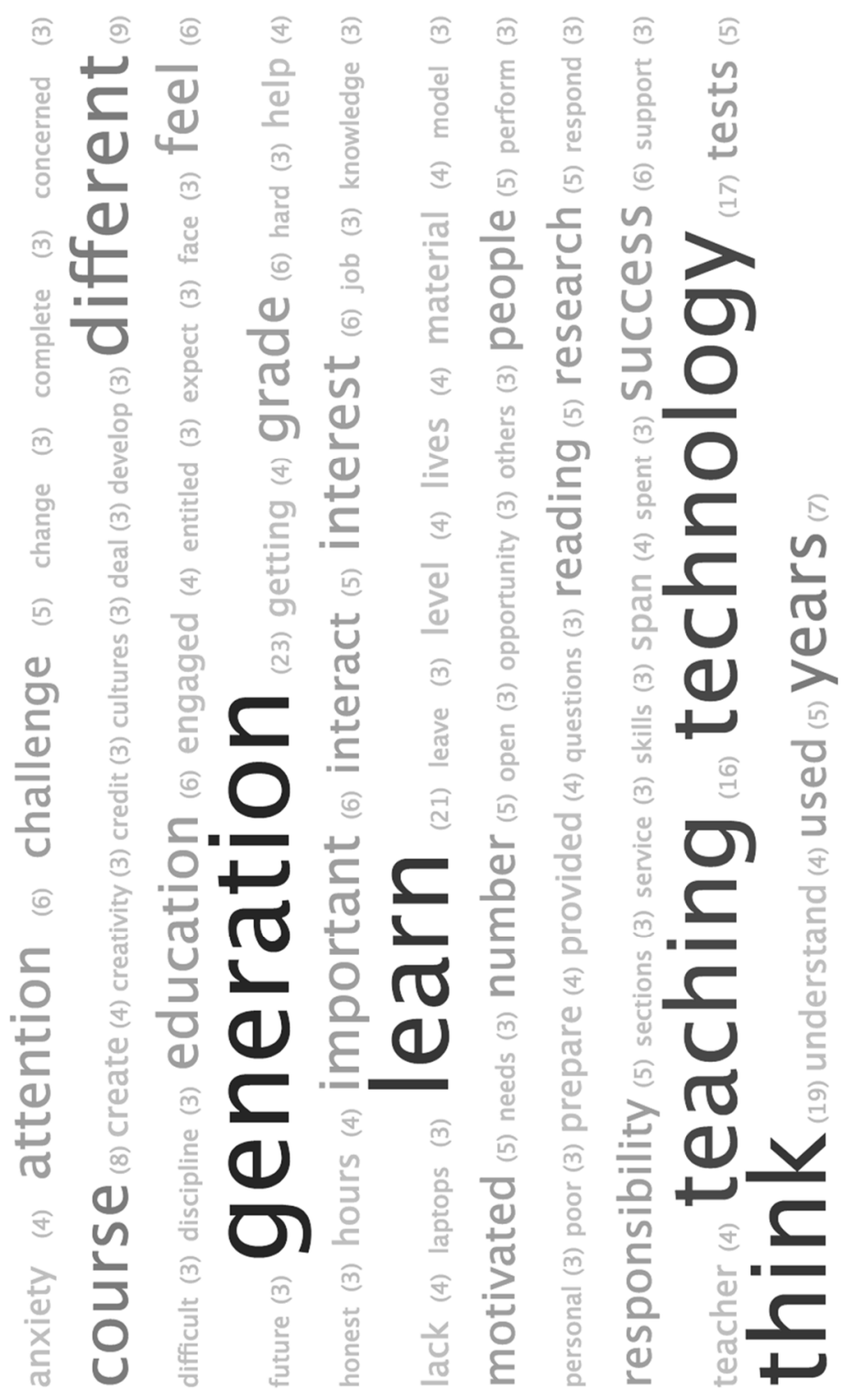

